\title{
1 New insights into the mechanics of fluvial bedrock erosion 2 through flume experiments and theory
}

Michael P. Lamb ${ }^{\mathrm{a}^{*}}$, Noah J. Finnegan ${ }^{\mathrm{b}}$, Joel S. Scheingross ${ }^{\mathrm{a}}$, Leonard S. Sklar ${ }^{\mathrm{c}}$

${ }^{a}$ Division of Geological and Planetary Sciences, California Institute of Technology, Pasadena, CA, USA.

*Corresponding author. Tel.: +1 626395 3612, E-mail: mpl@ gps.caltech.edu

${ }^{\mathrm{b}}$ Department of Earth and Planetary Sciences, University of California, Santa Cruz, CA, USA.

'Department of Earth \& Climate Sciences, San Francisco State University, San Francisco, CA, USA.

\section{Abstract}

River incision into bedrock drives the topographic evolution of mountainous terrain and may link climate, tectonics, and topography over geologic time scales. Despite its importance, the mechanics of bedrock erosion are not well understood because channel form, river hydraulics, sediment transport, and erosion mechanics coevolve over relatively long time scales that prevent direct observations, and because erosive events occur intermittently and are difficult and dangerous to measure. Herein we synthesize how flume experiments using erodible bedrock simulants are filling these knowledge gaps by effectively accelerating the pace of landscape evolution under reduced scale in the laboratory. We also build on this work by providing new theory for rock resistance to abrasion, thresholds for plucking by vertical entrainment, sliding and toppling, and assessing bedrock-analog materials. Bedrock erosion experiments in the last 15 years reveal that the efficiency of rock abrasion scales inversely with the square of rock tensile strength, sediment supply has a dominant control over bed roughness and abrasion rates, suspended sediment is an efficient agent of erosion, and feedbacks with channel form and roughness strongly influence erosion rates. Erodibility comparisons across rock, concrete, ice, and foam indicate that, for a given tensile strength, abrasion rates are insensitive to elasticity. The few experiments that have been conducted on erosion by plucking highlight the importance of block protrusion height above the river bed, and the dominance of block sliding and toppling 
29 at knickpoints. These observations are consistent with new theory for the threshold Shields

30 stress to initiate plucking, which also suggests that erosion rates in sliding- and toppling-

31 dominated rivers are likely transported limited. Major knowledge gaps remain in the processes

32 of erosion via plucking of bedrock blocks where joints are not river-bed parallel; waterfall

33 erosion by toppling and plunge-pool erosion; feedbacks between weathering and physical

34 erosion; erosional bedforms; and morphodynamic feedbacks between channel form and erosion

35 rates. Despite scaling challenges, flume experiments continue to provide much needed tests of

36 existing bedrock-erosion theory, force development of new theory, and yield insight into the

37 mechanics of landscapes.

39 Keywords: river incision; bedrock erosion; fluvial geomorphology; abrasion; plucking; flume 40 experiments

$42 \quad$ 1. Introduction

44 Models of landscape evolution driven by fluvial bedrock erosion are used to simulate 45 feedbacks between mountain growth, lithospheric deformation, and global climate change (e.g., 46 Willett, 1999); the structure of mountain belts (e.g., Howard, 1994); and the spacing of hills and 47 valleys (e.g., Perron et al., 2008). Inversely, these models are used to reconstruct the tectonic 48 and uplift history of continents (e.g., Whipple, 2004; Kirby and Whipple, 2012; Roberts et al., 49 2012; Croissant and Braun, 2014), decipher the imprint of glaciation and precipitation on 50 topography (e.g., Brocklehurst and Whipple, 2007; Ferrier et al., 2013), and quantify the history 51 of rainfall on Titan (Black et al., 2012) and on early Mars (e.g., Howard, 2007). The vast 
52 majority of these models drive landscape change through simple rules for river incision into

53 bedrock by assuming that fluvial erosion rates $(E)$ are a function of drainage area and local

54 channel slope, often referred to as the stream-power erosion model (Howard and Kerby, 1983),

$$
E=K A^{m} S^{n}
$$

58 where $A$ is drainage area; $S$ is channel slope; and $K, m$, and $n$ are empirical constants. Recent 59 developments in exposure-age dating have revealed that catchment-averaged erosion rates 60 (which typically average over $10^{3}$ to $10^{4}$ years) tend to follow Eq. (1) but that the coefficients in 61 Eq. (1) vary widely in different landscapes (e.g., Ouimet et al., 2009; DiBiase et al., 2010), often 62 attributed to differences in rock type and climate. These findings cast doubt on the predictive 63 power of Eq. (1) outside of the landscapes and time scales for which the model has been 64 calibrated. To build more robust predictive models, the past 15 years have seen a surge in research

66 focused on advancing new theory for the rate of bedrock river incision that attempts to 67 incorporate the mechanics of specific erosion processes while remaining computationally 68 tractable for landscape evolution simulations over geologic time. Much of the new insight to 69 drive quantitative theory has come from simulating bedrock erosion in laboratory flume 70 experiments, where bedrock erosion and channel evolution in the laboratory manifest over hours 71 to weeks rather than the thousands of years that would be required to observe equivalent 72 dynamics in nature. Outside of a few rare, extreme events (e.g., Lamb and Fonstad, 2010; Cook 73 et al., 2013), annual-to-decadal observations of fluvial bedrock erosion in nature are limited to 74 millimeters-to-centimeters of change (Fig. 1), resulting in negligible channel evolution and 
75 precluding direct observations of long-term feedbacks between water flow, sediment transport,

76 bedrock erosion, and channel form. In contrast, flume experiments now allow direct

77 measurements of these feedbacks through the development of erodible bedrock simulants and

78 downscaling channel size that together speed the pace of bedrock erosion and channel evolution.

79 This paper is a synthesis of some of the key new developments in the mechanics of

80 fluvial bedrock erosion from flume experiments, including new theories that have emerged as a

81 result of experimentation. The paper is mostly a review of previous work; however, we do offer

82 a few new ideas on bedrock erosion mechanics including bedrock-strength scaling, entrainment

83 thresholds for plucking, and an assessment of bedrock analogs for experimentation. We focus

84 solely on the mechanics of abrasion of rock by impacting fluvially transported particles and

85 plucking of blocks of fractured rock. We focus on these two processes because they are arguably

86 the most important erosion processes in bedrock rivers (e.g., Hancock et al., 1998; Whipple et

87 al., 2000), they have received the most attention in recent experiments, and they have not been

88 covered in detail in other review papers (Thompson and Wohl, 1998; Paola et al., 2009; Whipple

89 et al., 2013). Consequently, a number of important processes are not within the scope of this

90 paper. These processes include cavitation and groundwater sapping, and processes that have

91 been suggested to play a role in bedrock-river erosion but to date lack conclusive field evidence

92 (Whipple et al., 2000; Lamb et al., 2006). Entrainment of cohesive bed sediment from clear-

93 water flows has been studied extensively experimentally (e.g., Dzulynski and Sanders, 1962;

94 Shepherd and Schumm, 1974; Annandale, 1995; Brooks, 2001), but application of these results

95 to bedrock rivers is unclear because rock erosion typically involves brittle fracturing (Engle,

96 1978). Corrosion, the collective weathering processes that weaken rock fabric and joints, is

97 important in fluvial bedrock erosion, but to date has received little study experimentally 
98 (Hancock et al., 2011; Small et al., 2012; Whipple et al., 2013). Debris flows also erode bedrock

99 channels, and the growing work on debris-flow erosion mechanics from experiments (e.g., Hsu

100 et al., 2008). Finally, a number of exciting experimental studies have been conducted to simulate

101 the large-scale response of drainage basins or mountain ranges to climatic and tectonic forcing

102 through use of sediment tables with tightly packed noncohesive sediment, rainfall misters, and

103 base-level control (e.g., Hasbargen and Paola, 2000; Bonnet and Crave, 2003; Lague et al., 104 2003). These studies do not explicitly include the mechanics of abrasion and plucking, and we 105 refer the reader to Paola et al. (2009) for a recent review.

106 With our focus set on the mechanics of abrasion and plucking from experiments and 107 theory, we first discuss some of the issues in scaling laboratory experiments focusing on the 108 relationship between rock strength and rock erodibility, which ultimately opens the door to 109 quantitative-scaled experiments of bedrock erosion by abrasion. Second, we discuss how zero110 dimensional bedrock abrasion experiments reveal a dominant and dual role of sediment supply in 111 setting the rate of erosion, including the importance of bedload and of suspended sediment. 112 Third, we review experiments that reveal strong feedbacks between channel form, bed 113 roughness, sediment supply, and rock abrasion. Fourth, we derive new entrainment thresholds for 114 block plucking by vertical entrainment, sliding, and toppling and compare these expectations to 115 available experimental observations. Fifth, we discuss briefly the mechanics of abrasion and 116 plucking at waterfalls. Finally, we identify a number of promising areas for future 117 experimentation.

118 
Laboratory experiments provide a means to test hypotheses that are difficult to test in

122 natural rivers because in the lab specific mechanisms and functional relationships between

123 variables can easily be isolated. However, experiments are inherently limited to the length scales

124 that can be accommodated in a laboratory facility and to the time scales over which experiments

125 can be completed. Applying knowledge gleaned from controlled experiments to field settings

126 thus requires scaling relationships that apply across a wide range of length and time scales. As

127 illustrated in Fig.Fig. 1, incision rates measured in the field vary over nine orders of magnitude,

128 from the equivalent of $10^{6} \mathrm{~mm} / \mathrm{y}$ in a single dam release flood (Lamb and Fonstad, 2010), to $10^{-3}$

$129 \mathrm{~mm} / \mathrm{y}$ estimated over hundreds of million years of landscape evolution in Australia (Young and

130 McDougall, 1993). Incision rates measured in the lab span nearly as wide a range; however, the

131 length and time scales are much smaller.

132 Working at these smaller scales has advantages. Reduced size permits work at different

133 dimensions, including fully three-dimensional channels (Wohl and Ikeda, 1997; Carter and

134 Anderson, 2006; Finnegan et al., 2007), two-dimensional wide fixed-wall (Johnson and Whipple,

135 2007, 2010), one-dimensional narrow fixed-wall (Taki and Parker, 2005), and essentially zero-

136 dimensional abrasion mills (Sklar and Dietrich, 2001; Scheingross et al., 2014). Measurements

137 of erosion depths can be more precise under laboratory conditions, for example by using laser

138 scanning or mass differencing of samples small enough for precision balances. The trade off, 139 however, is that the magnitude of erosive forces is much less.

140 Big differences between experiments and natural rivers arise when comparing the time

141 scale of erosion. For example, Sklar and Dietrich (2001) and Brocard et al. (2003) measured

142 incision rates of $\sim 1 \mathrm{~mm} / \mathrm{yr}$ (Fig. 1), but the time scale between lab and field measurements

143 differed by seven orders of magnitude. Equivalent rates in the lab, despite smaller scales, are 
144 caused by two effects: the lack of intermittency and use of weak materials that erode more 145 rapidly for a given intensity of erosive attack. Lab experiments in effect simulate flood 146 conditions when incision and other morphologic change occurs. In the field, these flows could 147 happen $<1 \%$ of the time (Sklar and Dietrich, 2006) or much less frequently (e.g., Baker and 148 Pickup, 1987). Moreover, field incision rates over long time spans may include periods of 149 aggradation when even large floods cause no incision (Finnegan et al., 2014). Time intervals 150 with no vertical incision may still be important to morphologic evolution of bedrock channels 151 because of channel-wall erosion and reduction of rock strength by weathering; however, the 152 latter is difficult to capture experimentally. The shorter time scales and length scales of most laboratory experiments as compared to 154 natural bedrock rivers pose a number of challenges and considerations for scaling. Experiments 155 aimed at understanding the basic mechanics of transport processes typically follow classic 156 dynamic scaling where key dimensionless variables, like the Reynolds number (Re) are either 157 matched between experiment and nature or are designed to be within the same regime where 158 dynamics are self-similar. Strategies for dynamic scaling of hydraulic and sediment transport 159 experiments have been discussed at length previously (e.g., Yalin, 1977; Peakall et al., 1996), 160 and we review some of the key concepts in section 2.1. Bedrock erosion experiments pose an 161 additional challenge in that bedrock material properties and erodibility must also be considered 162 in scaling, and workers in the last 15 years have made progress identifying and testing 163 dimensionless variables for bedrock erosion (discussed in sections 2.2 and 2.3). In section 2.4 164 we introduce scaling concepts for bedrock erosion by plucking, and in section 2.5 we briefly 165 discuss the importance of channel-scale dimensionless variables in designing experiments aimed 166 at morphodynamic interactions. 
172 sediment. These are well developed from the long history of experimental work on hydraulic

173 modeling and sediment transport (Yalin, 1977; Peakall et al., 1996). Two fundamental

174 nondimensional numbers are used to compare hydraulic conditions between laboratory models

175 and field prototype channels. Reynolds number quantifies the ratio of turbulent to viscous forces 176 in the flow:

$$
\operatorname{Re}=\frac{\rho_{w} U h}{\mu}
$$

180 in which $\rho_{w}$ is the density of water, $U$ is the depth-averaged mean flow velocity, $h$ is mean flow 181 depth, and $\mu$ is the dynamic fluid viscosity. Froude number (Fr) quantifies the ratio of inertial to 182 gravitational forces

$$
\mathrm{Fr}=\frac{U}{\sqrt{g h}}
$$

186 where $g$ denotes the acceleration of gravity. Equation (3) also represents the ratio of the flow 187 velocity to the speed of a surface wave in shallow flow.

188 In scaling down from nature to lab, matching both Re and Fr generally is not feasible. 
189 Fortunately, Re does not need to match for dynamic similarity; researchers have shown that for 190 fully turbulent flow $\left(\operatorname{Re}>\sim 10^{3}\right.$ ), the vertical structure of steady and uniform unidirectional flow 191 is self-similar and follows

$$
\frac{u(z)}{u_{*}}=\frac{1}{\kappa} \ln \frac{z}{z_{0}}
$$

195 where $u$ is the time-averaged flow velocity, $u_{*}=\sqrt{\tau_{b} / \rho_{w}}$ is the bed shear velocity, $\tau_{b}$ is the bed

196 shear stress, $K=0.41$ is von Karman's constant, $z$ is the height above the bed, and $z_{0}$ is an

197 empirical constant that depends on whether the bed is hydraulically rough or smooth (e.g.,

198 Schlichting, 1979). For the case of a hydraulically rough bed, which is likely the case in most

199 natural rivers with gravel or larger bed roughness (e.g., Parker, 1991; Parker et al., 2007), $z_{0}=$

$200 k_{s} / 30$ and $k_{s}$ is the bed roughness length scale. Thus, for fully turbulent and hydraulically rough

201 flows, flow velocity is independent of the Reynolds number and fluid viscosity. This makes

202 laboratory experiments using water flows also applicable to different gravities and rivers of more

203 exotic fluids, such as brines on Mars (Lamb et al., 2012; Grotzinger et al., 2013) or methane

204 rivers on Titan (Perron et al., 2006; Burr et al., 2013), as long as they are also Reynolds-number

205 independent. Most bedrock erosion experiments to date have been conducted in the turbulent

206 regime (Fig. 2), except for those aimed at landscape-scale dynamics that did not explicitly

207 investigate abrasion or plucking (e.g., Hasbargen and Paola, 2000; Bonnet and Crave, 2003;

208 Lague et al., 2003).

209 The threshold value of $\mathrm{Fr}=1.0$ separates supercritical flow $(\mathrm{Fr}>1)$ from subcritical flow

210 (Fr < 1). In engineering scale models of particular flow configurations, Fr should match for 
211 dynamic similitude. However, most bedrock erosion experiments to date have been in the 212 supercritical regime (Fig. 2). In the field, Fr during active bed erosion is not well known, in part

213 because the discharge at which most incision occurs depends on many factors, including 214 sediment supply and grain size (Sklar and Dietrich, 2006). Surface waves and other indicators of 215 supercritical flow are often observed in bedrock channels (e.g., Richardson and Carling, 2006), 216 leading to the common assumption that supercritical flow is characteristic of incising bedrock 217 channels (Tinkler and Wohl, 1998).

218 Several nondimensional numbers are used for scaling interactions between water and 219 sediment. The Shields number quantifies the ratio of bed stress caused by fluid drag on a particle 220 to the submerged particle weight per unit area,

221

222

$$
\tau^{*}=\frac{\tau_{b}}{\left(\rho_{s}-\rho_{w}\right) g D}
$$

223

224 where $\rho_{s}$ is sediment density, and $D$ is particle diameter. The threshold of sediment motion is 225 expressed as a critical value, $\tau_{c}^{*}$, which for the median grain size varies primarily as a function of 226 particle size (through the particle Reynolds number, $\operatorname{Re}_{p}$ ) and channel slope (or equivalently flow 227 depth relative to sediment size) (e.g., Buffington and Montgomery, 1999; Lamb et al., 2008c). 228 The particle Reynolds number describes the balance between viscous and turbulent effects in the 229 boundary layer around the particle,

$$
\operatorname{Re}_{p}=\frac{\rho_{w} u_{*} D}{\mu}
$$


234 For example, particle drag coefficients $\left(C_{D}\right)$ and the critical Shields number $\left(\tau_{c}^{*}\right)$ have been

235 found to be independent of $\operatorname{Re}_{p}$ and sediment size for $\operatorname{Re}_{p}>\sim 10^{2}$ (equivalent to gravel or coarser

236 sediment) in a manner similar to Reynolds-number independence for velocity in fully turbulent

237 flows. This makes gravel, for example, a good scale analog for boulders in natural rivers. For

238 gravel-bedded and low gradient $(S<1 \%)$ rivers, $\tau_{c}^{*}$ is about 0.045 (Shields, 1936; Brownlie,

239 1983; Wilcock, 1993). The critical Shields stress can range up to $\tau_{c}^{*}=0.2$ for very steep channels

240 (Lamb et al., 2008c; Scheingross et al., 2013; Prancevic et al., 2014) and can be $\ll<0.01$ for

241 isolated grains on smooth bedrock beds (Hodge et al., 2011; Chatanantavet et al., 2013).

242 At high transport stages (i.e., $\tau^{*} / \tau_{c}^{*}$ ), the Rouse number $(\mathrm{Z})$ becomes important,

$$
Z=\frac{w_{s}}{\kappa u_{*}}
$$

246 where $w_{s}$ is the particle fall velocity. Generally particles transition from the bedload transport

247 regime to the suspension regime when the ratio $u_{*} / w_{s}$ exceeds $1(Z<2.5)$ (Bagnold, 1966).

248 These two regimes result in different particle trajectories (Fig. 3), different particle-bedrock

249 interactions, and consequently different bedrock erosion rates (explored in section 3.2).

250 In sediment transport experiments, achieving dynamic similarity for hydraulics and for

251 sediment transport is often difficult. For example, experiments can produce fully turbulent open-

252 channel flows with flow depths scaled down by orders of magnitude from natural rivers (Fig. 2).

253 Sediment size, however, cannot be scaled down by a commensurate amount because small

254 sediment sizes may produce particle Reynolds numbers that fall below $\operatorname{Re}_{p} \sim 10^{2}$; and even more 
255 important, other processes such as cohesion become important for mud. Consequently, alluvial 256 bed slopes tend to be steep in experiments in order to achieve sediment transport despite 257 relatively coarse sediment and shallow flows. Steeper slopes, in turn, often cause Fr to be larger 258 than in natural rivers. One solution to these issues has been to use low density sediment, such as 259 walnut shells or plastic beads, in laboratory experiments to produce transport on lower bed 260 slopes (e.g., Chatanantavet and Lamb, 2014). This is an effective strategy for alluvial river 261 experiments, but low-density sediment and sub-sand-sized particles pose an issue for bedrock262 erosion experiments because particle-bed impacts must have sufficient kinetic energy to produce 263 measurable erosion rates. Experiments indicate that particles also must have sufficiently large 264 particle Stokes numbers (St),

$$
\mathrm{St}=\frac{\rho_{s} w_{i} D}{9 \mu}
$$

268 for bedrock erosion to occur (Scheingross et al., 2014), where $w_{i}$ is the particle impact velocity. 269 Experiments measuring the rebound of spherical and natural particles against planar beds suggest 270 that particle impacts are viscously damped when collisions fall below particle Stokes numbers of $271 \sim 10^{1}-10^{2}$ (e.g., Joseph et al., 2001; Schmeeckle et al., 2001; Joseph and Hunt, 2004; Li et al., 272 2012).

\section{2.2. Bedrock simulants in abrasion experiments}


278 use bedrock analogs in place of natural rock in erosional experiments. Bedrock analogs can offer 279 advantages over natural rock including faster rates of erosion, ease of shaping or molding the bed 280 into a desired configuration, and the ability to be made in the laboratory or supplied 281 commercially. Several analog materials have been used, including cohesive sediments, concrete, 282 and polyurethane foam. The most suitable material analogs are those that replicate the 283 deformation and wear behavior of natural rock as close as possible, allow for erosion rates 284 sufficiently fast to be observable over experimental time scales, and follow scaling laws that can 285 be used to relate laboratory erosion rates to field time scales.

286 Beginning with the pioneering experiments of Schumm and colleagues (Schumm et al., 287 1987), many laboratory investigations have used clay-based bedrock analog materials to 288 accelerate incision and morphologic evolution. Clay added to mixtures of silt and fine sand 289 provides cohesion sufficient to form vertical walls (Shepherd and Schumm, 1974; Gardner, 290 1983; Wohl and Ikeda, 1997) and, when subject to flowing water and sediment, produces 291 sculpted bedforms such as flutes and potholes (Dzulynski and Sanders, 1962). Although the 292 morphologies formed in clay-silt cohesive materials may be similar to features found in hard 293 crystalline rock (e.g., Wohl and Ikeda, 1997), quantitatively scaling the erosion rates and flow 294 conditions to the field is challenging because the material deforms plastically and fails to 295 reproduce the brittle behavior of natural rock. These two limitations make it difficult to test 296 bedrock incision theories (e.g., Sklar and Dietrich, 2004); however, cohesive sediment mixtures 297 are likely excellent analogs for lowland rivers that have recently been shown to incise into 298 consolidated mud (e.g., Nittrouer et al., 2011; Shaw et al., 2013).

299 The past $\sim 15$ years have seen a shift toward the use of weak concrete as a bedrock analog 300 instead of cohesive sediments (e.g., Sklar and Dietrich 2001; Demeter et al., 2005; Carter and 
301 Anderson, 2006; Finnegan et al., 2007; Johnson and Whipple, 2007, 2010). Unlike cohesive

302 sediments, concrete is brittle and has been shown to erode following the same tensile-strength

303 scaling as observed in natural rock (Sklar and Dietrich, 2001). Concrete is similar in many

304 respects to clastic sedimentary rocks, and by varying particle grain size in concrete mixtures

305 experimenters can approximate natural rocks ranging from siltstones to conglomerates. The

306 tensile strength of concrete can be easily controlled by changing the ratio of sand to cement in

307 the mixture, allowing workers to adjust erosion resistance. As with cohesive sediment mixtures,

308 concrete produces erosional morphologies that are similar to erosional rock bedforms in natural

309 channels (e.g., Finnegan et al., 2007; Johnson and Whipple, 2007). Because concrete is initially

310 in a fluid state, it can be set in molds to produce desired morphologies, such as regular roughness

311 patterns (Davis, 2013). The main limitation of concrete is that it requires long curing times.

312 Concrete cures following a logarithmic time scale, typically taking more than 1 month to reach

313 its final tensile strength (Nelson, 2003), although this time can be reduced by additives that

314 accelerate curing. For example, Type III Portland cement reaches $70 \%$ of its ultimate strength in

3153 days (Kosmatka et al., 2002); rapid curing cements were used in making analog bedrock by

316 Hsu et al. (2008) and Fuller (2014). Because the change in tensile strength is initially rapid,

317 achieving a constant tensile strength over the length of laboratory experiments (which may take

318 multiple days or weeks to run), requires pouring concrete days to weeks in advance of starting 319 experiments.

320 Recently, closed-cell polyurethane foam has been explored as an alternative bedrock 321 analog for abrasion (Scheingross et al., 2014). Foam has been successfully used as a bedrock 322 analog in studies examining abrasion by wind-transported sediment, with results showing similar 323 morphologic patterns of erosion between foam and rock (Bridges et al., 2004; Laity and Bridges, 
324 2009). In fluvial abrasion experiments, foam has been shown to follow the same tensile-strength

325 scaling as rock and concrete (Scheingross et al., 2014) and produces erosional morphologies

326 consistent with those observed in nature. Foam can be easier to work with than concrete or

327 cohesive sediment mixtures as it requires no curing time, can be purchased commercially in a

328 variety of tensile strengths, and its low density makes it easy to transport. However, foam also

329 has disadvantages compared to concrete. Foam is $20-40$ times more costly per unit volume and is

330 supplied by the manufacturer in rectangular blocks and must be user-shaped. In addition, while

331 foam breaks in a brittle manner, it can also deform plastically under high energy sediment

332 impacts, although in most experiments impact energy will be below the threshold of plastic

333 deformation. For example, we found that when dropping particles from rest through $6 \mathrm{~cm}$ of

334 water, particles $D>2.5 \mathrm{~cm}$ were needed to produce plastic deformation in $0.32 \mathrm{MPa}$ tensile

335 strength foam; this coarse gravel is larger than the grain sizes typically used in most bedrock

336 abrasion experiments.

337 A final consideration in the choice of bedrock material analog is the role of eroded

338 material. Foam is low-density and erodes in submillimeter pieces such that eroded foam is

339 transported away in washload and does not produce further erosion. This is unlike concrete or

340 cohesive sediment mixtures where the sand liberated in erosion can produce further erosion

341 depending on the size of sand used and the hydraulics of the particular experiment.

342

343 2.3. Scaling rock resistance to abrasion

In the stream power model (Eq. 1), the erodibility or erosivity coefficient $K$ is assumed to

346 capture rock susceptibility to erosion. However, in practice, $K$ is a lumped parameter that also 
347 subsumes many other factors, including channel geometry, hydraulic roughness, sediment flux 348 and grain size, magnitude-frequency tradeoffs, and the efficiency of multiple potential 349 detachment mechanisms (Sklar and Dietrich, 1998; Whipple, 2004). As a result, $K$ cannot be 350 readily scaled between laboratory and field channels and has ambiguous physical meaning even 351 when comparing field sites at similar scales (Stock and Montgomery, 1999; Kirby and Whipple, 352 2001).

Physically explicit measures of rock resistance to erosion should differ depending on the

354 dominant mechanism for rock detachment. For rock wear by sediment impacts, arguably a 355 ubiquitous and frequently dominant mechanism, Sklar and Dietrich (2001) demonstrated 356 experimentally that mass erosion rate $\left(E_{m}\right)$ scales with the inverse square of rock tensile strength $357\left(\sigma_{T}\right)$ :

$$
E_{m}=E_{o}\left(\frac{\sigma_{T}}{\sigma_{0}}\right)^{-2}
$$

361 in which $E_{o}$ is the expected erosion rate at a reference tensile strength $\sigma_{0}$ (Fig. 4A). In these 362 experiments, 20-cm-diameter rock disks were eroded by sediment impacts at the base of 363 vertically oriented cylinders, or abrasion mills, that contained water and sediment circulated by 364 motor-driven propellers (Fig. 4D). Tensile strength was measured with the Brazilian splitting 365 tensile strength test (ISRM, 1978). Rock types tested spanned the range of strengths of rocks 366 found in the field, from very strong andesite and quartzite ( $\left.\sigma_{T}>20 \mathrm{MPa}\right)$ to weak mudstones 367 and weathered sandstones $\left(\sigma_{T}<0.1 \mathrm{MPa}\right)$. Sklar and Dietrich (2001) also found that disks of 368 weak concrete, made from Portland cement and fine sand in various ratios, followed the same 
369 inverse square scaling relation between erosion rate and tensile strength.

370 Although the scaling of erosion rate with the inverse square of tensile strength has now

371 been confirmed by several experiments (Sklar and Dietrich, 2001; Hsu et al., 2008; Scheingross

372 et al., 2014), a satisfactory theoretical explanation remains the subject of ongoing work.

373 Resistance to impact wear in brittle materials can be related to toughness, the capacity to store

374 energy through elastic strain (Engle, 1978). At the limit of brittle failure, the strain energy per

375 unit volume $(\beta)$ scales with ${\sigma_{T}}^{2}$ divided by Young's modulus of elasticity $(Y)$. On this basis,

376 Sklar and Dietrich (2004) proposed that rock resistance to wear by sediment impacts could be

377 quantified as the impact energy required to detach a unit volume $\left(\varepsilon_{v}\right)$,

$$
\varepsilon_{v}=k_{v} \beta=k_{v} \frac{\sigma_{T}^{2}}{Y}
$$

381 where $k_{v}$ is a dimensionless coefficient that depends in part on the efficiency of energy transfer. 382 Sklar and Dietrich (2004) determined $k_{v}$ to be $\sim 10^{6}$ by dropping gravel clasts from known 383 heights and measuring the resulting volumetric wear of rock disks of various strengths (Sklar and 384 Dietrich 2004, 2012). However, they assumed a constant value for $Y=5 \times 10^{5} \mathrm{MPa}$, hence the 385 empirical calibration of Eq. (10) can be written as

$$
\varepsilon_{v}=\frac{\sigma_{T}^{2}}{k_{Y}}
$$

389 where the dimensional coefficient $k_{Y} \sim 2 \mathrm{MPa}$ and includes the effects of elasticity. To explore 390 the influence of elasticity on rock resistance to abrasion, Beyeler and Sklar (2010) measured 
391 Young's modulus and several other rock properties for a large subset of the rock disks eroded by

392 Sklar and Dietrich (2001) and found that erosion rates scale with $\beta^{-1.5}$. However, compared to 393 tensile strength alone, including $Y$ in the regression substantially increased the scatter and 394 reduced the predictive power of the relationship.

396 using a rigid, polyurethane foam substrate in place of rock or concrete. The polyurethane foam 397 spans the same range of tensile strengths $\left(\sim 10^{-1}\right.$ to $\left.10^{1} \mathrm{MPa}\right)$ as natural rock, but varies 398 approximately an order of magnitude in bulk material density $\left(\rho_{r}\right)$ and two orders of magnitude 399 in Young's modulus. To the extent that polymer-based foam obeys the same fracture mechanics 400 as crystalline rock, the Scheingross et al. (2014) experiments can be used to test aspects of the 401 erosion theory (i.e., Eq. 10) in ways that cannot be done with natural rock or concrete that have 402 little variation in $\rho_{r}$ and $Y$.

403 Foam mass erosion rates have a slightly different power-law scaling with tensile strength 404 than observed in rock or concrete (Fig. 4A); however, volumetric erosion rate $\left(E_{v}\right)$ for all three 405 materials follow identical scaling with $E_{v}=E_{m} / \rho_{r}$ proportional to $\sigma_{T}^{-2}$ (Fig. 4b). This is in 406 agreement with the formulations of Bitter (1963) and Sklar and Dietrich (2004) that are based on 407 a finite volume of erosion for a given impact energy. A volumetric, rather than mass-based, 408 erosion law may be more appropriate for brittle material such as rock, where erosion occurs by 409 the formation and coalescing of cracks (Engle, 1978). When plotted against strain energy, foam 410 volumetric erosion rates differ greatly from rock and concrete because the Young's modulus of 411 foam is orders of magnitude lower than rock for a given tensile strength (Fig. 4C). This result 412 implies that for Eq. (10) to apply to both rock and foam, $k_{v}$ must vary proportionally with $Y$, 413 which is contrary to the theoretical expectation of constant $k_{v}$ (Engle, 1978). Together with the 
414 results of Beyeler and Sklar (2010), the foam results suggest that the relationship between 415 erosion rate and tensile strength is not improved by including Young's modulus as an

416 independent factor. This may reflect the fact that strength and elasticity are strongly correlated, 417 as are most other rock material properties, including bulk density and compressive strength. As 418 a result, erosion resistance could be indexed by measurements of other rock properties besides 419 tensile strength, including elasticity, which underlies the common use of the Schmidt hammer to 420 characterize relative rock resistance in the field (Goudie, 2006).

421 A better theoretical foundation for scaling rock resistance to erosion by particle impacts 422 may be provided by fracture toughness $\left(K_{I C}\right)$, which quantifies the material resistance to 423 propagation of fractures that originate from preexisting flaws (or 'cracks') of length $c$,

$$
K_{I C}=(\pi c)^{0.5} \sigma_{T}
$$

427 in which the subscript IC denotes open mode tensile loading at the crack tip (Lawn, 1993).

428 Preexisting flaws in rock are provided by boundaries between mineral grains in crystalline rock, 429 between clasts and cement in clastic sedimentary rocks (e.g., Hatzor and Palchik, 1997), as well 430 as between micropores and other discontinuities in rock fabric. To investigate the role of flaw 431 size, Beyeler and Sklar (2010) measured crystal and clast size $\left(D_{c}\right)$ in thin sections of disks 432 eroded by Sklar and Dietrich (2001) and found that grain size, together with porosity $(p)$, 433 explained a large fraction of the scatter in the fit between erosion rate and tensile strength present 434 in Fig. 4B.

435 Improved understanding of the scaling between rock material properties and resistance to 436 erosion by low velocity sediment impacts would also help inform studies of incision into 
437 surfaces of other planetary bodies, particularly outer solar system icy satellites such as Titan.

438 There, where surface temperature is $\sim 90 \mathrm{~K}$, channels may be actively incising into Titan's water-

439 ice bedrock by flows of liquid methane carrying water-ice clasts as bedload (Collins, 2005;

440 Perron et al., 2006; Burr et al., 2013). To extend rock erosion resistance scaling to ultracold ice,

441 Litwin et al. (2012) measured the tensile strength and fracture toughness of polycrystalline ice

442 across a temperature range spanning $-10^{\circ} \mathrm{C}$ to $-150^{\circ} \mathrm{C}$ and found ice tensile strength scales

443 linearly with temperature, with the strength of ice at Titan temperatures roughly double that of

444 terrestrial conditions. In a complementary laboratory study, Sklar et al. (2012) measured

445 volumetric erosion rates of ultracold ice subjected to particle impacts and found that the impact

446 energy required to erode a unit volume of ice was roughly equal to that measured by Sklar and

447 Dietrich (2004) for natural rock of similar tensile strength.

448 In summary, experiments suggest that rates of bedrock incision by particle impacts can be

449 scaled across a range of rock types and strengths, including analog bedrock materials and 450 ultracold ice, using

451

452

$$
E=\frac{q_{e}}{\varepsilon_{v}}=\frac{q_{e} k_{R}}{\sigma_{T}^{2}}
$$

454 in which $q_{e}$ is the flux of impact kinetic energy per unit bed area, and the dimensional coefficient $455 k_{R}$ is a function of other rock properties, i.e., $k_{R}=f\left(D_{c}, p, \rho_{r}, Y\right)$. Equation (13) shows how 456 incision rates can be accelerated in the lab relative to the field by a factor of $10^{6}$ or more (Fig. 1), 457 i.e., where laboratory bedrock tensile strength is weaker by a factor of $10^{3}$ or more (Fig. 4). 458 Moreover, with Eq. (13) it is possible to distinguish the effects of rock resistance to erosion from 459 intermittency in temporal scaling between lab and field and to isolate erosion resistance from the 
effects of differing erosional intensity, as represented by $q_{e}$.

465 plucking, including how to properly scale such experiments. Plucking involves the removal of 466 large chunks of rock along intersection joint planes, and it may dominate erosion rates in well467 jointed rock types (e.g., columnar basalt) and during large floods that are capable of entraining 468 and transporting large blocks (e.g., Malde, 1968; Baker, 1973; Lamb and Fonstad, 2010; Lang et 469 al., 2013; Lamb et al., 2014). Bedrock can be jointed caused by primary (e.g., cooling joints in 470 basalt) or secondary causes (e.g., tectonic- and topographic-induced fractures; Miller and Dunne, 471 1996; Martel, 2006; Clarke and Burbank, 2010). Fluid flow and sediment-transport processes 472 can also contribute to fracturing rock or loosening of preexisting joints through chemical and 473 physical weathering, hydraulic wedging of sediment into crack openings (Hancock et al., 1998), 474 crack development from saltating clasts, and hydraulic pressure fluctuations (Hancock et al., 475 1998; Whipple et al., 2000).

476 The physics of how rock came to be fractured at Earth's surface are not well understood, 477 and the few plucking experiments that have been conducted have focused instead on the 478 hydraulic removal of already-fractured rock (e.g., Coleman et al., 2003; Dubinski and Wohl, 479 2013). Under the special case of little to no interlocking of friction between blocks of rock, 480 plucking is seemingly analogous to bedload transport of noncohesive sediment (e.g., 481 Chatanantavet and Parker, 2009; Lamb and Fonstad, 2010). If this is the case, then successful 482 scaling relationships for plucking are likely to be similar to those for sediment transport, 
483 including a critical Shields number of block entrainment and a block-Reynolds number (c.f. Eqs.

4845 and 6). However, for the case of plucking, the characteristic length scales in the dimensionless 485 numbers may vary depending on block aspect ratios and whether the dominant process is vertical 486 entrainment, sliding, or toppling (e.g., Hancock et al., 1998; Whipple et al., 2000). In section 5 487 we formalize some of these ideas, propose dimensionless numbers for plucking thresholds, and 488 compare results to existing experimental data.

\subsection{Scaling morphodynamics}

In experiments investigating morphodynamic interactions - in which evolving bed 493 topography significantly influences the rates of water flow, sediment transport, and bedrock 494 erosion - additional dimensionless numbers can be identified and used for scaling of system495 scale dynamics (Paola et al., 2009; Ganti et al., 2014). For example, some bedrock rivers 496 meander and experience loop cutoff, and these dynamics likely manifest over lengths that scale 497 with the channel width and over times that scale with the time to erode laterally a channel width 498 (e.g., Limaye and Lamb, 2014). Similarly, bedrock river channels may adjust their width in 499 response to changes in sediment supply, and the rate of these changes may scale with the time for 500 a river to incise a characteristic channel depth (e.g., Finnegan et al., 2007). Thus, the faster 501 erosion rates and smaller length scales in laboratory experiments (Fig. 1), as compared to natural 502 rivers, allow experiments to be particularly effective in exploring morphodynamic interactions 503 and channel-scale dynamics over tractable study times, dynamics in nature that are typically 504 impossible to observe directly. Paola et al. (2009) addressed system-scale dimensionless 505 variables for much larger erosional and depositional systems, where dimensionless numbers 
506 related to tectonics and climate are also important.

\section{3. The role of sediment transport in bedrock abrasion in zero-dimensional experiments}

512 sediment exerts on the process of river incision into bedrock. On the one hand coarse sediment

513 supplies the abrasive tools that are required to sustain erosion (the tools effect). On the other

514 hand, when deposited coarse sediment protects the bed from abrasion (the cover effect). This

515 realization frames Gilbert's hypothesis that intermediate sediment supplies, which optimize the

516 tools and cover effects, result in the highest abrasion rates. Importantly, Gilbert's hypothesis

517 also suggests that stream power-based approaches to modeling bedrock river incision are limited

518 by the fact that they do not account for sediment supply directly. In other words, the dependence

519 of river incision rate on sediment supply results in a nonunique relationship between river 520 incision rate, channel slope, and drainage area (e.g., Sklar and Dietrich, 2004; Gasparini and 521 Brandon, 2011).

523 3.1. Effect of sediment cover

The first test of Gilbert's hypothesis was accomplished experimentally by Sklar and 526 Dietrich (2001). This study used experimental abrasion mills to simulate the wear of a planar 527 bedrock river bed caused by bedload impacts (Fig. 4D). Sediment of various amounts and sizes 528 was introduced into the mills. The shear stress of the circulating water acting on the coarse 
529 sediment led to the saltation of bedload across the surface of the bedrock disks. The results of

530 these experiments demonstrate that peak bedrock erosion rates occur at an intermediate amount

531 of coarse-grained sediment supply where the bedrock is only partially exposed on the bed (Fig.

532 5). The experiments thus provide direct support for Gilbert's hypothesis and, hence, for the

533 limitations of using topographic data alone (e.g., Eq. 1) to estimate incision rates and patterns. In

534 addition to sediment supply, experiments have also revealed that erosion rates are highly

535 sensitive to sediment size and transport mode.

536

537 3.2. Influence of particle size and trajectory

Particle size and transport trajectory bear a strong influence on fluvial bedrock abrasion

540 rates by influencing the rate and kinetic energy of sediment impacts. The abrasion mill

541 experiments of Sklar and Dietrich (2001) showed that, with all other variables held constant,

542 erosion rates increased with increasing grain size caused by higher kinetic energy of impacts

543 (Fig. 6). For very large particles, however, erosion rates dropped to zero because no particles

544 were moving, and for small particles transported primarily in suspension erosion rates were

545 relatively small (Fig. 6). Thus, in addition to the effects of tools and cover, bedrock abrasion can

546 be separated into three regimes based on transport mode: bedload, suspension, and no motion.

547 The controls on particle motion have been the subject of laboratory experiments for over

548 a century. Gilbert (1914) made detailed observation of the motion of particles in a 10-m-long

549 flume, noting that particles near the bed move predominately by saltation (Fig. 3). Subsequent

550 studies (e.g., Einstein, 1950; Francis, 1973; Abbott and Francis, 1977; Nino et al., 1994) have

551 made use of high-speed photography to analyze particle trajectories under variable shear stress 
552 and for sediment of different grain size, density, and angularity. Using experimental data, Sklar 553 and Dietrich (2004) showed that saltation hop length, height, and velocity follow a power-law 554 scaling relationship with fluvial transport stage, $\tau^{*} / \tau_{c}^{*}$, suggesting that particle trajectory is 555 controlled predominately by grain size, density, and fluid stress (Fig. 7). Chatanantavet et al. 556 (2013) performed experiments analyzing grain motion over a smooth, Plexiglas bed and showed 557 good agreement with the transport-stage power law scaling of Sklar and Dietrich (2004) — but 558 only after adjusting the critical Shields stress value to account for a sediment-free bed (Fig. 7).

559 Lower $\tau_{*_{\mathrm{c}}}$ on smooth beds results from the reduction in particle friction angle (e.g., Wiberg and 560 Smith, 1987; Kirchner et al., 1990), and Chantantavet et al. (2013) calculated $\tau_{c}^{*}$ as low as 0.007

561 for their experiments (compared to $\tau_{c}^{*} \sim 0.045$ for rough beds). Chantanantavet et al. (2013)

562 additionally showed that saltation hop height, length, and velocity could be well predicted by Fr563 based scaling that is independent of transport stage for both smooth and rough beds, and this may

564 provide an easier method to predict grain trajectories in bedrock streams where $\tau_{c}^{*}$ can be

565 difficult to estimate. These ideas were formalized in a mechanistic model (Sklar and Dietrich, 566 2004; commonly referred to as the saltation-abrasion model), which expands on the form of Eq.

567 (13) by parameterizing $q_{e}$ for impacts by saltating bedload (Fig. 6). The good comparison 568 between experiments and theory (Fig. 6) suggests that the observed decrease in erosion rates 569 with smaller particle sizes in the abrasion mill experiments (with flow velocity and all other 570 variables held constant) is caused by (i) lower energy particle-bed impacts associated with 571 smaller $w_{s}$, and (ii) less frequent particle-bed impacts because of longer saltation-hop lengths for 572 finer sediment moving at a higher transport stage.

573 The experimental observation that saltation hop length increases with transport stage 574 (Fig. 7) leads to a counter-intuitive prediction in the saltation-abrasion model that beyond a 
575 threshold size, larger floods or steeper reaches produce lower erosion rates. For the case of

576 sediment in suspension, the saltation-abrasion model assumes particles have infinite hop lengths

577 and forces erosion rates to go to zero. Evaluating these predictions has been difficult, in part

578 because, unlike saltation (Fig. 7), few data exist on particle impact rates at high transport stages

579 with suspended sediment. Within the suspension-regime (i.e., $Z<2.4$; Eq. 7), saltation

580 trajectories no longer follow ballistic paths but can be lofted high into the water column (Fig. 3)

581 and travel distances $>10^{2}-10^{3}$ particle diameters between impacts (e.g., Francis, 1973; Nino et

582 al., 2003). While individual particle motions within the suspension-regime are difficult to

583 describe, the bulk sediment behavior is well described by active interchange between a near-bed

584 layer where sediment may roll, slide, and saltate (i.e., the bedload) and a dilute layer above

585 where motion is controlled by turbulence (i.e., the suspended load) (e.g., Rouse, 1937; McLean, 586 1991, 1992) (Fig. 3).

587 To account for the change in sediment transport mechanics between the bedload regime 588 (i.e., $Z>2.4)$ and the suspension regime $(Z<2.4)$, Lamb et al. (2008b) recast the saltation589 abrasion model in terms of near-bed sediment concentration rather than individual particle hop 590 lengths. The Lamb et al. (2008b) model (hereafter referred to as the total-load model) predicts 591 that erosion rates can increase for $Z<2.4$ because of faster impact velocities associated with 592 particles suspended within turbulent eddies that impinge on the bedrock, which increase the total 593 impact rate and the volume of rock removed per impact. Scheingross et al. (2014) performed 594 abrasion mill experiments focusing specifically on abrasion within the suspension regime. They 595 measured finite erosion for grains as small as $D=0.4 \mathrm{~mm}(Z=0.8)$, well within the suspension596 regime, and observed suspended sediment transport with active particle-bed impacts and 597 sediment concentrations increasing toward the bed, in agreement with suspension theory (e.g., 
598 Rouse, 1937; McLean, 1992) and previous experimental observations (e.g., Garcia and Parker,

599 1993). Erosion rates decreased with decreasing grain size, similar to the Sklar and Dietrich

600 (2001) results, caused by the reduction in particle mass for small grain sizes, the lofting of a 601 portion of the suspended load above the bedload layer (effectively decreasing the near-bed 602 sediment concentration), and viscous dampening for fine sediment sizes (Fig. 6). The total-load 603 model provides good agreement with the abrasion mill data of Sklar and Dietrich (2001) and 604 Scheingross et al. (2014) in the bedload and in the suspension regimes when impacts are 605 viscously damped for St $<75$ (Eq. 8; Fig. 6).

606

607 3.3. Implications for zero-dimensional abrasion laws for field scale and comparison to stream 608 power.

609

The experiments of Sklar and Dietrich (2001) and Scheingross et al. (2014) were aimed

611 at isolating and exploring key variables, such as transport stage in conjunction with sediment

612 size, in existing bedrock-abrasion theory. In natural rivers, however, bed material size within a

613 given reach is relatively constant, and instead changes in transport stage typically occur through

614 changing water discharge and bed shear stress associated with floods. Analog experiments of

615 floods are difficult to perform in zero-dimensional abrasion mills because of complications with

616 secondary circulation that occurs under high shear stresses. Therefore, the total-load model is

617 useful to explore scenarios more realistic for natural rivers.

618 Analysis of the total-load model shows that erosion rates can vary by orders of magnitude

619 for the same transport stage (and therefore, the same particle trajectory), depending on the 620 relative grain size, flow depth, channel slope, and sediment supply (Fig. 8). Using base 
621 conditions representative of the South Fork Eel River reference site (Sklar and Dietrich, 2004),

622 Scheingross et al. (2014) explored total-load model predictions by varying transport stage by

623 changing either grain size, flow depth, or bed slope, while holding all other variables constant.

624 This was performed for the case of constant sediment supply, $q_{s}$ (as in the abrasion mills), and

625 for sediment supply proportional to transport capacity, $q_{s c}$ (as is more likely the case in bedrock

626 rivers where extensive bed-cover is common; e.g., Johnson et al., 2009; DiBiase and Whipple,

627 2011). As was observed in abrasion mill experiments, when transport stage is varied by changing

628 grain diameter, erosion rates decrease with increasing transport stage $\left(\tau^{*} / \tau_{c}^{*}\right)$ owing

629 predominately to the fine grain sizes that produce lower energy impacts (Fig. 8). For the case of

630 constant sediment supply, increasing transport stage by increasing bed slope produces an initial

631 decrease in erosion rate due to a lofting of a portion of the sediment above the bedload layer and

632 increased particle velocities, both of which reduce the particle-bedrock impact rate. However,

633 the increase in particle impact velocity associated with higher shear stress offsets the reduction in

634 impact rate such that for high $\tau^{*} / \tau_{c}^{*}$ erosion rates increase with $\tau^{*} / \tau_{c}^{*}$. If sediment supply is

635 allowed to vary with transport capacity, as is often the case in natural rivers, the total-load model

636 predicts that erosion rates continually increase with $\tau^{*} / \tau_{c}^{*}$, similar to stream power model

637 predictions (Eq. 1). For this case, higher sediment supply and faster impact velocities offset

638 reductions in impact rate associated with particle trajectories. Thus, suspension-regime erosion

639 creates a negative feedback in the development of knickpoints, whereby as channels steepen,

640 erosion rates increase on the knickpoint surface relative to the lower-sloping channel segments

641 above and below. This acts to reduce the knickpoint slope and also allows the knickpoint to

642 continue upstream propagation, in contrast to bedload only erosion models which predict that

643 knickpoints stall out and can grow infinite in height when slopes become large enough for 
644 sediment to enter the suspension regime (Wobus et al., 2006; Crosby et al., 2007; Gasparini et 645 al., 2007; Sklar and Dietrich, 2008).

646 In addition to the issues with abrasion mills in testing abrasion theories for the effects of

647 large floods and steep bed slopes (Fig. 8), the representation of a river in the abrasion-mill as

648 essentially zero-dimensional is a major limitation. Coarse sediment transport capacity (which is

649 determined by depth, width, slope, and roughness together) does not evolve in the experiments

650 but is instead imposed. Thus the effects of spatial variability of erosion within the channel as

651 well as deposition of sediment, which together modify hydraulic geometry and roughness, are

652 not addressed in these experiments, nor are they addressed in the saltation or total-load abrasion

653 theories. The influence of particle trajectories and particularly the role of suspended sediment

654 may be especially pronounced in channels with complex topography where suspended sediment

655 can abrade objects protruding above the bedload layer. Limited experiments and theory have

656 begun to address these factors as discussed in the next section.

657

658 4. Feedbacks among abrasion, bed roughness, and channel morphology

659

660

Several experiments have attempted to explore experimentally the coevolution of channel

661 form and abrasion in bedrock channels in order to build on the understanding gained from

662 abrasion mill experiments (Fig. 9; Table 1). Below we first highlight insight gained from

663 experiments on the role of roughness in influencing bedrock incision, as well as feedbacks

664 between incision and roughness. Next we highlight experimental evidence for the controls on

665 channel width in bedrock channels, as well as its importance to the process of incision. 
Roughness is important to incision by abrasion because it influences the efficiency of

670 sediment transport and the tendency for particles to be deposited on the bed. Because the

671 abrasion rate averaged over the bed is strongly controlled by the extent of alluvial cover (Fig. 5),

672 the growth of roughness on the bed may be a key mechanism that modulates the relationship

673 between channel abrasion and sediment supply. Specifically, roughening of the channel increases

674 the probability that mobile sediment grains will come to rest where they are shielded from the

675 flow (e.g., Kirchner et al., 1990; Buffington and Montgomery, 1999; Chatanantavet et al., 2013.

676 In addition, roughness will locally increase the friction angle for stationary grains on the bed,

677 thereby increasing grain resistance to motion (e.g., Kirchner et al., 1990). Lastly, channel

678 roughness can increase the form drag on conveyed fluid, thereby resulting in the progressive

679 reduction in shear stress available for bedload transport (e.g., Manga and Kirchner, 2000).

680 Chatanantavet and Parker (2008) explored the relationships among sediment supply,

681 sediment transport capacity, roughness, and alluvial deposition in a series of experiments using

682 three different fixed roughness bedrock-bed morphologies (Table 1). A key observation of this

683 experiment was a path dependence for bedrock channel alluviation. Smooth bedrock beds

684 (defined as bed hydraulic roughness less than the composite grain and bar hydraulic roughness)

685 developed stable partial alluvial cover if the initial condition was an alluvial bed. In contrast, a

686 channel under the same boundary conditions, but with an initially sediment-free bed, would

687 evolve to a completely alluviated state. This runaway alluviation process was also documented

688 in flume experiments by Demeter et al. (2005) and Finnegan et al. (2007) (Table 1).

689 Chatanantavet and Parker (2008) argued that the runaway process occurs when bedrock 
690 hydraulic roughness is lower than the composite grain/bar hydraulic roughness in the alluviated 691 state. Thus sediment deposition on a smooth bedrock bed is a positive feedback process in 692 which deposited sediment creates more roughness and thus encourages more deposition, which 693 in turn creates more roughness. In an experiment in which a 300-m-long, 0.8-m-deep channel 694 was carved into weak bedrock in the field, Inoue et al. (2014) observed that the critical Shields 695 stress of particles was typical of alluvial channels only when the ratio of bedrock hydraulic 696 roughness was comparable to grain roughness. Otherwise, for bedrock channels that were 697 hydraulically smoother than the alluviated bed, the critical Shields stresses were lower (0.01698 0.02) than what is typically observed in alluvial channels. This observation supports 699 Chatanantavet and Parker's (2008) argument in that it suggests that roughness because of 700 deposited grains extracts more momentum from the flow than that associated with smooth, bare 701 bedrock. Nelson and Seminara (2012), Inoue et al. (2014), and Johnson (2014) all presented 702 theories that explain these observations by postulating differing grain and bedrock hydraulic 703 roughnesses. A key prediction of these theories is that the nature of the transition from a bare 704 bedrock to an alluvial state is controlled by the ratio of grain roughness to bedrock roughness. 705 As inferred by Chatanantavet and Parker (2008), runaway alluviation occurs only when the grain 706 hydraulic roughness is larger than the bedrock hydraulic roughness. When grain hydraulic 707 roughness is comparable or smaller than bedrock hydraulic roughness, channels transition 708 gradually from a bedrock to an alluvial state (Nelson and Seminara, 2012; Inoue et al., 2014; 709 Johnson, 2014), a finding supported by the observation that a prealluviated bed did not 710 experience runaway deposition in Chatanantavet and Parker's (2008) experiments. In addition,

711 the theoretical findings of Nelson and Seminara (2012), Inoue et al. (2014), and Johnson (2014) 712 are reinforced by the fact that roughness from artificial boulders in Chatanantavet and Parker's 
713 (2008) experiments supported stable partial alluvial cover.

714 In a set of experiments that explored the specific relationship between bedrock roughness

715 and alluvial cover extent, Davis (2013) (Table 1) demonstrated essentially the same key result of

716 Chatanantavet and Parker (2008), namely that partial alluvial cover can be supported when bed

717 roughness is comparable to grain roughness. In addition, Davis (2013) and Johnson and Whipple

718 (2010) (Table 1) showed that within the partial cover regime, the extent of alluvial cover on a

719 bedrock bed for a given sediment supply is linearly related to the amount of bed roughness (Fig.

720 10), as measured via the standard deviation of the detrended bed topography (as opposed to

721 hydraulic roughness). These experimental results are also consistent with the theory of Nelson

722 and Seminara (2012), Inoue et al. (2014), and Johnson (2014): if grain roughness is smaller than

723 bedrock roughness, then deposition will smooth the bed, leading to an increase in transport

724 efficiency with increasing deposition. The rougher a bedrock bed is, the more deposition needs to

725 occur to smooth it to transport the imposed load. Thus, for a given supply rate, rougher beds

726 support more alluvial cover than smoother beds, as observed in Davis (2013) and Johnson and

727 Whipple (2010).

728 The observations in Davis (2013) and Johnson and Whipple (2010) demonstrated that bed

729 roughness strongly modulates the relationship between channel abrasion rate and sediment

730 supply through its influence on the efficiency of bedload transport and the deposition of alluvial

731 sediment. Indeed, they show that roughness growth during incision is as important a control on

732 alluvial cover as the supply of sediment itself. A key question that emerges from these

733 experiments, then, is what actually determines roughness in natural bedrock channels? Is it

734 determined by the process of abrasion, is it a property of the bedrock, or is it controlled by the

735 alluvium that is deposited in the channel? 
737 roughness during abrasion of a bedrock channel. Using a flume with an erodible, preroughened

738 concrete bed, Demeter et al. (2005) (Table 1) observed that at high sediment supply rates, 739 topographic highs were preferentially eroded because low points were buried in gravel. A similar 740 result was obtained by Finnegan et al. (2007) and Johnson and Whipple (2010). In these latter 741 two examples, bedload transport on an initially smooth bed led to the cutting of a narrow slot 742 (Fig. 9). Drag caused by the growth of this slot in both experiments ultimately led to deposition 743 of a protective layer of alluvial cover on the bed, which in turn caused preferential erosion of the 744 channel walls where they contacted the deposited gravel. Like Demeter et al. (2005), these 745 experiments showed that partial alluvial cover focuses incision on exposed high points and 746 thereby suppresses (Finnegan et al., 2007) or even reverses (Johnson and Whipple, 2010) the 747 growth of roughness because of bedrock abrasion.

748 In contrast to cases with high sediment supply rates, Wohl and Ikeda (1997) (Table 1), 749 Johnson and Whipple (2007; 2010), Finnegan et al. (2007), and Demeter et al. (2005) all showed 750 that at low sediment supply rates relative to transport capacity, topographic low points were free 751 of deposition and hence captured bedload and eroded more rapidly than neighboring high points, 752 thereby cutting slots into the bedrock and increasing channel roughness. Wohl and Ikeda's 753 (1997) experiments showed that the morphology of the emergent channel roughness depends 754 strongly on channel slope. In particular, with increasing slope, slots become more tortuous (Fig.

755 9B). A reasonable hypothesis to explain this emergent pattern is that it reflects the change in 756 erosional mechanics that occur as particles begin to transition from the saltation to the 757 suspension regime (Fig. 3). As particles become entrained in the flow, abrasion is more strongly 758 coupled to local turbulent flow structures. Thus emergent channel morphologies should depend 
759 on the Rouse number. Indeed, in Fig. 9 the two similarly tortuous channels $(9 B, C)$ have Rouse

760 numbers $(Z \sim 2.3-3.6)$ that put them very close to the suspension threshold $(Z<2.4)$.

761 Alternatively, Fig. 9A shows a much smoother and straighter channel with a Rouse number $(Z \sim$

762 6.2) that is well within the bedload regime $(Z>2.4)$.

763 It is worth emphasizing that even for channels developed close to the suspension

764 threshold (e.g., Wohl and Ikeda, 1997; Johnson and Whipple, 2007) the growth of bed roughness

765 during slot cutting decreased the efficiency of sediment transport and did eventually trigger

766 deposition of alluvial cover either locally or over the entire bed, thus returning the channel to a

767 cover-limited regime in which roughness growth was suppressed or reversed. In addition, even

768 in the absence of significant alluvial cover, isolated roughness elements that protrude into the

769 flow may focus bedload abrasion. Several experiments demonstrate that the front side of

770 protruding objects can be eroded and streamlined by sediment within the bedload regime

771 (Johnson and Whipple, 2010; Wilson et al., 2013; Wilson and Lavé, 2014). Similarly, recent

772 modification to the saltation-abrasion model by Huda and Small (2014) predicts enhanced

773 erosion on the front side of protruding obstacles compared to that expected for a flat bed because

774 of less oblique impacts on protruding obstacles resulting in higher energy impacts. Similar

775 effects may also occur where sediment is suspended, and preliminary experiments show

776 sediment in suspension preferentially erodes the upstream side of protruding objects (Cornell, 777 2007).

778 Taken together, the experiments described above hint at the possibility that the presence

779 or absence of significant alluvial cover on a bedrock river bed may control whether roughness

780 increases or decreases on a bedrock bed. Smooth bedrock beds lead to the growth of roughness

781 through slot cutting (Demeter et al., 2005; Finnegan et al., 2007; Johnson et al., 2007, 2010). 
782 Rough beds, because they encourage coarse sediment deposition in channel low points,

783 preferentially erode exposed highs and reduce roughness (Demeter et al., 2005; Finnegan et al.,

784 2007; Johnson and Whipple, 2010). Thus feedbacks between abrasion, roughness growth, and

785 sediment deposition clearly exist and point to a key future research question. Can a stable bed

786 roughness, alluvial cover extent, and abrasion rate emerge for a given sediment supply? Or is the

787 process of abrasion fundamentally unstable?

788

789

\subsection{Lateral abrasion rates, vertical incision, and channel width}

790

The width of a channel is important to river incision into bedrock because it determines

792 the bed area over which sediment can be transported and influences the magnitude and spatial

793 variation of fluid stresses applied to the bed. However, the controls on channel width and its

794 relationship to both sediment transport and incision in bedrock channels remain poorly

795 understood. Bedrock channel width adjustment can occur by widening caused by lateral wear of

796 channel walls and narrowing because of focused incision over only part of the channel cross

797 section. Thus, the variability in the spatial distribution of incision directly influences the extent

798 and rate of channel width adjustment.

799 Five experiments have addressed the controls on width adjustment in bedrock channels

800 undergoing abrasion (Wohl and Ikeda, 1997; Carter and Anderson, 2006; Finnegan et al., 2007;

801 Johnson and Whipple, 2010; and Fuller, 2014). In these experiments, roughness (through its

802 influence on sediment transport and deposition) and sediment supply (through its influence on

803 the width over which active incision occurs) represent potentially key controls on width 804 evolution. 
806 documented the growth of abrasional inner channels on the floor of initially flat flumes (Fig. 9).

807 Finnegan et al. (2007) and Johnson and Whipple (2010) observed that when their experimental

808 channels were free of alluvial cover on the bed, incision was focused over a fraction of the bed

809 width that varied strongly with bedload supply. For a fixed-slope channel with a smooth bed,

810 narrow slots were carved for low sediment supply rates and wider slots were carved for higher

811 supply rates. This change in slot width can be seen in Fig. 9A, where remnants of channels

812 evolved under different sediment supplies are visible. Both experiments discussed above

813 observed an approximately linear increase in slot width with sediment supply, suggesting that the

814 zone of active bedload transport and hence of active incision into bedrock varies as a function of

815 bedload supply. The scaling of abrasional channel width with sediment supply is explained in a

816 theoretical analysis by Nelson and Seminara (2011). Bedload moves downstream at a

817 characteristic velocity for a given shear stress (e.g., Sklar and Dietrich, 2004). To accommodate

818 an imposed sediment supply for a given stress, only the width over which active bedload

819 transport occurs can adjust. Hence abrasion width and bedload supply are linked.

820 In both experiments of Finnegan et al. (2007) and Johnson and Whipple (2010), the

821 growth of roughness because of slot cutting eventually led to the deposition of alluvial cover on

822 the bed. This, in turn, led to concentrated transport and incision on the edges of the alluvial

823 deposit and thereby encouraged channel widening. Thus, the results of these experiments

824 indicate that channels can adjust their width by changing the region over which vertical incision

825 takes place in the channel. Moreover, because the pattern of incision on the bed in these

826 experiments is controlled by sediment supply and sediment deposition, the results of these

827 experiments suggest that width, like roughness, may evolve in response to changes in sediment 
828 supply or transport capacity. That said, integrating all of the magnitude and frequency variation

829 in sediment supply and water flux experienced by a typical river is a key challenge in connecting 830 the experimental morphologies to natural channels.

831 Fuller (2014) addressed the role of roughness in governing lateral abrasion more directly.

832 In this experiment, bed roughness was varied systematically along the length of a synthetic

833 bedrock bed by changing the size of particles fixed to the bed. Rates and patterns of lateral wear

834 were then documented using a scanning laser. The key result of this experiment was that above a

835 critical roughness value, rough sections of the channel exhibited rates of lateral wear that were 3-

8365 times higher than adjacent smooth channel sections (Fig. 11). Fuller hypothesized that this

837 dramatic difference in lateral wear reflects the fact that rougher beds deflect particles away from

838 the downstream transport direction and into the channel walls more effectively than smooth beds.

839 Erosion by suspended sediment may also exert a key influence on bedrock channel width.

840 Suspended sediment lofted into the water column can erode channel sidewalls above the bedload

841 layer height, and erosion of sidewalls by suspended sediment can occur even if the bed is

842 partially or fully covered with sediment (Hartshorn et al., 2002). Widening of sidewalls from

843 suspension-regime erosion likely occurred in the flume experiments on slot-canyon evolution by

844 Carter and Anderson (2006), for example.

845

846 5. Erosion by plucking

847

848 In addition to abrasion, plucking is recognized as an important mechanism in fluvial

849 bedrock erosion (e.g., Miller, 1991; Annandale, 1995; Whipple et al., 2000), although it has

850 received considerably less study experimentally. Here we review theory and limited experiments 
851 for erosion rates by plucking in section 5.1; derive new thresholds for plucking by vertical 852 entrainment, sliding, and toppling in section 5.2; and assess the relative roles of entrainment 853 versus transport in setting the rate of plucking in section 5.3.

\subsection{Erosion rate}

In the only complete theoretical model for fluvial erosion by plucking to date,

858 Chatanantavet and Parker (2009) envision, through the process of exhumation, intact rock 859 moving vertically first through an aging layer, where rock fractures because of erosional 860 unloading and chemical weathering, and second through a battering layer where fracturing 861 progresses through impacts caused by saltating sediment (similar to the process of abrasion 862 discussed in section 4) until block sizes are sufficiently small to be removed hydraulically. In 863 Chatanantavet and Parker (2009), the entrainment rate $(E)$ follows a form well known for the 864 entrainment of loose bed sediment into transport:

$$
\frac{E}{\left(\operatorname{Rg} D_{b}\right)^{1 / 2}}=a_{p}\left(\tau^{*}-\tau_{p c}^{*}\right)^{n_{p}}
$$

868 where $R=\left(\rho_{r}-\rho_{w}\right) / \rho_{w}$ is the submerged specific density of sediment, $D_{p}$ is the characteristic

869 block size, $\tau_{p c}^{*}$ is the threshold value of Shields stress to initiation plucking, and $a_{p}$ and $n_{p}$ are 870 empirical coefficients. Tsujimoto (1999), for example, indicate $a_{p}=0.0199, n_{p}=1.5$, and $\tau_{p c}^{*}$ $871=0.045$ for loose sediment, values adopted by Chatanantavet and Parker for plucking. 872 Chatanantavet and Parker (2009) also include factors in Eq. (14) to account for the availability of 
873 pluckable chunks on the bed because of cover by alluvium or incomplete aging and battering.

874 Similar to experimentally verified models for alluvial cover discussed in Section 4 (e.g., Fig. 5),

875 alluvial cover is parameterized as a linear function of the sediment supply relative to sediment

876 transport capacity of bedload sediment:

877

878

$$
\frac{q_{s c}}{\left(R g D^{3}\right)^{1 / 2}}=a_{s}\left(\tau^{*}-\tau_{c}^{*}\right)^{n_{s}}
$$

879

880 in which $a_{s}$ and $n_{s}$ are empirical coefficients. Fernandez Luque and van Beek (1976), for 881 example, suggested $a_{s}=5.7$ and $n_{s}=1.5$.

882 Few tests of the plucking theory exist, and moreover it is not known whether rock 883 fracture, entrainment of blocks, or the downstream transport of blocks is the rate limiting step in 884 fluvial erosion by plucking (Howard et al., 1994). As discussed by Howard (1998) and Whipple 885 et al. (2000), the prevalence of alluvium in rivers cutting through jointed rocks suggests that 886 entrainment and transport are often the rate limiting mechanisms. The lack of observations in 887 natural rivers is in part because erosion by plucking occurs during infrequent, extreme events. 888 One rare test of the transport-limited idea comes from the formation of Canyon Lake Gorge, TX, 889 USA, a natural experiment in which lake spillover in 2001 created an 15-m-deep gorge in well890 jointed limestone in a matter of days. Lamb and Fonstad (2010) showed that formation of the 891 gorge is consistent with a model in which the erosion rate is limited by the transport of the 892 blocks, similar to Eq. (14). Similarly, Chatanantavet and Parker (2011) found good agreement 893 between their model (Chatanantavet and Parker, 2009) and observations of knickpoint retreat by 894 block plucking in a small plucking-dominated stream in Indiana, USA (Miller, 1991). 
The only experimental test of the rate of rock erosion by plucking, to our knowledge, is

896 the work of Dubinski and Wohl (2013) who cast abrasion-resistant, sand-cement mixtures into

897 rectangular blocks creating a bedrock bed with joints parallel and perpendicular to the bed

898 surface (Fig. 12). Although a few blocks were plucked through vertical entrainment, most

899 erosion occurred through block sliding at a knickpoint face (where blocks lacked a downstream

900 neighbor). Dubinski and Wohl (2013) found that the erosion rate followed expectations from

901 bedload transport and entrainment relationships similar to Eq. (15) and was consistent with

902 limited field observations (e.g., Lamb and Fonstad, 2010; Chatanantavet and Parker, 2011).

903 These results suggest that the rate of plucking erosion via block sliding at a knickpoint may also

904 be well represented by Eq. (14) even though the process of block sliding is not explicitly

905 included in the model.

906

\section{5.2. Threshold for block entrainment}

908

909 Although the threshold for sediment entrainment in rivers has been studied extensively in 910 experiments for nearly a century (Shields, 1936; Brownlie, 1983; Wilcock, 1993; Prancevic et

911 al., 2014), comparatively little work has been done on the threshold for block entrainment in

912 bedrock river beds (see Carling and Tinkler (1998) for a review). Three mechanisms that are

913 typically considered for block removal (e.g., George and Sitar, 2012) are: (i) vertical entrainment

914 leaving behind a hole, (ii) downstream block sliding where the downstream neighbor has already

915 been removed, and (iii) downstream toppling of a block where the downstream neighbor has

916 already been removed. Determining the controls on these thresholds is important for predicting

917 incision rates by plucking (e.g., Eq. 14). 
919 5.2.1. Vertical entrainment

920

921 For vertical entrainment, Hancock et al. (1998) considered the critical stress for entrainment by

922 balancing hydraulic lift with submerged block weight and argued that block height $(H$, Fig. 13$)$ is

923 the sole dimension of importance for resistance of block movement because of gravity. Whipple

924 et al. (2000) added frictional stresses along the block sides to the theory for vertical entrainment

925 and showed that, in addition to larger block heights, blocks with smaller lengths in the

926 downstream direction ( $L$, Fig. 13$)$ and widths in the cross-stream direction $(W)$ relative to block

927 height should be more resistant to erosion. Experimental tests to date have largely neglected

928 frictional wall stresses and instead focused on the important role of in-crack pressure fluctuations

929 (e.g., USBR, 2007) and protrusion of the block above the surrounding river bed. For example,

930 Reinius (1986) measured pressure around test blocks rotated at various angles relative to the

931 river flow and found block protrusion to be significant in inducing forces that entrain blocks.

932 Coleman et al. (2003) performed systematic experiments on vertical entrainment of prismatic

933 blocks with little sidewall friction and found that the threshold stress for block entrainment 934 depends linearly on the submerged block weight per unit bed area and inversely on the block 935 protrusion height ( $P$, Fig. 13) normalized by the block length. Coleman et al. (2003) cast their 936 experimental results in terms of a critical Shields stress for plucking as:

937

938

$$
\tau_{p c}^{*}=0.0015\left(\frac{P}{L}\right)^{-1}+0.002
$$

940 where 


$$
\tau_{p c}^{*} \equiv \frac{\tau_{b}}{\left(\rho_{r}-\rho_{w}\right) \mathrm{gH}}
$$

944 Equation (16) has been subsequently verified in additional flume experiments for the vertical 945 entrainment of prismatic blocks (Melville et al., 2006); however, as noted by Melville et al. 946 (2006) an exponential decay function may be more appropriate as $\tau_{p c}^{*}$ should not tend to infinity 947 for the limiting case of $P=0$.

948 To synthesize the existing theory and experimental work on vertical entrainment of 949 blocks and the relative roles of block side friction, protrusion, and block dimensions, here we 950 propose a new derivation for vertical entrainment building on the force balance model of 951 Whipple et al. (2000) but cast in terms of a critical Shields stress, following the work of Wiberg 952 and Smith (1987) for entrainment of sediment. In subsequent sections we will also derive new 953 relationships for the threshold of sliding and toppling that will aid in comparison of the relative 954 role of the three mechanisms and highlight where experimental tests are needed.

955 For river flow over the top of a well-jointed, fully submerged, rectangular block with 956 river-bed parallel and perpendicular joint sets, we consider the combined forces of buoyancy and 957 gravity $\left(F_{g}\right)$, downstream-directed bed shear stress $\left(F_{s}\right)$ and form drag associated with protrusion 958 of the block $\left(F_{D}\right)$, hydraulic lift directed perpendicular to the bed surface $\left(F_{L}\right)$, and frictional 959 forces along the block side walls $\left(F_{w}\right)$ (Fig. 14), as:

960

961

962

$$
F_{g}=\operatorname{LWHg}\left(\rho_{r}-\rho_{w}\right)
$$




$$
F_{s}=\tau_{b} L W
$$

964

$$
F_{D}=0.5 \rho_{w} C_{D} u^{2} P W
$$

965

966

$$
F_{L}=F_{L}^{*}\left(F_{D}+F_{s}\right)
$$

967

968 where $C_{D}$ is a local drag coefficient, $u$ is the downstream flow velocity acting on the protruded 969 part of the block, and $\tau_{w}$ is the frictional stress along the block sidewalls acting over an area $A_{w}$.

970 We parameterize the lift force as a linear function of the combined forces due to drag and shear

971 Wiberg and Smith (1987) suggest that the empirical constant $F_{L}^{*}=0.85$; however, this 972 coefficient has considerable variability (Schmeeckle et al., 2007).

973 To solve for the threshold for vertical entrainment, and assuming the river bed gradient is 974 at an angle of $\theta$ (Fig. 13), we set equal the destabilizing force of lift to the stabilizing forces of 975 gravity and frictional forces along the walls as,

976

977

$$
F_{L}=F_{g} \cos \theta+F_{w}=F_{g} \cos \theta+2 \tau_{w} H(L+W)
$$

979 which assumes that the frictional stresses are equal on all four sides of the block and the 980 protrusion height is small compared to the block height $(P<<H)$. Substituting Eq. (18) into (19) 981 and rearranging results in 


$$
\tau_{p c}^{*}=\frac{\tau_{b}}{\left(\rho_{r}-\rho_{w}\right) \mathrm{gH}}=\frac{\left(\cos \theta+2 \tau_{w}^{*}\left(1+\frac{W}{L}\right)\right)}{F_{L}^{*}\left(1+\frac{1}{2} C_{D}\left(\frac{u}{u_{*}}\right)^{2} \frac{P}{L}\right)}
$$

985 in which $\tau_{w}^{*}=\frac{\tau_{w}}{\left(\rho_{r}-\rho\right) \mathrm{gW}}$ is a dimensionless block sidewall stress.

987 explicitly including the parameters that depend on fluid viscosity and the effect of river and 988 block scale through the particle Reynolds number (Eq. 6) dependence of $C_{D}$ and the flow 989 Reynolds number dependence of $\frac{u}{u_{*}}$ (Eq. 4), as discussed in section 2.1 (e.g., Schlichting, 1979). 990 For example, $C_{D}$ varies with particle Reynolds number for small particle Reynolds numbers but 991 is approximately constant $\left(C_{D} \sim 1\right.$; e.g., Schlichting, 1979; Schmeeckle et al., 2007) for $\operatorname{Re}_{p}>$ 992100 , conditions typical of most natural rivers, allowing direct comparison to flume experiments 993 that also have $\operatorname{Re}_{p}>100$. Likewise, because we are interested in the velocity near the height of 994 the protruding block $(z=P)$, and assuming that bed roughness is similar to the block protrusion 995 height $\left(k_{s}=P\right)$ Eq. (4) reduces to a constant $u(z=P) / u_{*}=8.3$ for fully turbulent and 996 hydraulically rough flow. Equation (20) matches the experimental data of Coleman et al. (2003) 997 well (Fig. 14A). Data scatter at low $\tau_{p c}^{*}$ corresponds to cases with large protrusion heights 998 relative to block heights (e.g., $P / H>0.5$ ), which is unlikely in natural rivers and also violates our 999 assumption of $P<<H$ in the derivation of Eq. (20). 
1002 Hancock et al., 1998) and that the protrusion height relative to block length, rather than block 1003 height, is crucial in determining the threshold for entrainment (Coleman et al., 2003). The 1004 denominator of the right-hand side (rhs) of Eq. (20) contains two terms: the first of which is 1005 unity, and the second term contains block protrusion height. Because $C_{D} \sim 1$ and $1006\left(u(z=P) / u_{*}\right)^{2} \approx 8.3^{2}=69$ for turbulent, hydraulically rough flow, the protrusion height need 1007 only be a small fraction (greater than a few percent) of the block length to have a significant 1008 effect on block entrainment (Fig. 14B). This rationale is consistent with existing experiments 1009 that show a strong effect of $P / L$ on vertical entrainment (Coleman et al., 2003; Melville et al., 1010 2006) (Eq. 16). Coleman et al. (2003) noted that their results for $\tau_{p c}^{*}$ were significantly lower 1011 than expected by comparison of transport thresholds for sediment (e.g., $\tau_{c}^{*}=0.045$; Fig. 14A), 1012 and they speculated this may be a particle-shape effect as they investigated rectangular blocks 1013 rather than rounded particles. However, according to Eq. (20), particle-shape effects would need 1014 to manifest in more than an order of magnitude increase in drag $\left(C_{D}\right)$ for blocks relative to gravel 1015 to explain the data, which is unlikely based on drag-coefficient studies (e.g., Schlichting, 1979; 1016 Schmeeckle et al., 2007). Instead, we propose that the comparatively low values of $\tau_{p c}^{*}$ observed 1017 by Coleman et al. (2003) were because of their smooth perspex bed upstream of the blocks of 1018 interest, which resulted in a hydraulically smooth flow and near-bed flow velocities that were 1019 increased substantially compared to the hydraulically rough case. Our model results are 1020 consistent with data of Coleman et al. (2003) using $u(z=P) / u_{*}=20$ (Fig. 14A), which 1021 corresponds to the case of hydraulically smooth flow for the bed-shear stresses observed in their 1022 experiments. 
1024 that entrainment becomes increasingly difficult for $P / L<0.5$, which is likely for many natural

1025 rivers (Fig. 14B). For the case of $P=0, \tau_{p c}^{*}$ for vertical entrainment approaches unity, similar to 1026 criteria for incipient suspension (Eq. 7), which is highly unlikely for large blocks unless the river 1027 is experiencing a very extreme flood event.

1028 Equation (20) suggests that larger block widths $(W)$ reduce the role of wall stresses in 1029 resisting entrainment (Whipple et al., 2000). As expected, the data of Coleman et al. (2003) 1030 show no effect of block width because they had smooth, low-friction block sidewalls. The 1031 numerator of the rhs of Eq. (22) shows two terms, the first of which is $\cos \theta$ that is near unity for 1032 most rivers (Fig. 13). This suggests that $\tau_{w}^{*}$ must also be of order unity to play a significant role

1033 in resisting block entrainment (Fig. 14C). Dimensionless wall stress of $\tau_{w}^{*} \approx 1$ implies that 1034 sidewall stresses must be approximately equivalent to the block weight per unit area. Such large 1035 wall stresses are probably unlikely unless significant interlocking or cohesive bonds exist 1036 between blocks. This rationale may explain why experiments have yet to find a significant effect 1037 of wall stress, or block width and length, on entrainment thresholds (Coleman et al., 2003; 1038 Dubinski and Wohl, 2013). Experiments with significant interlocking have yet to be performed, 1039 however, and $\tau_{w}^{*}$ provides a dimensionless scale parameter to compare interlocking and 1040 frictional stresses along block walls between experimental and field cases.

\section{$1042 \quad$ 5.2.2. Sliding}

1043

Dubinski and Wohl (2013) observed that the main process of erosion in their experiments

1045 was not vertical entrainment but downstream sliding of blocks at a vertical-step knickpoint 
1046 (which in their case was also a waterfall) (Fig. 12). This is consistent with the experimental 1047 results of Carling et al. (2002) for their cases with isolated, fully submerged blocks. Hancock et 1048 al. (1998) derived a formula for the threshold of block sliding by considering the forces of fluid 1049 or bed shear stress and submerged block weight. Following Whipple et al. (2000), Dubinski and 1050 Wohl (2013) modified the formulation of Hancock et al. (1998) to include friction along the 1051 block sides, and the revised theory showed that smaller block width adds to stability whereas 1052 smaller block lengths may decrease stability. Despite including wall stresses (and therefore the 1053 role of block width and length) into the theory, the experimental results of Dubinski and Wohl 1054 for the threshold of sliding using concrete blocks showed nearly equivalent entrainment stresses 1055 of 16 and $17 \mathrm{~Pa}$ despite a factor of two increase in block width and length (i.e., a factor of four 1056 increase in block weight) for blocks of $W=L=3$ and $6 \mathrm{~cm}$ (all with $H=3 \mathrm{~cm}$ ). Using Eq. (20), 1057 these results are nearly equivalent, and $\tau_{p c}^{*}=0.036$ and 0.039 for their small and large blocks, 1058 respectively, and are counter to the theory of Whipple et al. (2000) that the critical stress for 1059 sliding should decrease with increasing block width and length.

Here we derive a critical Shields stress for block sliding following the assumptions and 1061 formulations used above for vertical block entrainment. Importantly, we assume that blocks are 1062 well submerged in the flow (e.g., see Carling et al. (2002) for the role of block emergence) and 1063 that there is not a waterfall at the free face (see section 6 for a separate discussion on bedrock 1064 erosion by waterfalls). We consider a force balance parallel to the bed in which the upstream1065 directed force that resists motion from bed friction follows a Mohr-coulomb friction relationship 1066 (e.g., Wiberg and Smith, 1987),

1067

1068

$$
F_{g} \sin \theta+F_{s}+F_{D}=\left(F_{g} \cos \theta-F_{L}\right) \tan \phi+F_{w}
$$


1070 in which $\left(F_{g} \cos \theta-F_{L}\right)$ represents the bed-normal force and $\tan \phi$ is a bed friction angle. For 1071 the case of sliding, the wall stress acts only on two walls of the block (parallel to the flow 1072 direction), so that $F_{w}=2 \tau_{w} L H$. Substituting these expressions into Eqs. (17) and (21) and 1073 rearranging results in

1074

1075

$$
\tau_{p c}^{*}=\frac{\tau_{b}}{\left(\rho_{r}-\rho_{w}\right) \mathrm{gH}}=\frac{\cos \theta(\tan \phi-\tan \theta)+2 \tau_{w}^{*}}{\left(1+\frac{1}{2} C_{D}\left(\frac{u}{u_{*}}\right)^{2} \frac{P}{L}\right)\left(1+F_{L}^{*} \tan \phi\right)}
$$

1077 Typical values of friction angles between slabs of rock range from about $\phi=20^{\circ}$ to $45^{\circ}$ (Selby, 1078 1993; Carling and Tinkler, 1998). 1080 (2013) and Carling et al. (2002) for block sliding (Fig. 14A). The experiments of Carling et al. 1081 (2002) are for initial motion of isolated, centimeter-scale, prismatic blocks (i.e., $\tau_{w}^{*}=0$ ) of 1082 various dimensions that slid across a planar, rough bed (i.e., $P=H$ ) with bed roughness lengths 1083 of 1 to $2 \mathrm{~mm}$ (Fig. 14A). Like the threshold model for vertical entrainment, inspection of Eq. 1084 (22) shows again that $\tau_{w}^{*}$ must be order unity (i.e., frictional wall stresses must be a significant 1085 portion of the block weight per unit sidewall area) in order for wall stresses or block width to be 1086 important in limiting sliding (Fig. 14C). Wall friction is less important for sliding, as compared 1087 to vertical entrainment, caused by reduction in wall-contact area (four frictional boundaries 1088 versus two). In contrast to wall friction, bottom friction and block protrusion (or lack thereof) 1089 likely dominate the resistance to sliding in well-jointed rock (Fig. 14B), consistent with 
1090 experimental results that show virtually no effect of block width on erosion thresholds (Carling

1091 et al., 2002; Dubinski and Wohl, 2013). As expected, the threshold for sliding is always

1092 significantly less than the threshold for vertical entrainment (Fig. 14), indicating that block

1093 sliding at steps in the river bed likely dominates over vertical entrainment in natural rivers, at 1094 least in bedrock with near river-bed-parallel joints.

1095

1096 5.2.3. Toppling

1097

1098

Lamb and Dietrich (2009) argued that blocks without a downstream neighbor (Fig. 13)

1099 are more likely to topple than to slide if $H / L>0.5$ and formulated a stability model for block

1100 toppling as a function of torques due to gravity, buoyancy, bed shear stress and drag associated

1101 with protrusion of the top of the block into the flow. Their specific application was for toppling

1102 of blocks at the face of waterfalls, and they found good agreement between model and

1103 measurement in a flume experiment using stacked blocks with large $H / L$ (Fig. 12). This is

1104 consistent with the experiments of Dubinski and Wohl (2013) in that they also observed block

1105 toppling more often for their case of $H / L=1$ (small blocks) in comparison to $H / L=0.5$ (large

1106 blocks) (I. Dubinski, Colorado State University, personal communication, 2014). In addition,

1107 Carling et al. (2002) demonstrated that toppling may dominate over sliding for isolated blocks

1108 that are partially emergent from the flow. Here we extend the torque-balance model of Lamb

1109 and Dietrich (2009) to the case of toppling of blocks at a bedrock step that is well submerged

1110 (i.e., no waterfall) and cast it in terms of a critical Shields stress to make comparisons between

1111 the theories derived above for vertical entrainment and sliding. To our knowledge, no 1112 experiments have been conducted on toppling of fully submerged blocks. 
1114 gravity (if the column is leaning downstream) against the resisting torques of gravity and

1115 frictional forces against the column walls (Fig. 13):

1116

1117

$$
\frac{1}{2} \mathrm{H} \sin \theta F_{g}+H\left(F_{s}+F_{D}\right)+\frac{1}{2} \mathrm{~L} \cos \theta F_{L}=\frac{1}{2} \mathrm{~L} \cos \theta\left(F_{g}+F_{w}\right)
$$

1119 In this case, like the sliding block, the frictional forces along the two sidewalls of the block are 1120 given by $F_{w}=2 \tau_{w} L H$. Rearranging Eq. (23) in terms of a critical Shields stress results in

$$
\tau_{p c}^{*}=\frac{\tau_{b}}{\left(\rho_{r}-\rho_{w}\right) \mathrm{gH}}=\frac{\frac{L}{H} \cos \theta\left[\frac{1}{2}\left(1-\frac{H}{L} \tan \theta\right)+\tau_{w}^{*}\right]}{\left(1+\frac{1}{2} C_{D}\left(\frac{u}{u_{*}}\right)^{2} \frac{P}{L}\right)\left(1+F_{L}^{*} \frac{1}{2} \frac{L}{H} \cos \theta\right)}
$$

Like the previous theories for vertical entrainment and sliding, similar parameters emerge

1125 in the toppling threshold including dimensionless wall stress $\left(\tau_{w}^{*}\right.$, which again is unlikely to be 1126 important unless it is order unity) and block protrusion height normalized by block length $(P / L)$ 1127 (Figs. 14B and 14C). Most importantly for toppling, however, is the dominant role of block 1128 height normalized by length $(H / L)$, which dramatically lowers stability for tall and skinny 1129 columns (Fig. 14D), consistent with the experimental results of Lamb and Dietrich (2009) (Fig. 1130 12). Inspection of Eq. (24) shows that for toppling, in contrast to vertical entrainment and 1131 sliding, the dominant length scale that determines the stabilizing stress due to block weight is the 1132 downstream block length $(L)$ rather than the block height $(H)$. This result occurs because an 
1133 increase in block height increases the block weight (which linearly adds stability) and increases

1134 the torque arm associated with drag and shear forces across the block top (which linearly

1135 decreases stability), such that results are only weakly sensitive to block height alone (except

1136 where block tilt angles are large). In contrast, block height to length ratio $(H / L)$ has a strong

1137 effect on the threshold for toppling, whereas it has no (independent) effect on the thresholds for

1138 vertical entrainment or sliding (Fig. 14D). Consequently, block toppling is expected to dominate

1139 over sliding and vertical entrainment at bedrock steps for $H / L>\sim 0.5$ to 1.

1140

\subsection{Entrainment versus transport-limited erosion}

1142

1143 There are no experimental or field tests of the relative roles of block entrainment versus 1144 downstream sediment transport (sensu Howard et al., 1994) in setting the rate of bedrock erosion

1145 by plucking. Assuming that the rate of rock fracture is not the rate-limiting mechanism (e.g.,

1146 Howard, 1998; Whipple et al., 2000), Eqs. (14) and (15) can be combined to evaluate the relative

1147 roles of entrainment and sediment transport in setting the erosion rate. Specifically, using mass

1148 balance and assuming a constant channel width, we can solve for the characteristic length scale

$1149\left(l_{E}\right)$, herein referred to as an adaption length, over which the capacity of the flow to transport

1150 entrained blocks (i.e., $q_{\text {sc }}$ ) in an initially clearwater flow becomes the rate-limiting step to further 1151 entrainment, as

1152

1153

$$
l_{E} \equiv \frac{q_{s c}}{E}=285 D\left(\frac{\tau^{*}-\tau_{c}^{*}}{\tau^{*}-\tau_{p c}^{*}}\right)^{1.5}
$$


1155 where $n_{p}=n_{s}=1.5$ and $a_{s} / a_{p}=285$ following the values reported above, and the characteristic

1156 block diameter is assumed to be equivalent to the characteristic sediment size $\left(D_{p}=D\right)$. Under

1157 the special case where the threshold for plucking blocks is the same threshold as for transport

1158 (i.e., $\tau_{p c}^{*}=\tau_{c}^{*}$ ), then Eq. (25) reduces to a linear function of block size:

$$
l_{E}=285 D
$$

1163 sediment transport will set the erosion rate for any reach longer than $l_{E}=285 \mathrm{~m}$ (assuming

1164 spatially uniform $\tau^{*}$ within the reach). Block entrainment is the rate limiting factor only for 1165 reach length smaller than $285 \mathrm{~m}$ - and potentially over much smaller length scales depending 1166 on the sediment supply to the reach from upstream and from the neighboring hillsides. However, 1167 if the threshold for block entrainment is larger than that for sediment transport (i.e., $\tau_{p c}^{*}>\tau_{c}^{*}$ ), 1168 then $l_{E}$ given by Eq. (25) can be significantly larger than $285 D$ signifying an increased role of 1169 block entrainment in limiting erosion. For example, Fig. 15 shows solutions to Eq. (25) for 1170 different transport stages (i.e., $\tau^{*} / \tau_{c}^{*}$ ), in which a value of $\tau^{*} / \tau_{s c}^{*}$ of 1.2 is common for gravel1171 bed rivers for reference (e.g., Parker et al., 2007). As the ratio of the plucking threshold relative 1172 to the sediment transport threshold (i.e., $\tau_{p c}^{*} / \tau_{c}^{*}$ ) approaches the transport stage, then $l_{E}$ grows 1173 infinitely large, indicating the dominance of block entrainment over sediment transport in setting 1174 the erosion rate. Fig. 15 also shows that erosion during extreme floods $\left(\tau^{*} / \tau_{c}^{*}>>1\right)$ is more 1175 likely to be transport-limited as $l_{E}$ is small, unless the threshold for entrainment is much larger 
1176 than the threshold for transport. In contrast, for more regular floods $\left(\tau^{*} / \tau_{c}^{*} \sim 1.2\right)$, subtle 1177 differences between the threshold to entrain blocks and the threshold for transport dictate 1178 whether erosion by plucking is entrainment or transport limited, and therefore likely depends on 1179 whether plucking is due to vertical entrainment, sliding or toppling.

1180 Entrainment thresholds for plucking are highly sensitive to block protrusion length 1181 relative to block length (Fig. 14B), with large relative protrusion tending toward transport1182 limited conditions, and zero protrusion tending toward entrainment-limited erosion rates. Wall 1183 stresses that approach the block weight per unit area also significantly limit block entrainment 1184 (Fig. 14C) and erosion rates shift toward a transport-limited state. If rivers are limited to 1185 plucking by vertical entrainment alone, entrainment rates are likely be the rate-limiting step to 1186 bedrock erosion even with negligible wall friction. However, erosion is more likely to be 1187 concentrated at bedrock steps that promote sliding and toppling because the erosion thresholds 1188 for these processes are typically far lower than the threshold for vertical block entrainment (Fig. 1189 14). This may explain the prevalence of stepped (rather than holey) topography in plucking1190 dominated landscapes and signifies the important role of knickpoint retreat in landscapes with 1191 well-jointed rock (e.g., Miller, 1991; Weissel and Seidl, 1997; Mackey et al., 2014). Thresholds 1192 for block sliding are similar to sediment transport, such that the limiting factors on erosion rates 1193 where sliding is dominant may vary from place to place depending largely on the block friction 1194 angle $(\phi)$. Plucking rates in the sliding-dominated Canyon Lake Gorge, TX, for example, 1195 appear to have been set by the rate of sediment transport (Lamb and Fonstad, 2010). Finally, at a 1196 bedrock step where $H / L>1$, toppling is likely to dominate over sliding, and toppling thresholds 1197 are typically far less than the threshold for transport indicating the likely scenario of transport- 
1198 limited erosion rates in these landscapes (Fig. 14D), consistent with field observations in 1199 canyons cut into columnar basalt (Lamb et al., 2008a, 2014).

1201 6. Abrasion and plucking at waterfalls

At a steep drop in the river bed, water may detach from the bedrock face forming a 1204 waterfall and plunge-pool. Erosion at waterfalls is important to understand because waterfalls 1205 can be the fastest eroding parts of some landscapes, and they can communicate changes in 1206 tectonics, climate, and sea-level throughout a drainage basin (e.g., Gilbert, 1907; Howard et al., 1207 1994; DiBiase et al., 2014; Mackey et al., 2014). Some workers have applied saltation-abrasion 1208 theories to steep river reaches and waterfalls (e.g., Chatanantavet and Parker, 2006; Wobus et al., 1209 2006; Crosby et al., 2007; Gasparini et al., 2007; Goode and Burbank, 2009); however, these 1210 theories are unlikely to hold for high gradient rivers. Beyond a certain river-channel slope of 1211 approximately 10\%, approximations (e.g., shallow water approximation) and empirical 1212 formulations for hydraulics and sediment transport discussed for abrasion and plucking become 1213 increasingly invalid (e.g., Yager et al., 2007; Lamb et al., 2008c). For example, the bedload-only 1214 saltation abrasion model shows a decrease in erosion rates with increasing channel bed slope, but 1215 limited experimental data indicate the opposite trend (Wohl and Ikeda, 1997; Johnson and 1216 Whipple, 2007). As another example, theory (Parker and Izumi, 2000) and experiments show 1217 that steep river beds rapidly evolve into a series of cyclic steps (or bedrock step pools) for 1218 clearwater flows over cohesive beds (Brooks, 2001) and for sediment-transporting flows over 1219 concrete beds (Yokokawa et al., 2013) because of strong morphodynamic feedbacks that do not 1220 occur for low-gradient bedrock rivers. At the extreme case of a waterfall, even the assumption of 
1221 hydrostatic pressure is no longer valid (Rouse, 1936). Consequently, new theories and 1222 experiments are needed that explicitly address abrasion and plucking erosion processes in steep 1223 rivers and at waterfalls.

1224 Most experiments on waterfall erosion to date have focused on waterfall formation and 1225 retreat following base-level drop. Gardner (1983) performed experiments in homogeneous 1226 cohesive sediments, where rapid erosion of vertical waterfall faces led to decreased waterfall 1227 slopes and the eventual replacement of waterfalls with steepened reaches extending across the 1228 majority of the flume length. Experiments in stratified sediments of alternating strength show 1229 different behavior. Holland and Pickup (1976) and Frankel et al. (2007) observed that vertical 1230 waterfalls tend to form on locally resistant layers and that undercutting of the weaker layer via 1231 plunge-pool erosion allows the waterfall to keep its form during retreat, similar to investigations 1232 of gully headcut erosion (e.g., Bennett et al., 2000) and the classic model of Gilbert (1907). 1233 Such experiments have led to models of waterfall retreat via failure of a cantilever caprock (e.g., 1234 Stein and LaTray, 2002; Haviv et al., 2010; Hayakawa and Matsukura, 2010); however, these 1235 models lack an explicit process-based treatment of plunge-pool bedrock abrasion and plucking.

1236 Wells et al. (2010) demonstrated that upstream sediment supply can slow plunge-pool erosion 1237 and headcut retreat in soil.

1238 Lamb et al. (2007) modified the saltation-abrasion model for waterfall plunge-pool 1239 erosion by accounting for the kinetic energy of particle-impacts as sediment accelerates over a 1240 waterfall and decelerates through a water-filled plunge pool. In their model, predictions of 1241 vertical plunge-pool erosion depend critically on the sediment transport capacity of the plunge 1242 pool, $q_{\text {sc-pool, }}$, as vertical incision requires the plunge pool floor to be cover-free. While 1243 experiments of clear water overspilling onto loose sediment have shown $q_{s c-p o o l}$ scales with shear 
1244 stress at the base of the pool (e.g., Stein et al., 1993; Stein and Julien, 1994), it is unclear if this

1245 formulation should hold for bedrock plunge pools where steep sidewalls require sediment to be

1246 suspended out of the pool. Only one experiment exists that investigates plunge-pool erosion by

1247 abrasion using a sand-cement mixture (Iguchi and Sekiguchi, 2008), but these results have yet to

1248 be compared to theory.

1249 In contrast to bedrock abrasion at waterfall plunge pools, a wealth of experiments have 1250 been performed on the plucking of jointed rock by high velocity jets within plunge pools due to 1251 the application to concrete dams and spillways (e.g., Annandale, 1995). Experiments by 1252 Robinson et al. (2001) showed that threshold for plucking of rectangular concrete blocks by a 1253 waterfall jet agree well with a simple force balance model (Hanson et al., 1998) in which blocks 1254 are plucked when the force associated with the stagnation pressure of the impinging jet 1255 overcomes the combined weight of the block and overlying column of water. Other models 1256 relate pressure fluctuations to the plucking of blocks (e.g., Bollaert, 2004), and numerous 1257 experimental studies have explored how pressure fluctuations on the plunge-pool floor vary with 1258 plunge-pool geometry, jet air entrainment, joint spacing, and more (e.g., Ervine et al., 1997; 1259 Bollaert and Schleiss, 2003; Manso et al., 2009). Little work has been done to extend this 1260 engineering-oriented work to natural waterfalls or to explore experimentally the long-term 1261 geomorphic implications of plucking in knickpoint retreat.

In addition to erosion within a waterfall plunge-pool, the brink of the waterfall 1263 escarpment may also erode. In this scenario, the fluvial erosion theories discussed in Sections 3 1264 and 4 for abrasion and plucking can be adapted for flow acceleration and loss of hydrostatic 1265 pressure at the waterfall lip (e.g., Stein and Julien, 1994; Haviv et al., 2006). For the cases of 1266 block sliding and toppling, Dubinski and Wohl (2013) and Lamb and Dietrich (2009) also 
1267 considered the potential lack of hydrostatic pressure at the downstream face of the block and the 1268 degree of submergence within a plunge pool, finding good agreement between experiments and 1269 theory.

1270

$1271 \quad$ 7. Some future opportunities

1272

1273

Although laboratory experiments have contributed greatly to our understanding of

1274 bedrock channel processes, tremendous opportunities remain for future experiments. Here we

1275 briefly suggest fruitful directions for experimentation, focusing in particular on the detachment

1276 mechanisms of abrasion and plucking.

1277 A key next step in understanding abrasion of bedrock by mobile sediments is to explore 1278 the effect of nonuniform sediment size distributions. Previous experiments have maintained 1279 narrow size distributions, but natural bedrock channels are supplied with and thus transport 1280 sediment mixtures containing a wide range of particle sizes. As the grain size distribution 1281 widens, particle interactions will influence the threshold and stability of transient alluvial 1282 deposits responsible for the cover effect. Size selective deposition and mobilization may affect 1283 the size distribution in transport for a given shear stress. Experiments that explore mixed 1284 sediment sizes in laboratory bedrock channels may need to be combined with experiments 1285 investigating the effect of variable discharge and the partially-decoupled nature of discharge and 1286 sediment supply. A rich parameter space encompassing distributions of discharge, sediment 1287 supply, and grain size remains to be explored.

1288 Future experiments are also needed to further explore the role of bedload and suspended 1289 sediment on erosion in complex topography and at high transport stages. Mixed sediment size 
1290 distributions supplied to erodible laboratory channels with significant bed roughness may result

1291 in spatial partitioning of incision mechanisms, with suspended sediments acting on elevated

1292 surfaces and bedload restricted to lower portions of the channel. Bed roughness is likely to

1293 evolve because of feedbacks between the relative mobility and spatial sorting of sediments. A

1294 related set of questions concerns wear of channel banks and evolution of cross section

1295 morphology. Abrasion by particle impacts may be an effective mechanism for channel widening

1296 and lateral migration, but perhaps only if channels have significant planform sinuosity and

1297 fluctuations in sediment supply limit vertical incision. An important consideration will be

1298 scaling morphodynamics for channel evolution in addition to producing hydraulics in laboratory

1299 channels with sufficient turbulence to drive suspended sediments against banks at velocities that

1300 overcome the viscous damping of impacts.

1301 Surprisingly few experiments have been conducted on erosion rate by plucking and the

1302 entrainment of blocks by fluvial processes. No experiments to our knowledge have investigated

1303 fracturing and weathering processes to create jointed rock, nor the interactions between rock

1304 fracturing, bedload saltation, and abrasion. Also missing are exploration of feedbacks between

1305 erosion rates and channel morphology in a plucking-dominated river, although initial progress

1306 has been made for the special case of plucking at waterfalls (Lamb and Dietrich, 2009; Dubinski 1307 and Wohl, 2013).

1308 Other morphodynamic topics ripe for experimental investigation include channel

1309 response to transient base-level fall, plunge-pool erosion below waterfalls, and the formation of

1310 strath terraces by alternating episodes of lateral and vertical incision. Detachment mechanisms

1311 other than abrasion and plucking also deserve experimental attention, including the potential for

1312 cavitation and segregation ice growth to influence rock erosion when conditions are favorable. 


\section{8. Conclusions}

1317 erosion models in ways that are difficult or impossible to perform in natural rivers. Equally

1318 important, exploratory experiments yield much needed insight into the evolving interactions 1319 between river-channel form, hydraulics, and sediment transport - dynamics that typically 1320 unfold over thousands of years or longer in nature. A significant milestone in bedrock erosion 1321 experiments is the discovery that rock erodibility by abrasion, across substrates including 1322 concrete, foam, ice, and a variety of bedrock lithologies, is a function of rock tensile strength, 1323 which allows erosion laws calibrated in the laboratory to be readily scaled for natural rivers on 1324 Earth and other planets and moons. In addition to rock tensile strength, erodibility experiments 1325 suggest that rock resistance to abrasion is better represented by fracture toughness rather than 1326 elasticity, and we propose a new representation of abrasion theory that can incorporate fracture 1327 toughness, which motivates future experiments.

1328 In addition to rock strength, abrasion experiments have revealed the dominant and 1329 nonlinear role of sediment, including sediment size, transport mode, particle trajectories, and 1330 sediment supply, in setting erosion rates. The frontier of bedrock-erosion experiments includes 1331 unraveling the morphodynamic feedbacks between hydraulics, channel roughness, sediment 1332 transport, and evolving channel morphology. Specifically, roughness, through its influence on 1333 the patterns of sediment deposition and through its influence on saltation trajectories, exerts a 1334 strong control on channel width, a long-standing fundamental unknown in geomorphology.

1335 Revised and unified theory for the threshold for vertical entrainment, sliding and toppling 
1336 of blocks, combined with limited experimental data, highlights the dominant role that 1337 knickpoints play in bedrock erosion by plucking. These theories also highlight key 1338 dimensionless parameters that can be used to scale plucking experiments to natural rivers. The 1339 combination of rate laws for plucking and sediment transport shows that block toppling is likely 1340 a transport-limited process, whereas vertical entrainment and in cases sliding may be

1341 detachment-limited. However, the competition between rate-limiting mechanisms also depends 1342 on the magnitude of flood events, in which large floods tend toward transport-limited conditions.

1343 Observations from laboratory experiments continue to force the advancement of theory in 1344 fluvial bedrock erosion, which in turn exposes knowledge gaps in field observations and leads to 1345 new expectations in landscape evolution.

\section{Acknowledgements}

1349 With pleasure we thank Paul Carling, Sean Bennett, and Cheryl McKenna Neuman for formal 1350 reviews that strengthened the paper, Richard Marston for his detailed edits, and the conveners 1351 and scientific committee of the $46^{\text {th }}$ Annual Binghamton Symposium for bringing this special 1352 issue to fruition. MPL and JSS thank Daniel Lo for helping in foam erosion rate calibration 1353 studies and Brian Fuller for bringing river experimentation back to life at Caltech. Ian Dubinski 1354 kindly shared photos and insight from his study. Paul Carling made available data from his block 1355 sliding experiments. This work was supported by NSF grant EAR-1147381 and NASA grant 1356 12PGG120107 to MPL, and NSF grant EAR-0345344 to LSS. JSS was partially supported by 1357 an NSF Graduate Student Research Fellowship. 


\section{Author Contributions}

1360

1361 All authors contributed equally to this work.

1362

1363

\section{References}

1364

1365

1366

1367

1368

1369

1370

1371

1372

1373

1374

1375

1376

1377

1378

1379

1380

1381

Abbott, J.E., Francis, J.R.D., 1977. Saltation and suspension trajectories of solid grains in a water stream. Philosophical Transactions of the Royal Society a-Mathematical Physical and Engineering Sciences, 284(1321), 225-254, doi: 10.1098/rsta.1977.0009.

Annandale, G.W., 1995. Erodibility. Journal of Hydraulic Research, 33(4), 471-494.

Bagnold, R.A., 1966. An approach to the sediment transport problem for general physics. US Geological Survey Professional Paper 422-I, Washington, D.C.

Baker, V.R., 1973. Paleohydrology and sedimentology of the Lake Missoula flooding in eastern Washington. Geological Society of America Special Paper, 144, 79.

Baker, V.R., Pickup, G., 1987. Flood geomorphology of the Katherine-Gorge, NorthernTerritory, Australia. Geological Society of America Bulletin, 98(6), 635-646, doi: 10.1130/0016-7606(1987)98<635:fgotkg>2.0.co;2.

Bennett, S.J., Alonso, C.V., Prasad, S.N., Romkens, M.J.M., 2000. Experiments on headcut growth and migration in concentrated flows typical of upland areas. Water Resources Research, 36(7), 1911-1922, doi: 10.1029/2000wr900067.

Beyeler, J.D., and L.S. Sklar, 2010. Bedrock resistance to fluvial erosion: the importance of rock tensile strength, crystal grain size and porosity in scaling from the laboratory to the field, Eos Trans. AGU, 91(52), Fall Suppl., Abstract EP41D-0740. 
1382 Bitter, J.G.A., 1963. A study of erosion phenomena: Part I. Wear, 6, 5-21.

1383 Black, B.A., Perron, J.T., Burr, D.M., Drummond, S.A., 2012. Estimating erosional exhumation on Titan from drainage network morphology. Journal of Geophysical Research-Planets, 117, doi: 10.1029/2012je004085.

Bollaert, E., 2004. A new and comprehensive model to evaluate scour formation in plunge pools. Hydropower and Dams, (1).

Bollaert, E., Schleiss, A., 2003. Scour of rock due to the impact of plunging high velocity jets Part II: Experimental results of dynamic pressures at pool bottoms and in one- and twodimensional closed end rock joints. Journal of Hydraulic Research, 41(5), 465-480.

Bonnet, S., Crave, A., 2003. Landscape response to climate change: Insights from experimental modeling and implications for tectonic versus climatic uplift of topography. Geology, 31(2), 123-126, doi: 10.1130/0091-7613(2003)031<0123:lrtcci>2.0.co;2.

1394 Bridges, N.T., Laity, J.E., Greeley, R., Phoreman, J., Eddlemon, E.E., 2004. Insights on rock abrasion and ventifact formation from laboratory and field analog studies with applications to Mars. Planet Space Sci, 52(1-3), 199-213, doi: 10.1016/j.pss.2003.08.026.

Brocard, G.Y., Van Der Beek, P.A., Bourlès, D.L., Siame, L.L., Mugnier, J.L., 2003. Long-term fluvial incision rates and postglacial river relaxation time in the French Western Alps from $10 \mathrm{Be}$ dating of alluvial terraces with assessment of inheritance, soil development and wind ablation effects. Earth and Planetary Science Letters, 209(1), 197-214.

1402

Brocklehurst, S.H., Whipple, K.X., 2007. Response of glacial landscapes to spatial variations in rock uplift rate. Journal of Geophysical Research-Earth Surface, 112(F2), doi: 10.1029/2006jf000667. 
1404 Brooks, P.C., 2001. Experimental study of erosional cyclic steps. Masters, University of 1405 Minnesota, Minnesota.

1406 Brownlie, W.R., 1983. Flow depth in sand-bed channels. Journal of Hydraulic Engineering1407 ASCE, 109(7), 959-990.

1408 Buffington, J.M., Montgomery, D.R., 1999. Effects of hydraulic roughness on surface textures of 1409 gravel-bed rivers. Water Resources Research, 35(11), 3507-3521, doi: 10.1029/1999WR900138.

1411 Burr, D.M., Perron, J.T., Lamb, M.P., Irwin, R.P., III, Collins, G.C., Howard, A.D., Sklar, L.S., 1412 Moore, J.M., Adamkovics, M., Baker, V.R., Drummond, S.A., Black, B.A., 2013. Fluvial 1413

Carling, P. and Tinkler, K., 1998. Conditions for the entrainment of cuboid boulders in bedrock features on Titan: Insights from morphology and modeling. Geological Society of America Bulletin, 125(3-4), 299-321, doi: 10.1130/b30612.1. streams: An historical review of litterature with respect to recent investigagations. In: K.J. Tinkler, E.E. Wohl (Eds.), Rivers over rock: Fluvial processes in bedrock channels. American Geophysical Union, Geophysical Monograph 107, Washington, D.C., pp. 1933.

Carling, P.A., Hoffmann, M., Blatter, A.A., Dittrich, A., 2002. Drag of emergent and submerged rectangular obstacles in turbulent flow above bedrock surface. In Schleiss, A.J. and Bollaert, E. (Eds.), Rock Scour due to Falling High-Velocity Jets. Swets and Zeitlinger, Lisse, pp. $83-94$.

Carter, C.L., Anderson, R.S., 2006. Fluvial erosion of physically modeled abrasion-dominated slot canyons. Geomorphology, 81(1-2), 89-113, doi: 10.1016/j.geomorph.2006.04.006. 
1426 Chatanantavet, P., Lamb, M.P., 2014. Sediment transport and topographic evolution of a coupled 1427 river and river-plume system: An experimental and numerical study. Journal of 1428 Geophysical Research - Earth Surface, doi: 10.1002/2013JF002810.

1429 Chatanantavet, P., Parker, G., 2006. Modeling the bedrock river evolution of western Kaua'i, 1430 Hawai'i, by a physically-based incision model based on abrasion. In: G. Parker, M. 1431 Garcia (Eds.), River, Coastal and Estuarine Morphodynamics 2005. Taylor and Francis 1432 Group.

Chatanantavet, P., Parker, G., 2008. Experimental study of bedrock channel alluviation under varied sediment supply and hydraulic conditions. Water Resources Research, 44(12), W12446, doi: 10.1029/2007WR006581.

Chatanantavet, P., Parker, G., 2009. Physically based modeling of bedrock incision by abrasion, plucking, and macroabrasion. Journal of Geophysical Research-Earth Surface, 114, doi: $10.1029 / 2008 j f 001044$.

Chatanantavet, P., Parker, G., 2011. Quantitative testing of model of bedrock channel incision by plucking and macroabrasion. Journal of Hydraulic Engineering-ASCE, 137(11), 13111317, doi: 10.1061/(asce)hy.1943-7900.0000421.

Chatanantavet, P., Whipple, K.X., Adams, M.A., Lamb, M.P., 2013. Experimental study on 1447 coarse grain saltation dynamics in bedrock channels. Journal of Geophysical ResearchEarth Surface, 118(2), 1161-1176, doi: 10.1002/jgrf.20053.

Clarke, B.A., Burbank, D.W., 2010. Bedrock fracturing, threshold hillslopes, and limits to the magnitude of bedrock landslides. Earth and Planetary Science Letters, 297(3-4), 577-586, doi: 10.1016/j.eps1.2010.07.011. 
1448 Coleman, S.E., Melville, B.W., Gore, L., 2003. Fluvial entrainment of protruding fractured rock.

1449 Journal of Hydraulic Engineering-ASCE, 129(11), 872-884, doi: 10.1061/(asce)0733$1450 \quad 9429(2003) 129: 11(872)$.

1451 Collins, G.C., 2005. Relative rates of fluvial bedrock incision on Titan and Earth. Geophysical $1452 \quad$ Research Letters, 32(22), doi: 10.1029/2005g1024551.

1453 Cook, K.L., Turowski, J.M., Hovius, N., 2013. A demonstration of the importance of bedload 1454 transport for fluvial bedrock erosion and knickpoint propagation. Earth Surface Processes 1455 and Landforms, 38(7), 683-695, doi: 10.1002/esp.3313.

1456 Cornell, K.M., 2007. Suspended Sediment Erosion in Laboratory Flume Experiments. Masters, 1457 Massachusetts Institute of Technology, Cambridge, MA, 50 pp.

1458 Croissant, T., Braun, J., 2014. Constraining the stream power law: a novel approach combining a 1459 landscape evolution model and an inversion method. Earth Surface Dynamics, 2, $155-$ $1460 \quad$ 166, doi: 10.5194/esurf-2-155-2014.

1461 Crosby, B.T., Whipple, K.X., Gasparini, N.M., Wobus, C.W., 2007. Formation of fluvial 1462 hanging valleys: Theory and simulation. Journal of Geophysical Research-Earth Surface, $1463 \quad$ 112(F3), doi: 10.1029/2006jf000566.

1464 Davis, J.R., 2013. The influence of bed roughness on partial alluviation in bedrock channels. 1465 MS, San Francisco State University, San Francisco, CA.

1466 Demeter, G.I., Sklar, L.S., Davis, J.R., 2005. The influence of variable sediment supply and bed 1467 roughness on the spatial distribution of incision in a laboratory bedrock channel. Eos 1468 Trans. AGU, 86(52), Abstract H53D-0519. 
DiBiase, R.A., Whipple, K.X., 2011. The influence of erosion thresholds and runoff variability on the relationships among topography, climate, and erosion rate. Journal of Geophysical Research-Earth Surface, 116, doi: 10.1029/2011jf002095.

DiBiase, R.A., Whipple, K.X., Heimsath, A.M., Ouimet, W.B., 2010. Landscape form and millennial erosion rates in the San Gabriel Mountains, CA. Earth and Planetary Science Letters, 289(1-2), 134-144, doi: 10.1016/j.epsl.2009.10.036.

DiBiase, R.A., Whipple, K.X., Lamb, M.P., Heimsath, A.M., 2014. The role of waterfalls and knickzones in controlling the style and pace of landscape adjustment in the western San Gabriel Mountains, CA, Geological Society of America Bulletin, doi:10.1130/B31113.1.

Dubinski, I.M., Wohl, E., 2013. Relationships between block quarrying, bed shear stress, and stream power: A physical model of block quarrying of a jointed bedrock channel. Geomorphology, 180, 66-81, doi: 10.1016/j.geomorph.2012.09.007.

Dzulynski, S., Sanders, J.E., 1962. Current marks on frim mud bottoms, Transactions of the Connecticut Academy of Arts and Sciences. The Connecticut Academy of Arts and Sciences, New Haven, pp. 57-96.

Einstein, H.A., 1950. The bed-load function for sediment transportation in open channel flow. US Dept Agric Tech Bull, 1026, 1-71.

Engle, P., 1978. Impact wear of materials. Elsevier Sci., New York.

Ervine, D.A., Falvey, H.T., Withers, W., 1997. Pressure fluctuations on plunge pool floors. Journal of Hydraulic Research, 35(2), 257-279.

Fernandez Luque, R., van Beek, R., 1976. Erosion and transport of bed-load sediment. Journal of Hydraulic Research, 14, 127-144. 
1491 Ferrier, K.L., Huppert, K.L., Perron, J.T., 2013. Climatic control of bedrock river incision. $1492 \quad$ Nature, 496(7444), 206-209, doi: 10.1038/nature11982.

1493 Finnegan, N.J., Sklar, L.S., Fuller, T.K., 2007. Interplay of sediment supply, river incision, and 1494 channel morphology revealed by the transient evolution of an experimental bedrock 1495 1496

1497 Finnegan, N.J., Schumer, R., Finnegan, S., 2014. A signature of transience in bedrock river 1498 1499 channel. Journal of Geophysical Research-Earth Surface, 112(F3), doi: 10.1029/2006jf000569. incision rates over time scales of 104-107 years. Nature, 505, 391-394, doi: 10.1038/nature12913.

Francis, J.R.D., 1973. Experiments on motion of solitary grains along bed of a water-stream. Proceedings of the Royal Society of London Series A-Mathematical Physical and Engineering Sciences, 332(1591), 443-471, doi: 10.1098/rspa.1973.0037.

Frankel, K.L., Pazzaglia, F.J., Vaughn, J.D., 2007. Knickpoint evolution in a vertically bedded substrate, upstream-dipping terraces, and Atlantic slope bedrock channels. Geological Society of America Bulletin, 119(3-4), 476-486, doi: 10.1130/b25965.1.

Fuller, T.K., 2014. Field, experimental and numerical investigations into the mechanisms and drivers of lateral erosion in bedrock channels. $\mathrm{PhD}$, University of Minnesota, Minneapolis, MN.

Ganti, V., Lamb, M.P., McElroy, B., 2014. Quantitative bounds on morphodynamics and 1511 implications for reading the sedimentary record. Nature Communications, 5, doi: 10.1038/ncomms4298. 
1512 Garcia, M., Parker, G., 1993. Experiments on the entrainment of sediment into suspension by a 1513 dense bottom current. Journal of Geophysical Research-Oceans, 98(C3), 4793-4807, doi: $10.1029 / 92 \mathrm{jc} 02404$.

1515 Gardner, T.W., 1983. Experimental study of knickpoint and longitudinal profile evolution in 1516 cohesive, homogeneous material. Geological Society of America Bulletin, 94(5), 664672, doi: 10.1130/0016-7606(1983)94<664:esokal>2.0.co;2.

1518 Gasparini, N.M., Brandon, M.T., 2011. A generalized power law approximation for fluvial 1519 1520

1524 George, M. and Sitar, N., 2012. Evaluation of rock scour using block theory. ICSE6 Paris, p. 1525

1526 Gilbert, G.K., 1877. Report on the geology of the Henry Mountains. Geographical and 1527 geological survey of the Rocky Mountain region: Washington D.C., Government Printing Office, $106 \mathrm{p}$.

Gilbert, G.K., 1907. The rate of recession of Niagara Falls. US Geological Survey Bulletin, 306, $1-31$

1531 Gilbert, G.K., 1914. The transportation of debris by running water. US Geological Survey 1532 Professional Paper 86, Washington D.C., Government Printing Office, 263 p. 
1533 Goode, J.K., Burbank, D.W., 2009. Numerical study of degradation of fluvial hanging valleys 1534 due to climate change. Journal of Geophysical Research-Earth Surface, 114, doi: 10.1029/2007jf000965.

1536 Goudie, A.S., 2006. The Schmidt hammer in geomorphologlical research. Progress in Physical 1537 Geography, 30(6), 703-718, doi: 10.1177/0309133306071954.

1538 Grotzinger, J.P., Hayes, A.G., Lamb, M.P., McLennan, S.M., 2013. Sedimentary processes on 1539 Earth, Mars, Titan and Venus. In: S. Mackwell, M. Bullock, J. Harder (Eds.), 1541 Hancock, G.S., Anderson, R.S., Whipple, K.X., 1998. Beyond power: Bedrock river incision 1542 1543 1544 process and form. In: K.J. Tinkler, E.E. Wohl (Eds.), Rivers over rock: Fluvial processes in bedrock channels. American Geophysical Union, Geophysical Monograph 107, Washington, D.C., pp. 35-60.

Hancock, G. S., E. E. Small, and C. Wobus, 2011. Modeling the effects of weathering on bedrock-floored channel geometry, J. Geophysical Research, 116, F03018, doi:10.1029/2010JF001908.

Hanson, G.J., Robinson, K.M., Cook, K.R., 1998. Erosion of structured material due to impinging jet. Proceedings of the 1998 ASCE International Water Resources Engineering Conference, Memphis, Tenn, pp. 1102-1107.

Hartshorn, K., Hovius, N., Dade, W.B., Slingerland, R.L., 2002. Climate-driven bedrock incision

1554 Hasbargen, L.E., Paola, C., 2000. Landscape instability in an experimental drainage basin. 1555 Geology, 28(12), 1067-1070, doi: 10.1130/0091-7613(2000)28<1067:liiaed>2.0.co;2. 
Hatzor, Y.H., Palchik, V., 1997. The influence of grain size and porosity on crack initiation stress and critical flaw length in dolomites. International Journal of Rock Mechanics and Mining Sciences, 34(5), 805-816, doi: 10.1016/s1365-1609(96)00066-6.

Haviv, I., Enzel, Y., Whipple, K.X., Zilberman, E., Stone, J., Matmon, A., Fifield, L.K., 2006. Amplified erosion above waterfalls and oversteepened bedrock reaches. Journal of Geophysical Research-Earth Surface, 111(F4), doi: 10.1029/2006jf000461.

Haviv, I., Enzel, Y., Whipple, K.X., Zilberman, E., Matmon, A., Stone, J., Fifield, K.L., 2010. Evolution of vertical knickpoints (waterfalls) with resistant caprock: Insights from numerical modeling. Journal of Geophysical Research-Earth Surface, 115, doi: 10.1029/2008jf001187.

Hayakawa, Y.S., Matsukura, Y., 2010. Stability analysis of waterfall cliff face at Niagara Falls: An implication to erosional mechanism of waterfall. Engineering Geology, 116(1-2), 178-183, doi: 10.1016/j.enggeo.2010.08.004.

Hodge, R.A., Hoey, T.B., Sklar, L.S., 2011. Bed load transport in bedrock rivers: The role of sediment cover in grain entrainment, translation, and deposition. Journal of Geophysical Research-Earth Surface, 116, doi: 10.1029/2011jf002032.

Holland, W.N., Pickup, G., 1976. Flume study of knickpoint development in stratified sediment. Geological Society of America Bulletin, 87(1), 76-82, doi: 10.1130/00167606(1976)87<76:fsokdi>2.0.co;2.

Howard, A.D., 1994. A detachment-limited model of drainage-basin evolution. Water Resources Research, 30(7), 2261-2285, doi: 10.1029/94wr00757.

Howard, A.D., 1998. Long profile development of bedrock channels: Interaction of weathering, mass wasting, bed erosion, and sediment transport. In: K.J. Tinkler, E.E. Wohl (Eds.), 
Rivers over rock: Fluvial processes in bedrock channels. American Geophysical Union, Geophysical Monograph 107, Washington, D.C., p. 297-319.

1581 1582 1583

Howard, A.D., 2007. Simulating the development of Martian highland landscapes through the interaction of impact cratering, fluvial erosion, and variable hydrologic forcing. Geomorphology, 91(3-4), 332-363, doi: 10.1016/j.geomorph.2007.04.017.

Howard, A.D., Kerby, G., 1983. Channel changes in badlands. Geological Society of America Bulletin, 94(6), 739-752, doi: 10.1130/0016-7606(1983)94<739:ccib>2.0.co;2.

Howard, A.D., Dietrich, W.E., Seidl, M.A., 1994. Modeling fluvial erosion on regional to continental scales. Journal of Geophysical Research-Solid Earth, 99(B7), 13971-13986, doi: $10.1029 / 94 j b 00744$.

Hsu, L., Dietrich, W.E., Sklar, L.S., 2008. Experimental study of bedrock erosion by granular flows. Journal of Geophysical Research-Earth Surface, 113(F2), doi: 10.1029/2007jf000778.

Hu, C., Hui, Y., 1996a. Bed-load transport I: Mechanical characteristics. Journal of Hydraulic Engineering, 122, 245-254.

Hu, C., Hui, Y., 1996b. Bed-load transport II: Stochastic characteristics. Journal of Hydraulic Engineering, 122, 255-261.

Huda, S.A., Small, E.E., 2014. Modeling the effects of bed topography on fluvial bedrock erosion by saltating bed load. Journal of Geophysical Research-Earth Surface, doi: 10.1002/2013JF002872.

Iguchi, T., Sekiguchi, T., 2008. A preliminary experiment of plunge pool formation using artificial rock. University of Tsukuba Terrestrial Environment Research Center report, 9, 43-48. 
1602 Inoue, T., N. Izumi, Y. Shimizu, and G. Parker, 2014. Interaction among alluvial cover, bed 1603 roughness, and incision rate in purely bedrock and alluvial-bedrock channel, J. 1604 Geophysical Research, 119, 2123-2146, doi:10.1002/2014JF003133.

1605 International Society for Rock Mechanics (ISRM), 1978. Suggested methods for determining 1606 tensile strength of rock materials, Int. J. Mech. Min. Sci. Geomech. Abstr., 21, 145-153.

1607 Johnson, J. P. L., 2014. A surface roughness model for predicting alluvial cover and bed load 1608 transport rate in bedrock channels, J. Geophysical Research, 119, 2147-2173, 1609 doi:10.1002/2013JF003000.

1610 Johnson, J.P., Whipple, K.X., 2007. Feedbacks between erosion and sediment transport in 1611 experimental bedrock channels. Earth Surface Processes and Landforms, 32(7), 1048$1612 \quad$ 1062, doi: 10.1002/esp.1471.

1613 Johnson, J.P.L., Whipple, K.X., 2010. Evaluating the controls of shear stress, sediment supply, 1614 alluvial cover, and channel morphology on experimental bedrock incision rate. Journal of 1615 Geophysical Research: Earth Surface, 115(F2), F02018, doi: 10.1029/2009JF001335.

1616 Johnson, J.P.L., Whipple, K.X., Sklar, L.S., Hanks, T.C., 2009. Transport slopes, sediment 1617 cover, and bedrock channel incision in the Henry Mountains, Utah. Journal of 1618 Geophysical Research-Earth Surface, 114, doi: 10.1029/2007jf000862.

1619 Johnson, J.P.L., Whipple, K.X., Sklar, L.S., 2010. Contrasting bedrock incision rates from 1620 snowmelt and flash floods in the Henry Mountains, Utah. Geological Society of America $1621 \quad$ Bulletin, 122(9-10), 1600-1615, doi: Doi 10.1130/B30126.1.

1622 Joseph, G.G., Hunt, M.L., 2004. Oblique particle-wall collisions in a liquid. Journal of Fluid 1623 Mechanics, 510, 71-93, doi: 10.1017/s002211400919x. 
1624 Joseph, G.G., Zenit, R., Hunt, M.L., Rosenwinkel, A.M., 2001. Particle-wall collisions in a 1625 viscous fluid. Journal of Fluid Mechanics, 433, 329-346.

1626 Kirby, E., Whipple, K., 2001. Quantifying differential rock-uplift rates via stream profile 1627 analysis. Geology, 29(5), 415-418, doi: 10.1130/00917613(2001)029<0415:qdrurv>2.0.co;2.

1629 Kirby, E., Whipple, K.X., 2012. Expression of active tectonics in erosional landscapes. Journal 1630 of Structural Geology, 44, 54-75, doi: 10.1016/j.jsg.2012.07.009.

1631 Kirchner, J.W., Dietrich, W.E., Iseya, F., Ikeda, H., 1990. The variability of critical shear stress, 1632 friction angle, and grain protrusion in water-worked sediments. Sedimentology, 37(4), 1633 647-672, doi: 10.1111/j.1365-3091.1990.tb00627.x.

1634 Kosmatka, S.H., Kerkhoff B., and Panarese, W.C., 2002. Design and Control of Concrete 1635 Mixtures, PCA Engineering Bulletin EB 001, Portland Cement Association, Skokie, IL 1636 2002.

Lague, D., Crave, A., Davy, P., 2003. Laboratory experiments simulating the geomorphic 1638 1639 response to tectonic uplift. Journal of Geophysical Research-Solid Earth, 108(B1), doi: 10.1029/2002jb001785.

Laity, J.E., Bridges, N.T., 2009. Ventifacts on Earth and Mars: Analytical, field, and laboratory studies supporting sand abrasion and windward feature development. Geomorphology, 105(3-4), 202-217, doi: DOI 10.1016/j.geomorph.2008.09.014.

1645 Lamb, M.P., Fonstad, M.A., 2010. Rapid formation of a modern bedrock canyon by a single 1646 flood event. Nature Geoscience, 3(7), 477-481, doi: 10.1038/ngeo894. 
1647

1648

1649

1650

1651

1652

1653

1654

1655

1656

1657

1658

1659

1660

1661

1662

1663

1664

1665

1666

1667

1668

1669

Lamb, M.P., Howard, A.D., Johnson, J., Whipple, K.X., Dietrich, W.E., Perron, J.T., 2006. Can springs cut canyons into rock? Journal of Geophysical Research-Planets, 111(E7), doi: 10.1029/2005je002663.

Lamb, M.P., Howard, A.D., Dietrich, W.E., Perron, J.T., 2007. Formation of amphitheaterheaded valleys by waterfall erosion after large-scale slumping on Hawai'i. Geological Society of America Bulletin, 119(7-8), 805-822, doi: 10.1130/b25986.1.

Lamb, M.P., Dietrich, W.E., Aciego, S.M., DePaolo, D.J., Manga, M., 2008a. Formation of Box Canyon, Idaho, by megaflood: Implications for seepage erosion on Earth and Mars. Science, 320(5879), 1067-1070, doi: 10.1126/science.1156630.

Lamb, M.P., Dietrich, W.E., Sklar, L.S., 2008b. A model for fluvial bedrock incision by impacting suspended and bed load sediment. Journal of Geophysical Research-Earth Surface, 113(F3), doi: 10.1029/2007jf000915.

Lamb, M.P., Dietrich, W.E., Venditti, J.G., 2008c. Is the critical Shields stress for incipient sediment motion dependent on channel-bed slope? Journal of Geophysical ResearchEarth Surface, 113(F2), doi: F02008 10.1029/2007jf000831.

Lamb, M.P., Grotzinger, J.P., Southard, J.B., Tosca, N.J., 2012. Were ripples on Mars formed by flowing brines? In: J. Grotzinger, R. Milliken (Eds.), Sedimentary Geology on Mars. SEPM, pp. 139-150.

Lamb, M.P., Mackey, B.H., Farley, K.A., 2014. Amphitheater-headed canyons formed by megaflooding at Malad Gorge, Idaho. Proceedings of the National Academy of Sciences, 111(1), 57-62, doi: 10.1073/pnas.1312251111.

Lang, K.A., Huntington, K.W., Montgomery, D.R., 2013. Erosion of the Tsangpo Gorge by megafloods, Eastern Himalaya. Geology, 41(9), 1003-1006, doi: 10.1130/g34693.1. 
1670 Lawn, B., 1993. Fracture of brittle solids. Cambridge University Press, New York, 381 p.

1671 Lee, H.Y., Hsu, I.S., 1994. Investigation of saltating particle motions. Journal of Hydraulic 1672 Engineering-ASCE, 120(7), 831-845, doi: 10.1061/(asce)0733-9429(1994)120:7(831).

1673 Li, X., Hunt, M.L., Colonius, T., 2012. A contact model for normal immersed collisions between 1674 a particle and a wall. Journal of Fluid Mechanics, 691, 123-145, doi: $1675 \quad$ 10.1017/jfm.2011.461.

1676 Limaye, A.B.S., Lamb, M.P., 2014. Numerical simulations of bedrock valley evolution by 1677 meandering rivers with variable bank material. Journal of Geophysical Research - Earth $1678 \quad$ Surface, 119, doi: 10.1002/2013JF002997.

1679 Litwin, K.L., Zygielbaum B.R., Polito P.J., Sklar L.S., Collins G.C., 2012. Influence of 1680 temperature, composition and grain size on tensile failure of water ice: implications for 1681 1682

1683 Mackey, B.H., Scheingross, J.S., Lamb, M.P., Farley, K.A., 2014. Knickpoint formation, rapid 1684 1685 1686

1687 Malde, H.E., 1968. The catastrophioc late Pleistocene Bonneville Flood in the Snake River Plain, 1688 Idaho. USGS Professional Paper, 596, 1-52.

1689 Manga, M., Kirchner, J.W., 2000. Stress partitioning in streams by large woody debris. Water $1690 \quad$ Resources Research, 36(8), 2373-2379, doi: 10.1029/2000wr900153.

1691 Manso, P.A., Bollaert, E.F.R., Schleiss, A.J., 2009. Influence of plunge pool geometry on high1692 velocity jet impact pressures and pressure propagation inside fissured rock media. Journal 
of Hydraulic Engineering-ASCE, 135(10), 783-792, doi: 10.1061/(asce)hy.19437900.0000090.

1695 1696 1697 1698 1699

1700 1701

1702

1703

1704

1705 1706

1707

1708 1709

1710

1711

1712

1713

1714 1715

Martel, S.J., 2006. Effect of topographic curvature on near-surface stresses and application to sheeting joints. Geophysical Research Letters, 33(1), doi: 10.1029/2005g1024710.

McLean, S.R., 1991. Depth-integrated suspended-load calculations. Journal of Hydraulic Engineering-ASCE, $\quad 117(11), \quad 1440-1458, \quad$ doi: $\quad 10.1061 /($ asce $) 0733-$ 9429(1991)117:11(1440).

McLean, S.R., 1992. On the calculation of suspended-load for noncohesive sediments. Journal of Geophysical Research-Oceans, 97(C4), 5759-5770, doi: 10.1029/91jc02933.

Melville, B., van Ballegooy, R., van Ballegooy, S., 2006. Flow-induced failure of cable-tied blocks. Journal of Hydraulic Engineering-ASCE, 132(3), 324-327, doi: 10.1061/(asce)0733-9429(2006)132:3(324).

Miller, D.J., Dunne, T., 1996. Topographic perturbations of regional stresses and consequent bedrock fracturing. Journal of Geophysical Research-Solid Earth, 101(B11), 2552325536, doi: 10.1029/96jb02531.

Miller, J.R., 1991. The influence of bedrock geology on knickpoint development and channelbed degradation along downcutting streams in south-central Indiana. Journal of Geology, 99(4), 591-605.

Nelson, P.A., Seminara, G., 2011. Modeling the evolution of bedrock channel shape with erosion from saltating bed load. Geophysical Research Letters, 38(17), L17406, doi: 10.1029/2011GL048628.

Nelson, P.A., Seminara, G., 2012. A theoretical framework for the morphodynamics of bedrock channels. Geophysical Research Letters, 39(6), L06408, doi: 10.1029/2011GL050806. 
1716 Nelson, P.K., 2003. Handbook of nondestructive and innovative testing equipment for concrete, 1717 Final Report, Washington, D.C.

1718 Nino, Y., Garcia, M., Ayala, L., 1994. Gravel saltation: 1. Experiments. Water Resources 1719 Research, 30(6), 1907-1914, doi: 10.1029/94wr00533.

1720 Nino, Y., Lopez, F., Garcia, M., 2003. Threshold for particle entrainment into suspension. 1721 Sedimentology, 50(2), 247-263, doi: 10.1046/j.1365-3091.2003.00551.x.

1722 Nittrouer, J.A., Mohrig, D., Allison, M.A., Peyret, A.-P.B., 2011. The lowermost Mississippi 1723 River: a mixed bedrock-alluvial channel. Sedimentology, 58(7), 1914-1934, doi: $1724 \quad$ 10.1111/j.1365-3091.2011.01245.x.

1725 Ouimet, W.B., Whipple, K.X., Granger, D.E., 2009. Beyond threshold hillslopes: Channel 1726 adjustment to base-level fall in tectonically active mountain ranges. Geology, 37(7), 579$1727 \quad$ 582, doi: $10.1130 / \mathrm{g} 30013 \mathrm{a} .1$.

1728 Paola, C., Straub, K., Mohrig, D., Reinhardt, L., 2009. The "unreasonable effectiveness" of 1729 stratigraphic and geomorphic experiments. Earth-Science Reviews, 97(1-4), 1-43, doi: 10.1016/j.earscirev.2009.05.003.

1731 Parker, G., 1991. Selective sorting and abrasion of river gravel: II. Applications. Journal of $1732 \quad$ Hydraulic Engineering, 117(2), 150-171.

1733 Parker, G., Izumi, N., 2000. Purely erosional cyclic and solitary steps created by flow over a 1734 1735 cohesive bed. Journal of Fluid Mechanics, 419, 203-238, doi: 1736 Parker, G., Wilcock, P.R., Paola, C., Dietrich, W.E., Pitlick, J., 2007. Physical basis for quasi1737 universal relations describing bankfull hydraulic geometry of single-thread gravel bed 1738 rivers. Journal of Geophysical Research-Earth Surface, 112, doi: 10.1029/2006jf000549. 
1739 Peakall, J., Ashworth, P., Best, J.L., 1996. Physical modelling in fluvial geomorphology: 1740 principles, applications and unresolved issues. In: L.B. Rhoads, E.C. Thorn (Eds.), The 1741 Scientific Nature of Geomorphology. Wiley \& Sons, Chichester, pp. 221-253.

1742 Pederson, J.L., Anders, M.D., Rittenhour, T.M., Sharp, W.D., Gosse, J.C., Karlstrom, K.E., 1743 2006. Using fill terraces to understand incision rates and evolution of the Colorado River 1744 in eastern Grand Canyon, Arizona. Journal of Geophysical Research-Earth Surface, $1745 \quad$ 111(F2), doi: 10.1029/2004jf000201.

1746 Perron, J.T., Lamb, M.P., Koven, C.D., Fung, I.Y., Yager, E., Adamkovics, M., 2006. Valley 1747 formation and methane precipitation rates on Titan. Journal of Geophysical Research$1748 \quad$ Planets, 111(E11), doi: 10.1029/2005je002602.

1749 Perron, J.T., Dietrich, W.E., Kirchner, J.W., 2008. Controls on the spacing of first-order valleys. 1750 Journal of Geophysical Research-Earth Surface, 113(F4), doi: 10.1029/2007jf000977.

1751 Prancevic, J.P., Lamb, M.P., Fuller, B.M., 2014. Incipient sediment motion across the river to 1752 debris-flow transition. Geology, 42(3), 191-194, doi: 10.1130/g34927.1.

1753 Reinius, E., 1986. Rock erosion. Water Power and Dam Contruction, 38(6), 43-48.

1754 Reneau, S.L., 2000. Stream incision and terrace development in Frijoles Canyon, Bandelier 1755 National Monument, New Mexico, and the influence of lithology and $1756 \quad$ climate. Geomorphology, 32(1), 171-193.

1757 Reusser, L.J., Bierman, P.R., Pavich, M.J., Zen, E.A., Larsen, J., Finkel, R., 2004. Rapid Late 1758 Pleistocene incision of Atlantic passive-margin river gorges. Science, 305(5683), 499$1759 \quad 502$.

1760 Richardson, K., Carling, P.A., 2006. The hydraulics of a straight bedrock channel: Insights from 1761 solute dispersion studies. Geomorphology, 82(1), 98-125. 
1762 Roberts, G.G., White, N.J., Martin-Brandis, G.L., Crosby, A.G., 2012. An uplift history of the 1763 Colorado Plateau and its surroundings from inverse modeling of longitudinal river $1764 \quad$ profiles. Tectonics, 31, doi: 10.1029/2012tc003107.

1765 Robinson, K.M., Hanson, G.J., Cook, K.R., Kadavy, K.C., 2001. Erosion of fractured materials. 1766 Transactions of the ASAE, 44(4), 819-823.

1767 Rouse, H.R., 1936. Discharge characteristics of the free overfall. Civil Engineering, 7, 518.

1768 Rouse, H.R., 1937. Modern conceptions of the mechanics of turbulence. Trans. Am. Soc. Civ. $1769 \quad$ Eng., 102(1), 463-543.

1770 Scheingross, J.S., Winchell, E.W., Lamb, M.P., Dietrich, W.E., 2013. Influence of bed 1771 patchiness, slope, grain hiding, and form drag on gravel mobilization in very steep 1772 streams. Journal of Geophysical Research-Earth Surface, 118(2), 982-1001, doi: $1773 \quad 10.1002 /$ jgrf.20067.

1774 Scheingross, J.S., Brun, F., Lo, D.Y., Omerdin, K., Lamb, M.P., 2014. Experimental evidence 1775 for fluvial bedrock incision by suspended and bedload sediment. Geology, 42(6), doi: 1776 doi:10.1130/G35432.1.

1777 Schlichting, H., 1979. Boundary-layer theory. McGraw-Hill.

1778 Schmeeckle, M.W., Nelson, J.M., Pitlick, J., Bennett, J.P., 2001. Interparticle collision of natural 1779 sediment grains in water. Water Resources Research, 37(9), 2377-2391, doi: $1780 \quad 10.1029 / 2001 \mathrm{wr} 000531$.

1781 Schmeeckle, M.W., Nelson, J.M., Shreve, R.L., 2007. Forces on stationary particles in near-bed 1782 turbulent flows. Journal of Geophysical Research-Earth Surface, 112(F2), doi: $1783 \quad$ 10.1029/2006jf000536. 
1784 Schumm, S.A., Mosley, M.P., Weaver, W., 1987. Experimental fluvial geomorphology. John $1785 \quad$ Wiley \& Sons, New York. 413p.

1786 Selby, M.J., 1993. Hillslope materials and processes. Oxford University Press, Oxford, 451p.

1787 Shaw, J.B., Mohrig, D., Whitman, S.K., 2013. The morphology and evolution of channels on the 1788 Wax Lake Delta, Louisiana, USA. Journal of Geophysical Research-Earth Surface, $1789 \quad 118(3), 1562-1584$, doi: 10.1002/jgrf.20123.

1790 Shepherd, R.G., Schumm, S.A., 1974. Experimental Study of River Incision. Geological Society 1791 of America Bulletin, 85(2), 257-268, doi: Doi 10.1130/0016$1792 \quad$ 7606(1974)85<257:Esori>2.0.Co;2.

1793 Shields, A., 1936. Application of similarity principles and turbulence research to bed-load 1794 movement. Hydrodynamics Laboratory Publication, 167. U.S. Dept of Agriculture Soil 1795 Conservation Service Cooperative Laboratory, California Institute of Technology, $1796 \quad$ Pasadena, CA.

1797 Sklar, L.S., Dietrich, W.E., 1998. River longitudinal profiles and bedrock incision models: 1798 Stream power and the influence of sediment supply. In: K.J. Tinkler, E.E. Wohl (Eds.), 1799 Rivers over rock: Fluvial processes in bedrock channels. American Geophysical Union, 1800 Geophysical Monograph 107, Washington, D.C., p. 237-260.

1804 Sklar, L.S., Dietrich, W.E., 2004. A mechanistic model for river incision into bedrock by 1805 saltating bed load. Water Resources Research, 40(6), doi: 10.1029/2003wr002496. 
1806 Sklar, L.S., Dietrich, W.E., 2006. The role of sediment in controlling steady-state bedrock 1807 channel slope: Implications of the saltation-abrasion incision model. Geomorphology, 1808 82(1-2), 58-83, doi: 10.1016/j.geomorph.2005.08.019.

1809 Sklar, L.S., Dietrich, W.E., 2008. Implications of the saltation-abrasion bedrock incision model 1810 for steady-state river longitudinal profile relief and concavity. Earth Surface Processes and Landforms, 33(7), 1129-1151, doi: 10.1002/esp.1689.

Sklar, L.S., Dietrich, W.E., 2012. Correction to "A mechanistic model for river incision into bedrock by saltating bed load". Water Resources Research, 48, doi: $10.1029 / 2012 \mathrm{wr} 012267$.

Sklar, L.S., Collins, G.C., Litwin, K.L., Polito, P.J., Zygielbaum, B.R., 2012. Erodibility of Titan 1816 ice bedrock constrained by laboratory measurements of ice strength and erosion by sediment impacts, Eos Trans. AGU, 93(52), Fall Suppl., Abstract EP44A-06.

1818 Small, E.E., Hancock, G., Wobus, C.W., 2012. Variations in rock erodibility across bedrock1819 floored stream channels, Eos Trans. AGU, 93(52), Fall Suppl., Abstract EP13A-0815.

1820 1821

Smith, C.E., 1998. Modeling high sinuosity meanders in a small flume. Geomorphology, 25(1), 19-30.

Stein, O.R., Julien, P.Y., 1994. Sediment concentration below free overfall. Journal of Hydraulic Engineering-ASCE, 120(9), 1043-1059, doi: $\quad 10.1061 /($ asce $) 0733-$ 9429(1994)120:9(1043).

1825 Stein, O.R., LaTray, D.A., 2002. Experiments and modeling of head cut migration in stratified 1826 soils. Water Resources Research, 38(12), doi: 10.1029/2001wr001166.

1827 Stein, O.R., Alonso, C.V., Julien, P.Y., 1993. Mechanics of jet scour downstream of a headcut. $1828 \quad$ Journal of Hydraulic Research, 31(6), 723-738. 
1829 Stock, J.D., Montgomery, D.R., 1999. Geologic constraints on bedrock river incision using the stream power law. Journal of Geophysical Research-Solid Earth, 104(B3), 4983-4993, doi: $10.1029 / 98 \mathrm{jb} 02139$.

1832 Stock, J.D., Montgomery, D.R., Collins, B.D., Dietrich, W.E., Sklar, L., 2005. Field 1833

Taki, K., Parker, G., 2005. Transportational cyclic steps created by flow over an erodible bed. Part 1. Experiments. Journal of Hydraulic Research, 43(5), 488-501.

Thompson, D., Wohl, E., 1998. Flume Experimentation and Simulation of Bedrock Channel Processes. In: K.J. Tinkler, E.E. Wohl (Eds.), Rivers over rock: Fluvial processes in bedrock channels. American Geophysical Union, Geophysical Monograph 107, Washington, D.C.

Tinkler, K.J., Wohl, E., 1998. A primer on bedrock channels, in Tinkler, K.J., Wohl E.E., eds., Rivers Over Rock: Fluvial Processes in Bedrock Channels. Geophysical Monograph Series, 107, American Geophysical Union, Washington DC, p. 1-18.

Tsujimoto, T., 1999. Sediment transport processes and channel incision: Mixed size sediment 1850 transport, degradation and armoring, in S.E. Darby and A. Simon, eds., Incised River Channels, John Wiley, Hoboken, NJ, p. 37-67.

U.S. Bureau of Reclemation (USBR), 2007. Uplift and crack flow resulting from high velocity discharges over open offst joints, Report DSO-07-07, United States Bureau of Reclemation, Denver. 
1851 Weissel, J.K., Seidl, M.A., 1997. Influence of rock strength properties on escarpment retreat 1852 1853 across passive continental margins. Geology, 25(7), 631-634, doi: 10.1130/00917613(1997)025<0631:iorspo>2.3.co;2.

1854 Wells, R. R., S. J. Bennett, and C. V. Alonso, 2010. Modulation of headcut soil erosion in rills 1855 due to upstream sediment loads, Water Resources Research, 46, W12531, 1856 doi:10.1029/2010WR009433.

1857 Whipple, K.X., 2004. Bedrock rivers and the geomorphology of active orogens. Annual Review 1858 of Earth and Planetary Sciences, 32, 151-185.10.1146/annurev.earth.32.101802.120356.

1859 Whipple, K.X., Hancock, G.S., Anderson, R.S., 2000. River incision into bedrock: Mechanics 1860 1861 1862 1863 1864 1865 1866 and relative efficacy of plucking, abrasion, and cavitation. Geological Society of America Bulletin, 112(3), 490-503, doi: 10.1130/0016-7606(2000)112<0490:riibma>2.3.co;2.

Whipple, K.X., DiBiase, R.A., Crosby, B.T., 2013. Bedrock Rivers. In: J. Shroder, Jr., E.E. Wohl (Eds.), Treatise on Geomorphology. Academic Press, San Diego.

Wiberg, P.L., Smith, J.D., 1987. Calculations of the critical shear-stress for motion of uniform and heterogeneous sediments. Water Resources Research, 23(8), 1471-1480, doi: 10.1029/WR023i008p01471.

1867 Wilcock, P.R., 1993. Critical Shear-Stress of Natural Sediments. Journal of Hydraulic $1868 \quad$ Engineering-ASCE, 119(4), 491-505.

1869 Willett, S.D., 1999. Orogeny and orography: The effects of erosion on the structure of mountain 1870 belts. Journal of Geophysical Research-Solid Earth, 104(B12), 28957-28981, doi: $1871 \quad 10.1029 / 1999 j b 900248$. 
1872 Wilson, A., Lavé, J., 2014. Convergent evolution of abrading flow obstacles: Insights from 1873 analogue modelling of fluvial bedrock abrasion by coarse bedload. Geomorphology, 1874 208(0), 207-224, doi: 10.1016/j.geomorph.2013.11.024.

1875 Wilson, A., Hovius, N., Turowski, J.M., 2013. Upstream-facing convex surfaces: Bedrock 1876 bedforms produced by fluvial bedload abrasion. Geomorphology, 180, 187-204, doi: 10.1016/j.geomorph.2012.10.010.

1878 Wobus, C.W., Crosby, B.T., Whipple, K.X., 2006. Hanging valleys in fluvial systems: Controls 1879 1880 on occurrence and implications for landscape evolution. Journal of Geophysical Research-Earth Surface, 111(F2), doi: 10.1029/2005jf000406.

1881 Wohl, E., Ikeda, H., 1997. Experimental simulation of channel incision into a cohesive substrate 1882 at varying gradients. Geology, 25(4), 295-298, doi: 10.1130/00911883 7613(1997)025<0295:esocii>2.3.co;2.

1884 Yager, E.M., Kirchner, J.W., Dietrich, W.E., 2007. Calculating bed load transport in steep 1885 boulder bed channels. Water Resources Research, 43(7), doi: 10.1029/2006wr005432.

1886 Yalin, M.S., 1977. Mechanics of sediment transport. Pergamon Press, Oxford.

1887 Yokokawa, M., Kyogoku, A., Kotera, A., Izumi, N., 2013. Cyclic steps incised on experimental 1888 bedrock, Eos Trans. AGU, 94(52), Fall Suppl., Abstract EP24B-06.

1889 Young, R.W., 1983. The tempo of geomorphological change: evidence from southeastern 1890 Australia. The Journal of Geology, 91(2), 221-230.

1891 Young, R., McDougall, I., 1993. Long-term landscape evolution: Early Miocene and modern 1892 rivers in southern New South Wales, Australia. The Journal of Geology, 101(1), 35-49.

1893

1894 FIG. CAPTIONS

1895 
Fig. 1. Length and time scales for laboratory and field measurements of bedrock incision rates. Laboratory experiments reproduce a wide range of incision rates observed in the field but at vastly reduced length and time scales. Shorter measurement time intervals are due to lack of intermittency and use of weak bedrock analog materials; smaller incision depth measurements are possible because of controlled conditions and high-precision measurement techniques.

Fig. 2. Hydraulic regimes of laboratory bedrock channel experiments. Solid line represents threshold between subcritical and supercritical flow $(\mathrm{Fr}=1)$; dashed line represents threshold between laminar and turbulent flow $(\operatorname{Re}=2000)$.

Fig. 3. A) Schematic cartoon of individual particle trajectories for sediment in the bedload regime where particles follow ballistic trajectories and for sediment in the suspension regime where trajectories are controlled by fluid turbulence. Modified from Francis (1973). (B) Schematic plot of sediment concentration versus height within the suspension-regime. Sediment concentration increases toward the bed (Rouse, 1937); and the near-bed sediment concentration, $c_{b}$, is assumed constant throughout the entire bedload layer. Mass erosion rate versus tensile strength with lines showing fits to rock and concrete data (solid line) and foam data (dashed line). (B) Volumetric erosion rate versus tensile strength with solid line showing best fit to rock, concrete, and foam data. (C) Volumetric erosion rate versus $\varepsilon_{v}$ (Eq. 10) with $k_{v}=10^{6}$. (D) Schematic of the abrasion mills used in Sklar and Dietrich (2001) and Scheingross et al. (2014).

Fig. 5. Variation in erosion rate with sediment loading (Sklar and Dietrich, 2001). Data for three rock types are collapsed by multiplying the erosion rate $(g / h)$ by the square of rock tensile strength (MPa).

Fig. 6. Volumetric erosion rate, $E_{v}$, versus grain diameter, $D$, for abrasion mill experiments by Sklar and Dietrich (2001) and Scheingross et al. (2014). Lines show theoretical predictions for the saltation-abrasion model and the total load model with and without viscous dampening. Fig. modified from Scheingross et al. (2014).

Fig. 7. Compilation of saltation hop length $\left(L_{s}\right)$ normalized by grain diameter $(D)$ versus excess shear stress. Line shows empirical fit by Sklar and Dietrich (2004) that matches well with saltation hop lengths on smooth beds after accounting for reductions in critical Shields stress. Rough bed saltation hop lengths originally compiled by Sklar and Dietrich (2004); data sources include Abbott and Francis (1977), Lee and Hsu (1994), Nino et al. (1994), and Hu and Hui 
Fig. 8. Erosion rate predicted with total-load model for transport stage $\left(\tau^{*} / \tau_{c}^{*}\right)$ varied by changing either grain size $(D)$, channel slope $(S)$, or flow depth $(h)$, while holding all other values constant, for constant sediment supply $\left(q_{s}\right.$; gray lines) and sediment supply proportional to transport capacity ( $q_{s c}$; black lines) as predicted by Fernandez Luque and van Beek (1976). Also shown is erosion rate predicted by stream power. All parameter values are representative of the South Fork Eel River, CA, USA, reference site (Sklar and Dietrich, 2004). The formulation $E \propto$ $\tau^{a}$, where $a$ is a constant commonly assumed equal to $\sim 1.5$, can be converted to the more familiar form of $E \propto A^{m} S^{n}$ (Eq. 1) by assuming steady, uniform flow and combining a flow resistance relationship with empirical relationships relating channel width and water discharge to drainage area (e.g., Whipple et al., 2013).

Fig. 9. Emergent channel morphologies evolved under increasing transport stage $\left(\tau^{*} / \tau^{*} c\right)$ from left (A) to right (C). The increase in channel tortuosity may reflect the evolution of these channels away from a saltation dominated channel toward a suspension-dominated channel. Images are taken from (A) Finnegan et al. (2007), (B) Wohl and Ikeda (1997, and (C) Johnson and Whipple (2010).

Fig. 10. Alluvial cover extent as a function of relative bed roughness from Davis (2013). Relative roughness is the standard deviation of residual bedrock-bed topography normalized by the grain diameter.

Fig. 11. Patterns of wall abrasion from Fuller (2014) for a single sediment supply rate with variable channel roughness. Higher lateral erosion rates associated with larger bed roughness shift the channel profile to the right.

Fig. 12. Blocks eroded primarily by sliding (top) at a waterfall face from Dubinski and Wohl (2013) looking upstream (left) and in planview (right). Toppling of blocks (bottom) before (left) and after (right) failure at a waterfall from Lamb and Dietrich (2009).

Fig. 13. Forces and dimensions considered for plucking of a block of height $H$ and length $L$ by vertical entrainment, sliding or toppling from a bed inclined at angle $\theta$. For sliding and toppling the downstream block is assumed to be missing and for toppling the torque balance is about the pivot point at bottom right corner of the block (filled circle). Forces considered include buoyancy and gravity $\left(F_{g}\right)$, bed shear stress $\left(F_{s}\right)$, form drag associated with protrusion of the block $\left(F_{D}\right)$ by amount $P$, hydraulic lift $\left(F_{L}\right)$, and frictional forces along the block side walls $\left(F_{w}\right)$. Not shown are the block width $(W)$, frictional stress along the base of the block when sliding, and frictional wall stresses along the page-parallel planes. 
Fig. 14. Critical Shields stress for plucking through vertical entrainment (Eq. 20), sliding (Eq. 22) and toppling (Eq. 24), and the critical Shields stress for incipient sediment transport. (A) Model predictions for sliding (Eq. 22) and vertical entrainment (Eq. 20) versus measured critical Shields numbers calculated from the experimental data of Carling et al. (2002), Coleman et al. (2003), and Dubinski and Wohl (2013). The solid line represents a one-to-one correspondence. For these cases $u / u_{*}$ was calculated using the log law and bed roughness values from the experiments (1.5 mm for Carling et al. (2002), hydraulically smooth for Coleman et al. (2003) and hydraulically rough for Dubinski and Wohl (2013)). We assume wall stresses are zero $\left(\tau_{w}^{*}=\right.$ 0) in Coleman et al. (2003) owing to the smooth blocks. Carling et al. (2002) used isolated blocks resting on a planar bed, thus $P=H$ and $\tau_{w}^{*}=0$ for those experiments. The remaining panels show model predictions versus $(\mathrm{B})$ relative block protrusion $(P / L),(\mathrm{C})$ dimensionless block wall friction $\left(\tau_{w}^{*}=\tau_{w} /\left[\left(\rho_{r}-\rho_{w}\right) \mathrm{gW}\right]\right)$, and (D) relative block height $(H / L)$ with all other parameters held constant at $C_{D}=1, F_{L}^{*}=0.85, \tan \theta=0.007, \phi=30^{\circ}, \tau_{w}^{*}=0.1, W / L=1, H / L=$ $1, P / L=0.2$. Panels (B) - (D) assume $u(z=P) / u_{*}=8.3$ corresponding to hydraulically rough, turbulent flow where the bed roughness length is equal to $P$, conditions that are likely in natural

Fig. 15. Normalized adaption length beyond which entrainment rates by plucking in an initially clearwater flow becomes transport limited (Eq. 25) as a function of the critical Shields stress for plucking normalized by that for sediment transport $\left(\tau_{p c}^{*} / \tau_{c}^{*}\right)$. Solid contours show different flood events with different transport stages $\left(\tau^{*} / \tau_{c}^{*}\right)$. The dashed line is the solution to Eq. 25 for

2005 the case of $\tau_{p c}^{*} / \tau_{c}^{*}=1$. For this figure, the characteristic block diameter is assumed to be equivalent to the characteristic sediment size $\left(D_{p}=D\right)$. 
Table 1

Experimental parameters from bedrock incision experiments focused on the interaction of abrasion, roughness, sediment deposition, and channel form

\begin{tabular}{|c|c|c|c|c|c|c|c|c|c|}
\hline Study & $\mathrm{Fr}$ & $\operatorname{Re}$ & $\begin{array}{c}\text { Flow } \\
\text { velocity } \\
(\mathrm{m} / \mathrm{s})\end{array}$ & $\begin{array}{c}\text { Flow } \\
\text { depth }(m)\end{array}$ & Slope & $\begin{array}{c}\text { Flume } \\
\text { length } \\
(\mathrm{m}) \\
\end{array}$ & $\begin{array}{c}\text { Flume } \\
\text { width } \\
\text { (m) }\end{array}$ & Substrate & $\begin{array}{c}\text { Sediment } \\
\text { diameter (m) }\end{array}$ \\
\hline $\begin{array}{l}\text { Wohl and } \\
\text { Ikeda (1997) }\end{array}$ & $\begin{array}{c}1.1- \\
1.6\end{array}$ & $\begin{array}{l}9000- \\
93,500\end{array}$ & $\begin{array}{c}0.5- \\
1.1\end{array}$ & $\begin{array}{c}0.015- \\
0.085\end{array}$ & $\begin{array}{c}0.01- \\
0.2\end{array}$ & 4 & 0.2 & $\begin{array}{c}70 \% \text { fine } \\
\text { sand, } 30 \% \\
\text { bentonite }\end{array}$ & 0.001 \\
\hline $\begin{array}{l}\text { Finnegan et } \\
\text { al. (2007) }\end{array}$ & $\begin{array}{l}1.2- \\
1.4\end{array}$ & $\begin{array}{c}120,000- \\
140,000\end{array}$ & $\begin{array}{l}1.2- \\
1.4\end{array}$ & 0.1 & 0.02 & 6 & 0 & $\begin{array}{l}\text { cement, fine } \\
\text { sand, fly ash, } \\
\text { flow additive }\end{array}$ & 0.006 \\
\hline $\begin{array}{c}\text { Johnson and } \\
\text { Whipple (2007) }\end{array}$ & $\begin{array}{l}1.3- \\
2.5\end{array}$ & $\begin{array}{l}60,000- \\
171,000\end{array}$ & $\begin{array}{l}1.2- \\
1.9\end{array}$ & $\begin{array}{c}0.05- \\
0.09\end{array}$ & $\begin{array}{c}0.02- \\
0.1\end{array}$ & 5 & 0.4 & $\begin{array}{l}15: 1 \text { sand } \\
\& \text { Portland } \\
\text { cement }\end{array}$ & 0.0025 \\
\hline $\begin{array}{c}\text { Chatanantavet and } \\
\text { Parker (2008) }\end{array}$ & $\begin{array}{c}0.86- \\
2.4\end{array}$ & $\begin{array}{l}23,450- \\
122,400\end{array}$ & $\begin{array}{c}0.67- \\
1.53\end{array}$ & $\begin{array}{c}0.035- \\
0.08\end{array}$ & $\begin{array}{c}0.0115- \\
0.03\end{array}$ & 13 & 0.9 & $\begin{array}{l}\text { sand, } \\
\text { cement, } \\
\text { vermiculite }\end{array}$ & $\begin{array}{c}0.002 \& \\
0.007\end{array}$ \\
\hline $\begin{array}{c}\text { Johnson and } \\
\text { Whipple (2010)* }\end{array}$ & $\begin{array}{c}2.4- \\
3.5\end{array}$ & $\begin{array}{l}6,000- \\
96,000\end{array}$ & $\begin{array}{l}0.3- \\
0.8\end{array}$ & $\begin{array}{l}0.02- \\
0.12\end{array}$ & 0.1 & 4 & 0.3 & $\begin{array}{l}\text { 15:1 sand } \\
\text { \& Portland } \\
\text { cement }\end{array}$ & $\begin{array}{c}0.0027- \\
0.0055\end{array}$ \\
\hline $\begin{array}{c}\text { Davis (2013) \& } \\
\text { Demeter et al. (2005) }\end{array}$ & $\begin{array}{c}0.68- \\
1.26\end{array}$ & $\begin{array}{l}70,000- \\
82,000\end{array}$ & $\begin{array}{l}0.75- \\
1.12\end{array}$ & $\begin{array}{c}0.0056- \\
0.0073\end{array}$ & $\begin{array}{c}0.0056- \\
0.0073\end{array}$ & 6 & 0.3 & $\begin{array}{c}\text { 10:1 fine sand } \\
\text { \& Portland } \\
\text { cement }\end{array}$ & 0.005 \\
\hline
\end{tabular}

*Back-calculated flow velocity from reported Froude number and flow depth. 


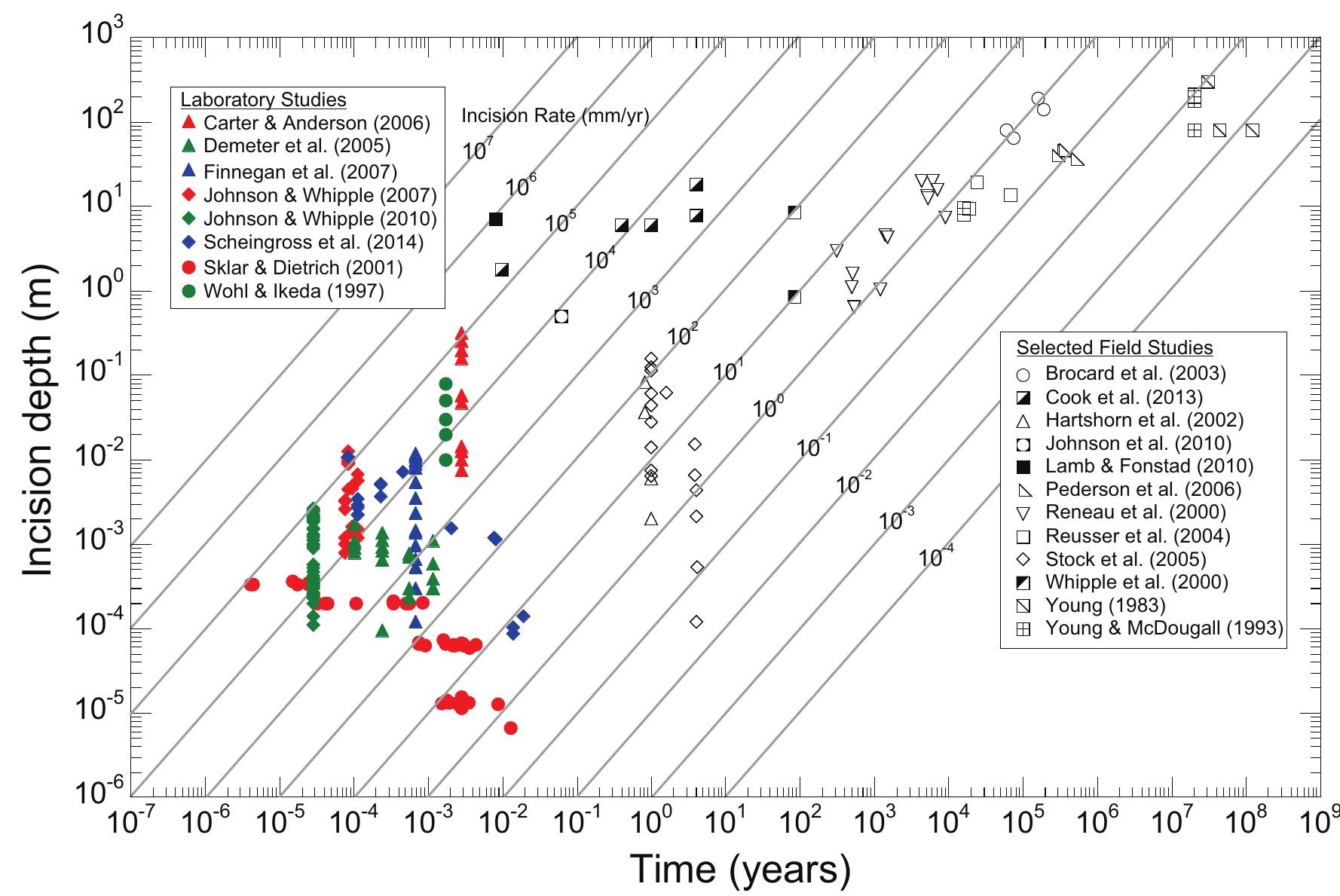


Figure 5 (Color)

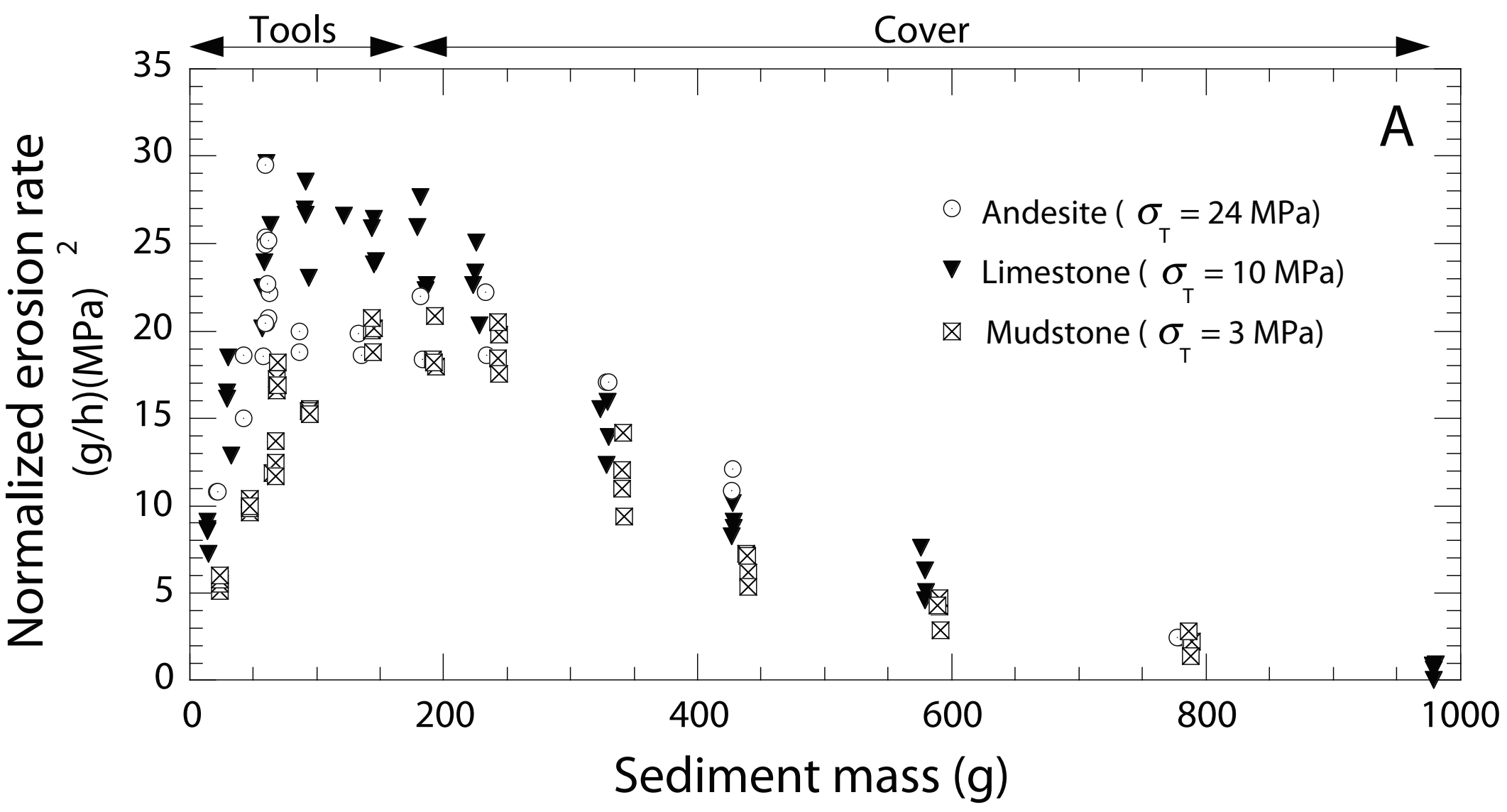

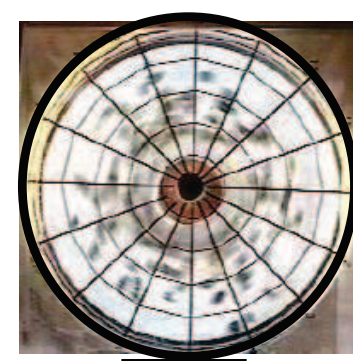

$50 \mathrm{~g}$

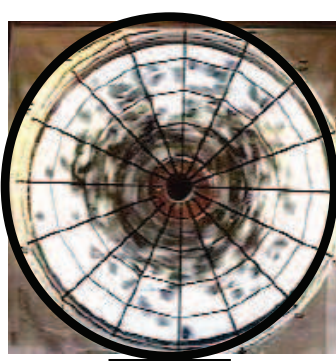

$150 \mathrm{~g}$

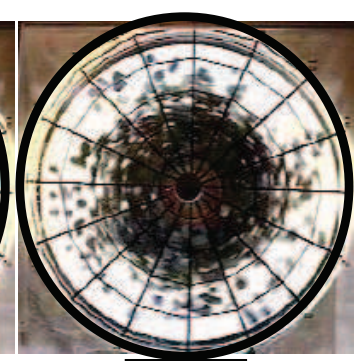

$250 \mathrm{~g}$

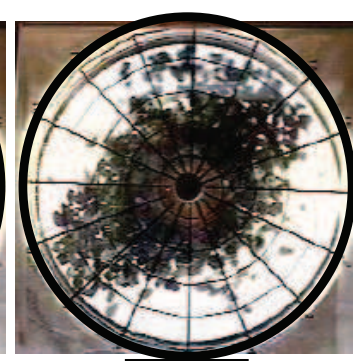

$400 \mathrm{~g}$

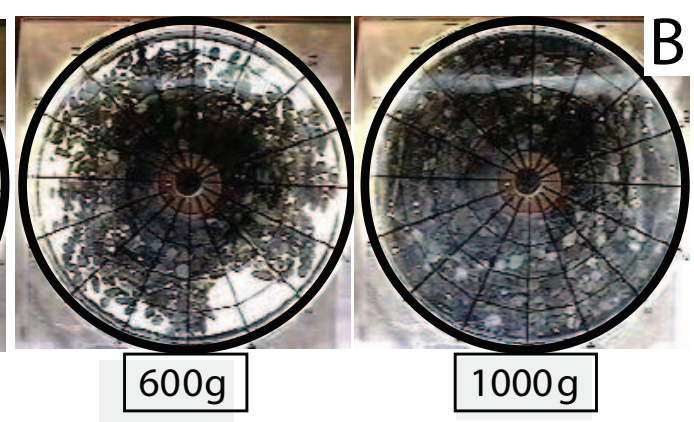

$1000 \mathrm{~g}$ 

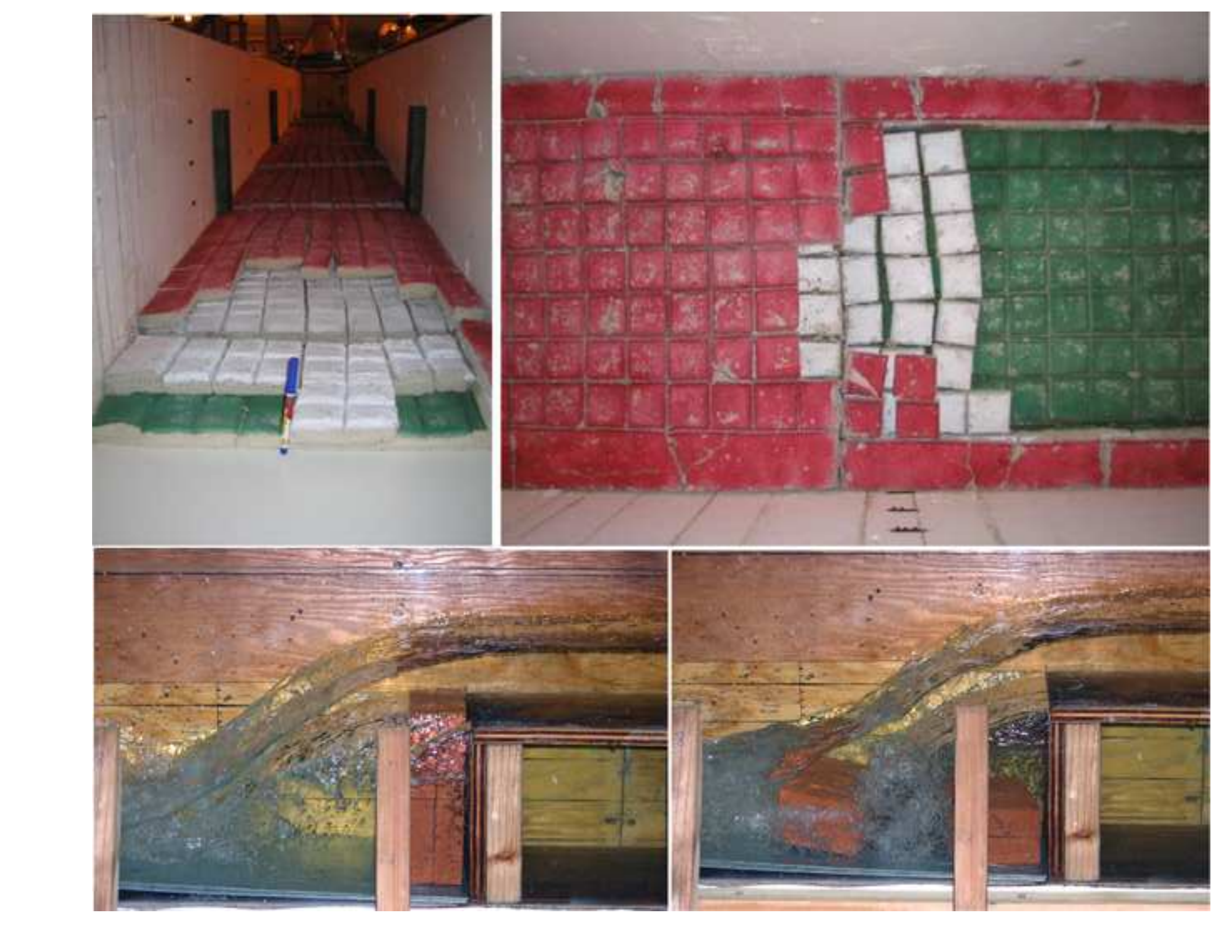

$$
-
$$

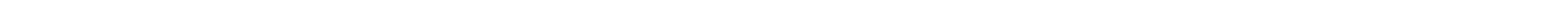

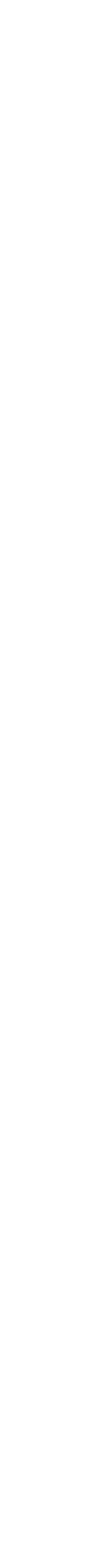

$-1$

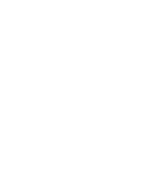




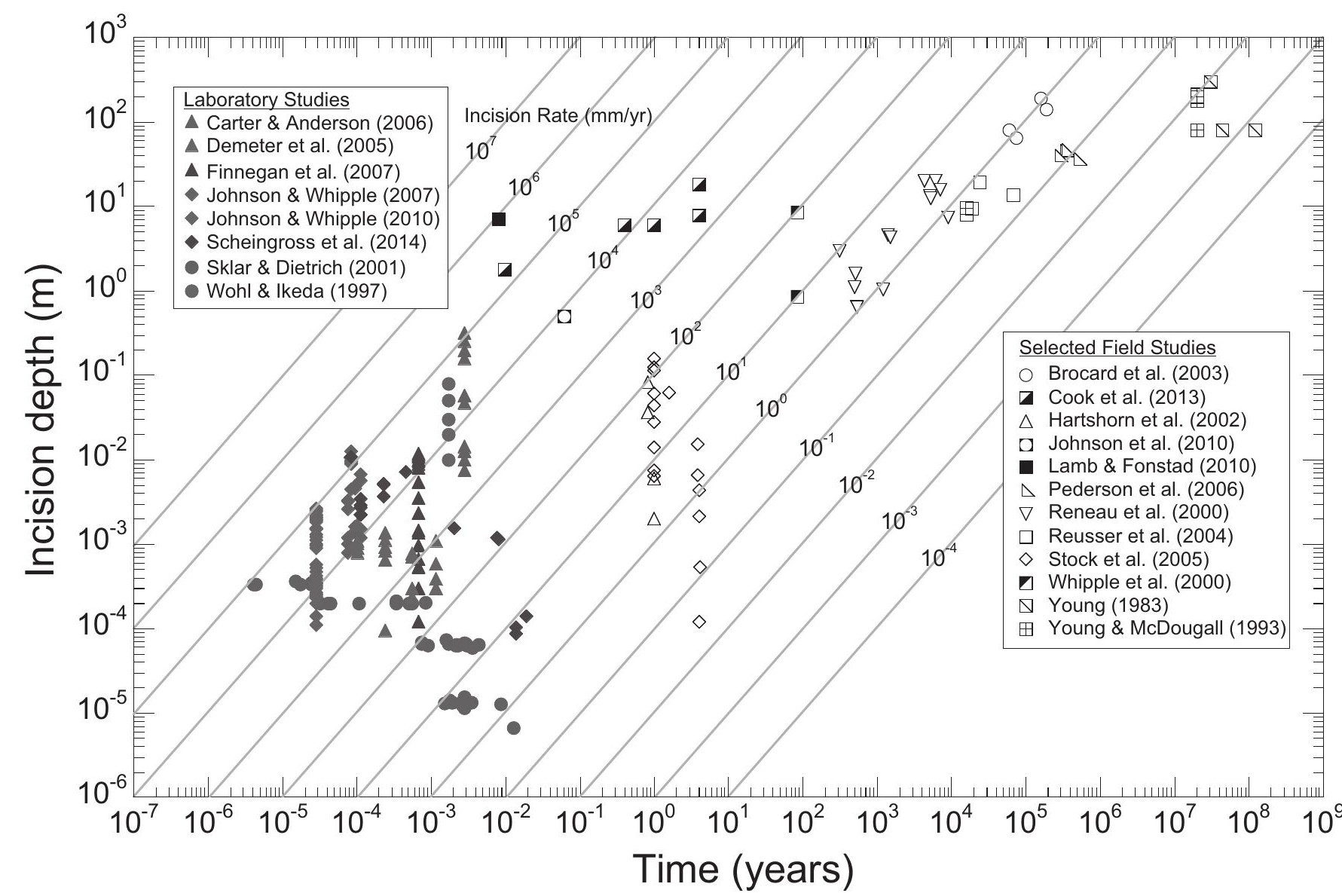


Figure 3 (Greyscale)
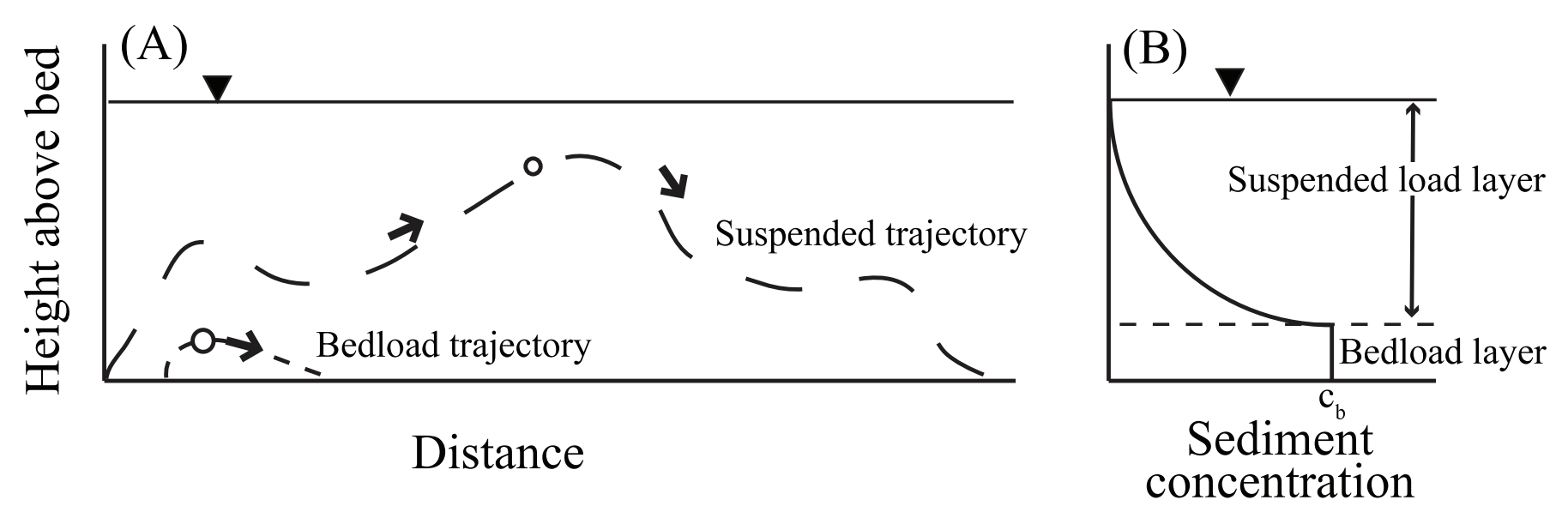
Figure 4 (Greyscale)
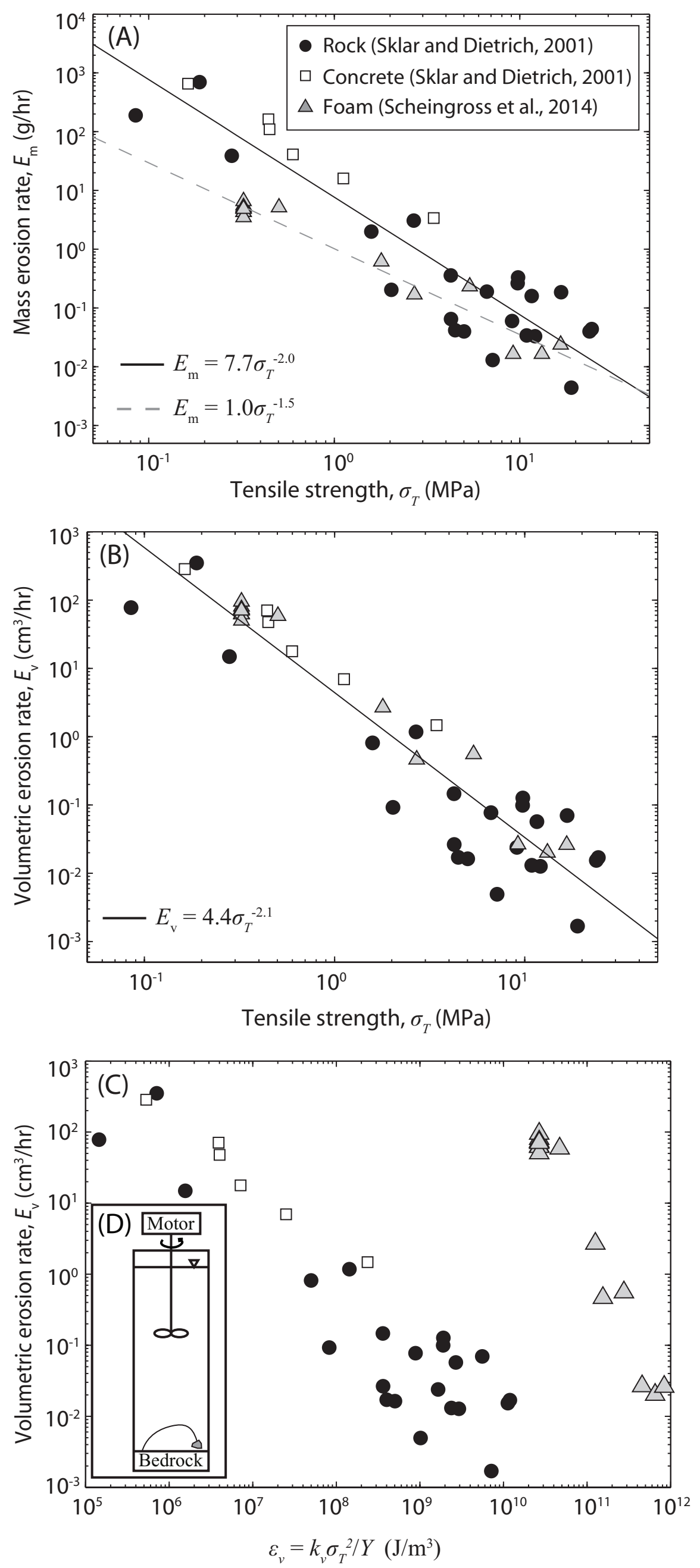

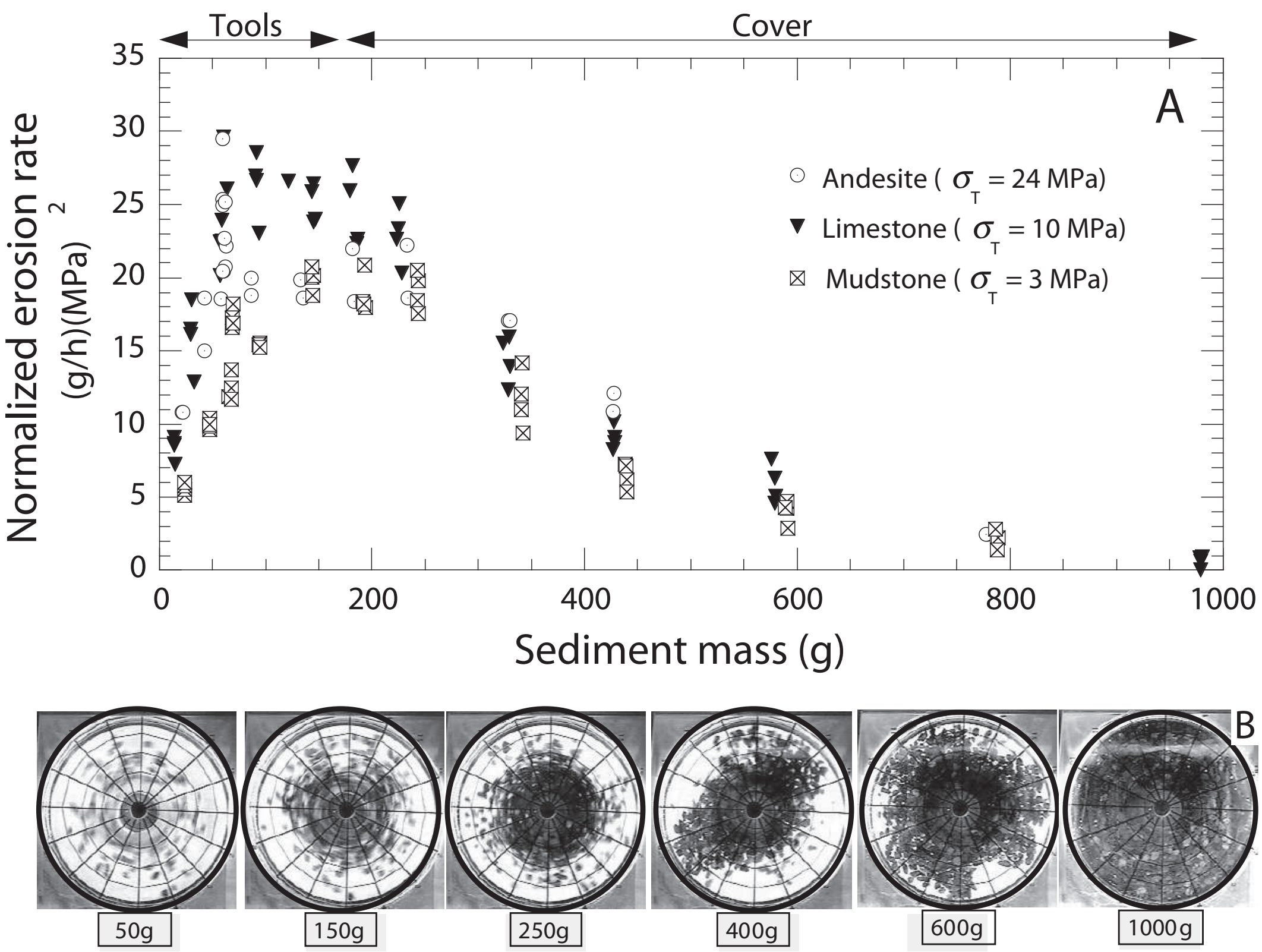


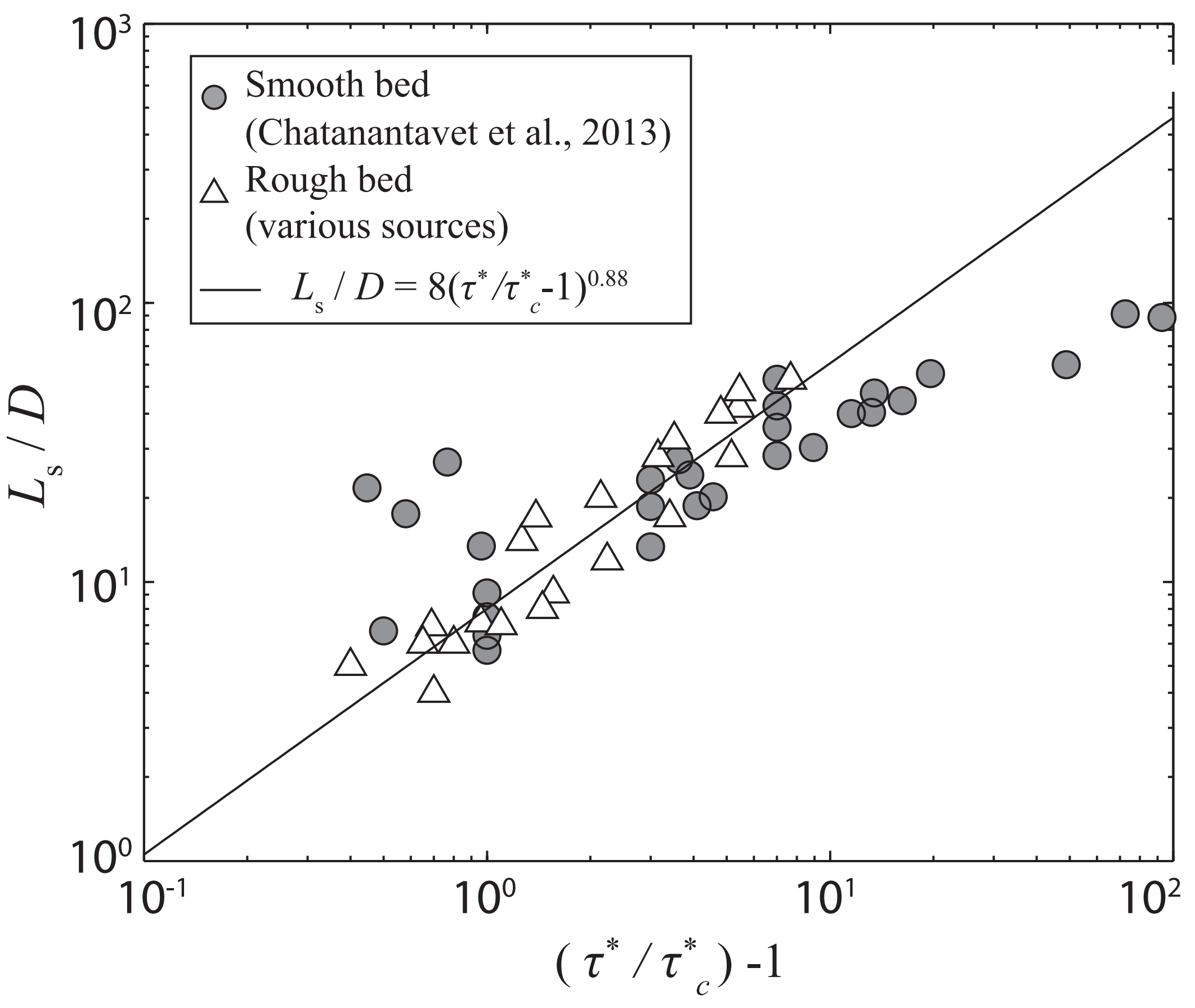




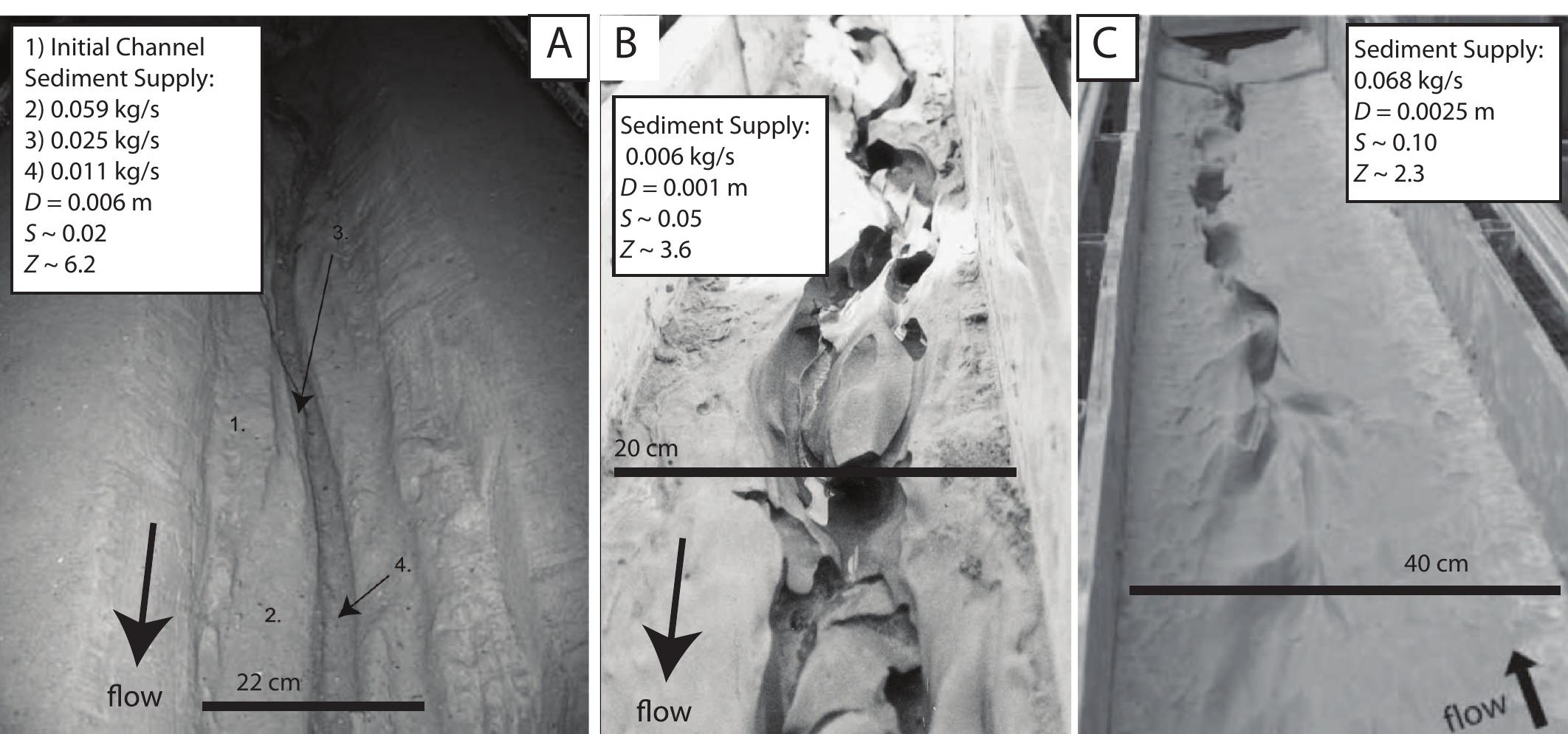

1) Initial Channel

Sediment Supply:

2) $0.059 \mathrm{~kg} / \mathrm{s}$

3) $0.025 \mathrm{~kg} / \mathrm{s}$

4) $0.011 \mathrm{~kg} / \mathrm{s}$

$D=0.006 \mathrm{~m}$

$S \sim 0.02$

$Z \sim 6.2$ 


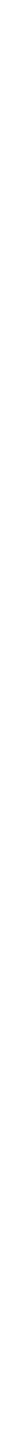

Figure 10 (Greyscale) 


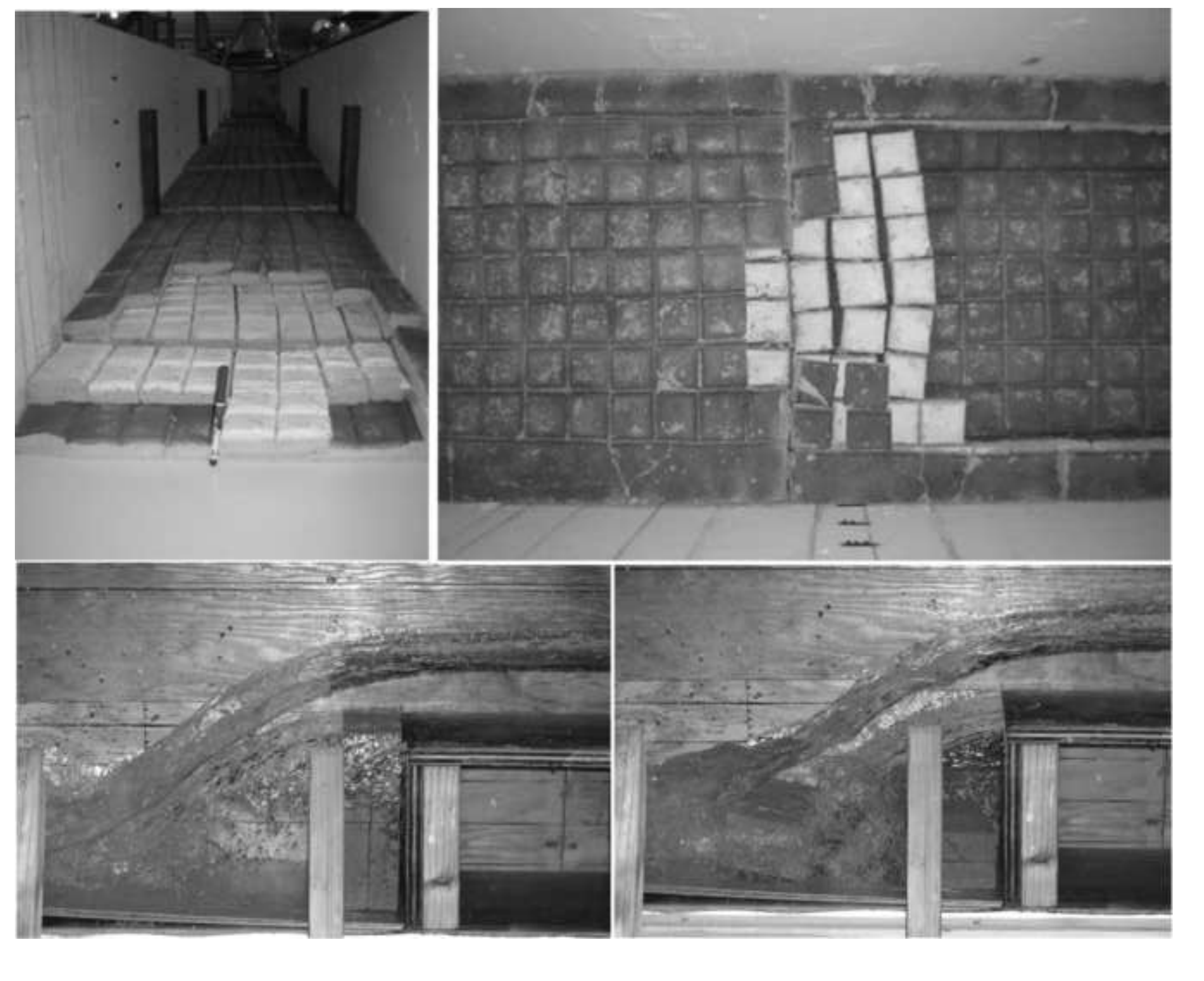

Fig

. 


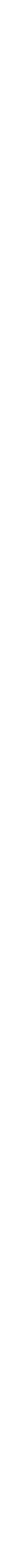

Figure 13 (Greyscale)

\section{然

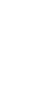

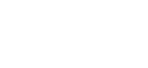

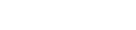
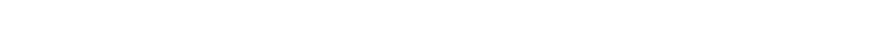

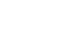

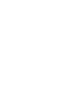
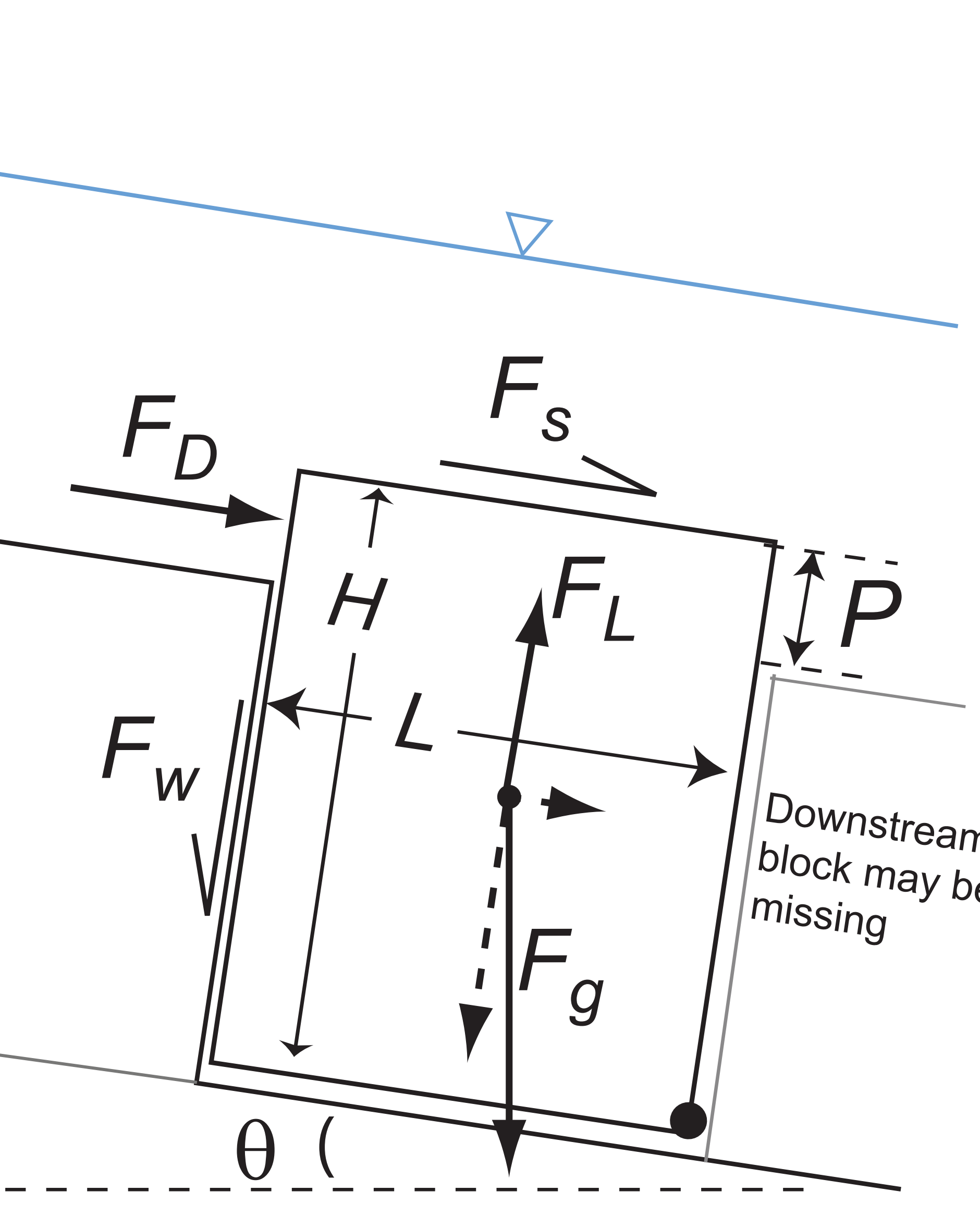

$$
\text { ( }
$$



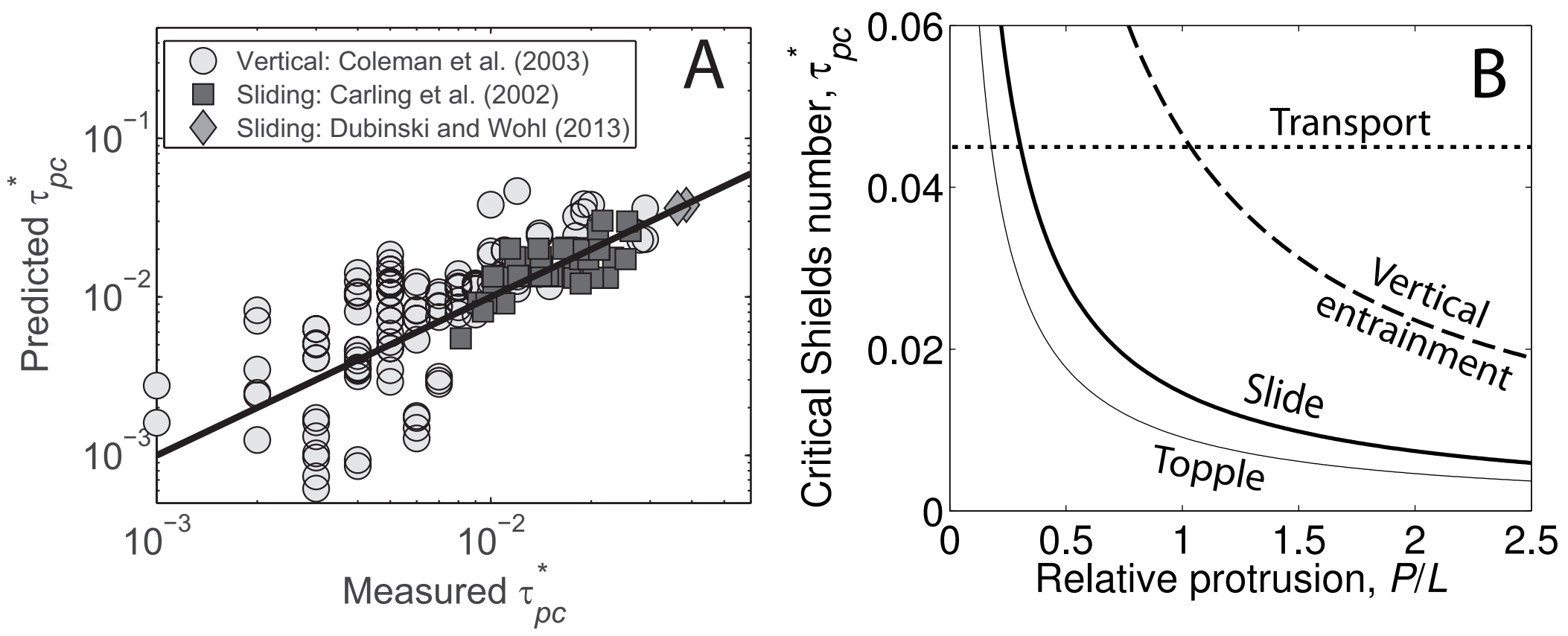

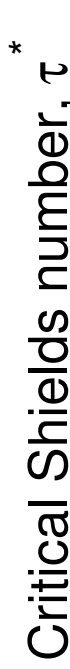
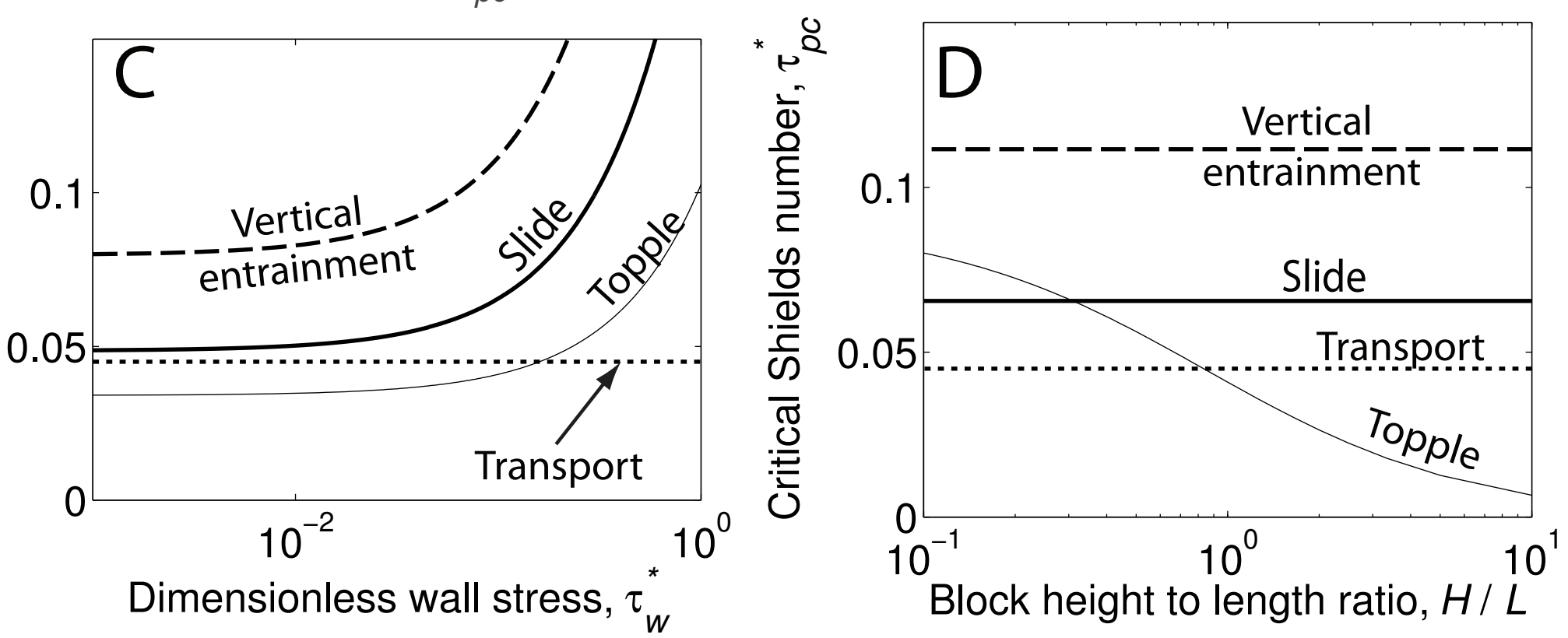
Figure 15 (Grey)

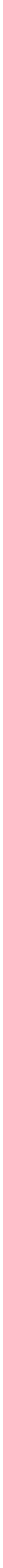

